\title{
AVALIAÇÃO DA DEFORMAÇÃO DO TECIDO CEREBRAL DURANTE O PROCEDIMENTO CIRÚRGICO: UM ESTUDO IN VITRO.
}

Tese apresentada à Faculdade de Filosofia, Ciência e Letras de Ribeirão Preto da Universidade de São Paulo para obtenção do título de Doutor em Ciências.

Área de concentração:

Física Aplicada à Medicina e Biologia.

Orientador:

Prof. Dr. Antonio Adilton Oliveira Carneiro

Ribeirão Preto

2014

Versão Corrigida (Versão Original se encontra na FFCLRP) 
Autorizo a reprodução e divulgação total ou parcial deste trabalho, por qualquer meio convencional ou eletrônico, para fins de estudo e pesquisa, desde que citada a fonte.

Lemos, Tenysson Will de.

Avaliação da deformação do tecido cerebral durante o procedimento cirúrgico: Um estudo in vitro / Tenysson Will de Lemos; orientador: Prof. Dr. Antonio Adilton Oliveira Carneiro. Ribeirão Preto. 2014. 95 p.

Tese (Doutorado - Programa de Pós-graduação em Física Aplicada à Medicina e Biologia) - Faculdade de Filosofia, Ciências e Letras de Ribeirão Preto da Universidade de São Paulo, 2014.

1. Corregistro. 2. Ultrassom. 3. Fantoma. 4. Neuronavegação. 5.Deformação 
Nome: LEMOS, Tenysson Will de.

Título: Avaliação da deformação do tecido cerebral durante o procedimento cirúrgico: Um estudo in vitro.

Tese apresentada à Faculdade de Filosofia, Ciência e Letras de Ribeirão Preto da Universidade de São Paulo, como parte das exigências para a obtenção do título de Doutor em Ciências.

Aprovado em:

BANCA EXAMINADORA

Prof. Dr.: Instituição:

Julgamento: Assinatura:

Prof. Dr.: Instituição:

Julgamento: Assinatura:

Prof. Dr.: Instituição:

Julgamento: Assinatura:

Prof. Dr. Instituição: Julgamento: Assinatura:

Prof. Dr.: Instituição:

Julgamento: Assinatura: 
Dedico este trabalho a minha esposa e companheira Michela, pela paciência e compreensão, a minha filha Laís, pela alegria, a minha mãe Ana Rosa e a minha sogra Irene, pela fé, a minha avó Geralda, pela sabedoria e à memória de minha mãezinha Fátima (Tia Nenê). 


\section{Agradecimentos}

Ao Prof. Adilton por ter me orientado e me dado esta oportunidade de crescimento científico, profissional e pessoal.

Ao Prof. Luiz Otávio pela atenção e ajuda nas discussões científicas, processamentos e nos momentos de dificuldade durante este trabalho.

A Michele pela ajuda na construção dos fantomas, sem os quais seria impossível a realização deste trabalho.

Ao Felipe pelo companheirismo, fidelidade e ensino conjunto.

Ao Agnelo pela prontidão e prestatividade.

Aos colegas do Grupo de Inovação em Instrumentação Médica e Ultrassom GIIIMUS, pela amizade e colaboração.

Ao Grupo de Computação, Sinais e Imagens Médicas - CSIM, pela disponibilidade de recursos computacionais.

A Faculdade de Filosofia Ciências e Letras de Ribeirão Preto, pela oportunidade de ingresso no programa de pós-graduação em Física Aplicada à Medicina e Biologia.

A CAPES, a FAPESP e ao CNPq pelo apoio financeiro e a CAPES pela concessão da bolsa de Doutorado.

Ao pessoal do NAP-DCD pela ajuda e compreensão. 
"Posso suportar um pouco de dúvida: é o preço que se tem de pagar pela pureza." Jean-Paul Sartre 


\section{Resumo}

Lemos, Tenysson Will de. Avaliação da deformação do tecido cerebral durante o procedimento cirúrgico: um estudo in vitro. Ribeirão Preto: Faculdade de Filosofia, Ciências e Letras de Ribeirão Preto, Universidade de São Paulo, 2014. 95 p. Tese de Doutorado em Física Aplicada à Medicina e Biologia.

Durante um procedimento cirúrgico cerebral existe o deslocamento das estruturas que é um problema tipicamente não-rígido e não-linear. A ultrassonografia intra-operatória é utilizada como guia cirúrgico e pode ser utilizada para correção das imagens préoperatórias através do corregistro rígido entre estas e um sistema de rastreio. Isto torna possível a visualização do deslocamento das estruturas devida a remoção de parte delas durante $\mathrm{o}$ ato cirúrgico. O objetivo deste trabalho é um estudo do corregistro livre não-rígido a partir de um modelo in vitro experimental que simule uma situação cirúrgica de retirada de uma inclusão líquida, de forma controlada, para medir os deslocamentos das estruturas próximas, utilizando imagens de ultrassom. Alguns fantomas que simulam o tecido humano nas imagens de ultrassom, feitos de gelatina e parafina, foram escolhidos como modelo. Para realizar o corregistro foi escolhida a transformação geométrica por splines simples (B-Splines), o otimizador Limitedmemory Broyden-Fletcher-Goldfarb-Shanno (LBFGS) e a métrica de similaridade soma do quadrado das diferenças (SQD) e, utilizada a biblioteca Insight Segmentation and Registration Toolkit (ITK), assim como o estudo dos parâmetros adequados para a nossa tarefa. Foi demonstrado para as condições envolvidas que para as imagens em modo $B$ as deformações até $5 \%$ e mapas de RF até $9 \%$, sem nenhuma otimização dos parâmetros do corregistro, é factível sem uso excessivo de tempo computacional. Foi analisada a influência da grade em relação a dois tipos diferentes de deformação, ambas com valor de $2 \%$. O tamanho da grade, levando em consideração o erro e 0 tempo, foram a $5 \times 11$ para as imagens em Modo B e 11x17 para os mapas de RF, independentemente do tipo de deformação. Os parâmetros do otimizador (Default Step Length, Gradient Convergence Tolerance e Line Search Accuraccy) também foram avaliados e os valores obtidos foram 1,6; 0,03 e 0,8 para as imagens modo $\mathrm{B} e$ 1,2; 0,05 e 1,0 para os mapas de RF. No entanto ao comparamos, utilizando os parâmetros propostos obtidos, os campos de deslocamentos esperados com os gerados pelo modo $\mathrm{B}$ e pelos mapas RF, foi demonstrado que os mapas de RF fornecem valores abaixo do esperado e que as imagens em modo $B$ retratam mais fielmente os deslocamentos e isto se deve a escolha do conjunto de valores testados para o otimizador. Foram aplicados estes parâmetros em dois fantomas de parafinagel e em dois de gelatina. Nos três primeiros fantomas foi retirada um inclusão líquida em várias etapas. Os deslocamentos das estruturas vizinhas foram avaliados durante as etapas de remoção para demonstrar os campos de sução e de torção. No último fantoma, que simula morfologicamente um cérebro humano, foram retiradas, em várias etapas, regiões sólidas, simulando a retirada de tecido e foram calculados os deslocamentos e demonstrados os campos provenientes deste tipo de intervenção. Os trabalhos futuros se concentrarão em utilizar os volumes para medir os movimentos das estruturas e em novos parâmetros do otimizador para os mapas de RF.

Palavras-chave: Corregistro. Ultrassom. Deformação. Neuronavegação. Fantoma. 


\begin{abstract}
Lemos, Tenysson Will de. Evaluation of brain tissue deformation during surgery: A study in vitro. Ribeirão Preto: Faculdade de Filosofia, Ciências e Letras de Ribeirão Preto, Universidade de São Paulo, 2014. 95 p. Tese de Doutorado em Física Aplicada à Medicina e Biologia.

During a brain surgery there is the displacement of the structures that is a typical nonrigid and non-linear problem. Intraoperative ultrasound is used as a surgical guide and can be used for spatial correction of preoperative images through the rigid registration between these and a track system. This makes it possible to visualize the displacement of structures due to removal of some piece of them during surgery. This work is a study of the non-rigid free-from registration using an experimental in vitro model to simulate a surgical situation withdrawal of a fluid inclusion in a controlled manner, to measure the displacement of nearby structures, using ultrasound images. Some phantoms that simulate the human tissue in the ultrasound images made of gelatin and paraffin were chosen as a model. To perform the registration it was used the framework Insight Segmentation and Registration Toolkit (ITK) and were chosen a geometric transformation of simple splines (B-splines), the Limited-memory Broyden-FletcherGoldfarb-Shanno (LBFGS) optimizer and the similarity metric sum of the squared differences (SQD). The search for the suitable parameters for our task are done and it has been shown that for the conditions involved for B-mode images deformations up to $5 \%$ and RF maps up to $9 \%$ without any optimization of the parameters of registration, is feasible without excessive use of computational time. The influence of the grid was examined for two different types of deformation, both for $2 \%$. The size of the grid, taking into account the error and time were the $5 \times 11$ for the images in B mode and $11 \times 17$ maps for RF, regardless of the type of deformation. The parameters of the optimizer (Default Step Length, Gradient Convergence Tolerance and Line Search Accuraccy) were also evaluated and the values obtained were 1.6, 0.03 and 0.8 for the B-mode images and 1.2, 0.05 and 1.0 for RF maps. However when comparing the expected displacement fields with the generated by B-mode images and the RF maps, using the obtained parameters, it have been shown that RF maps provide values are lower than expected and that the B-mode images portray more faithfully displacements. This is due to the choice set of values tested for the optimizer. Finally, image registration parameters for B-mode were applied in two paraffin-gel and two gelatin phantoms. In the first three phantoms the fluid inclusion was removed in several stages and the displacements of neighboring structures were evaluated during the removal steps to demonstrate the fields of suction and torsion. The last phantom, which morphologically mimics a human brain, a solid region was removed, also in several stages, simulating a surgery. The displacements were calculated and demonstrated the fields from this type of intervention. Future work will focus on using the volumes to measure the movements of the structures and new parameters test of the optimizer to RF maps.
\end{abstract}

Keywords: Image registration. Ultrasound. Deformation. Neuronavigation. Phantoms. 


\section{Lista de llustrações}

Figura 1: Imagens de ressonância magnética pré-operatória (esquerda) e intra-operatória

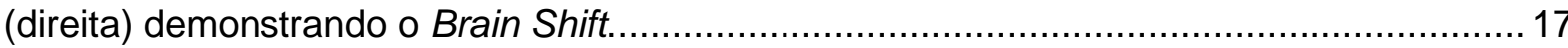

Figura 2: Imagem tipo raster de Tons de Cinza. ............................................................. 20

Figura 3: Esquema de Pulso Eco utilizado para a geração de sinais de ultrassom] .............21

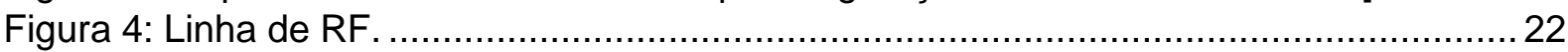

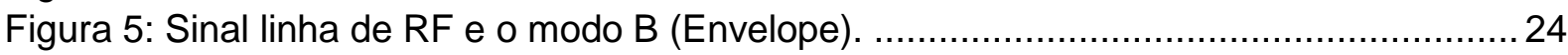

Figura 6: Eco adquirido antes e após a deformação da amostra ...................................... 25

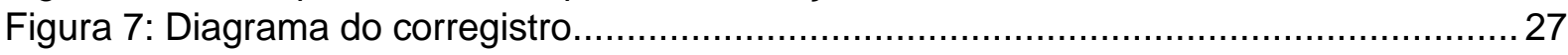

Figura 8: Conceitos geométricos associados com a imagem no ITK ................................29

Figura 9: Imagens com todos os conceitos geométricos diferentes, mas pode se tratar do

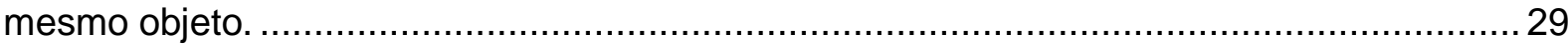

Figura 10: Mapa de deslocamento por grade de BSpline ................................................. 33

Figura 11: Transformação geométrica cujo as coordenadas dos pixels assumem valores

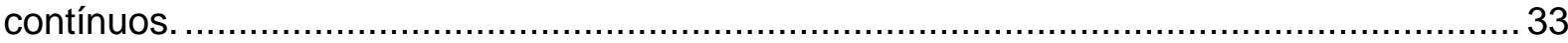

Figura 12: Sistema Estereotáxico (esquerda) e parafusos fixados ao crânio - Fiduciais -

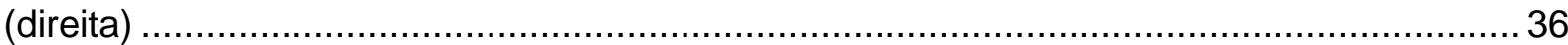

Figura 13: Polhemus Patriot ${ }^{\mathrm{TM}}$ (esquerda), os Polaris Spectra ${ }^{\mathrm{TM}}$ e Polaris Vicra ${ }^{\mathrm{TM}}$ (centro) e

as NDI Passive Spheres ${ }^{\text {TM }}$ fixadas em um objeto de metal (direita).................................... 37

Figura 14: Sistema de Rastreio utilizado para aquisição das imagens. ................................ 38

Figura 15: Detalhes do carrinho e do goniômetro do sistema de rastreio............................. 39

Figura 16: Fantoma cúbico dentro da caixa de acrílico com o suporte para a agulha. ......... 40

Figura 17: Fantoma Antropomórfico a base de gelatina animal Bloom 250 e composto de 8

partes montado em um crânio humano............................................................................ 41

Figura 18: Aquisições Linear (direita) e Angular (esquerda) ............................................... 42

Figura 19: Imagem em Modo-B (esquerda) e o seu respectivo mapa de RF(direita) do fantoma de parafina Gel-B utilizada para os estudos dos parâmetros do Corregistro (Seções

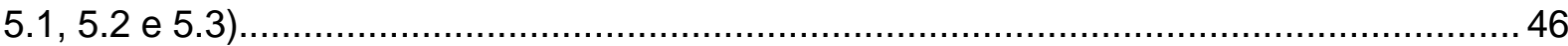

Figura 20: Imagens em Modo B deformadas, conforme a equação 13. As imagens

superiores correspondem à deformação de $0 \%$ (original), $2 \%$ e $4 \%$ e, as inferiores à $6 \%, 8 \%$

e $10 \%$. A linha amarela auxilia a visualização da deformação.

Figura 21: Imagens em Modo B corregistradas. As imagens superiores correspondem à deformação de $0 \%$ (original), $2 \%$ e $4 \%$ e, as inferiores à 6\%, 8\% e 10\%. A linha amarela auxilia a visualização do corregistro............................................................................. 48

Figura 22: Gráficos da Variação da Função Custo por deformação (esquerda) e do Tempo

Gasto pelo algoritmo por deformação (direita) para imagem modo B.

Figura 23: Gráficos da Variação da Função Custo por deformação (esquerda) e do Tempo Gasto pelo algoritmo por deformação (direita) para mapas de RF.

Figura 24: Imagens em modo B quadradas (Fator 1). A imagem à esquerda é a original e à direita foi deformada em $2 \%$ utilizando a equação 13.

Figura 25: Variação da Função Custo para uma Imagem Quadrada (Fator 1) transformada pela equação $13 \mathrm{com}$ deformação de $2 \%$. A barra lateral ilustra os valores em pixels ao quadrado.

Figura 26: Tempo de processamento para uma Imagem Quadrada (Fator 1) transformada pela equação $13 \mathrm{com}$ deformação de $2 \%$. A barra lateral ilustra os valores em segundos. . 52 
Figura 27: Variação da Função Custo em função do tamanho da grade para imagens deformadas pela equação 13. Cada fator indica uma proporção axial-lateral. A barra lateral ilustra os valores em pixels ao quadrado.

Figura 28: Tempo de processamento em função do tamanho da grade para imagens deformadas pela equação 13. Cada fator indica uma proporção axial-lateral. A barra lateral ilustra os valores em segundos

Figura 29: Imagens em modo B quadradas (Fator 1). A imagem à esquerda é a original e à direita foi deformada em $2 \%$ utilizando a equação 14 55 Figura 30: Variação da Função Custo para uma Imagem Quadrada (Fator 1) transformada pela equação $14 \mathrm{com}$ deformação de $2 \%$. A barra lateral ilustra os valores em pixels ao quadrado.

Figura 31: Tempo de processamento para uma Imagem Quadrada (Fator 1) transformada pela equação $14 \mathrm{com}$ deformação de $2 \%$. A barra lateral ilustra os valores em segundos. . 56 Figura 32: Variação da Função Custo em função do tamanho da grade para imagens deformadas pela equação 14. Cada fator indica uma proporção axial-lateral. A barra lateral ilustra os valores em pixels ao quadrado.

Figura 33: Tempo de processamento em função do tamanho da grade para imagens deformadas pela equação 14. Cada fator indica uma proporção axial-lateral A barra lateral ilustra os valores em segundos.

Figura 34: Valor final da função custo (erro) para vários valores de Default Step Length, Gradient Convergence Tolerance e Line Search Accuracy para uma imagem em Modo B deformada de $2 \%$ pela equação 14 . A barra lateral ilustra os valores em pixels ao quadrado.

Figura 35: Tempo gasto no corregistro para vários valores de Default Step Length, Gradient Convergence Tolerance e Line Search Accuracy para uma imagem em Modo B deformada de $2 \%$ pela equação 14 . A barra lateral ilustra os valores em segundos.

Figura 36: Valor final da função custo (erro) para vários valores de Default Step Length, Gradient Convergence Tolerance e Line Search Accuracy para um mapa de RF deformado de $2 \%$ pela equação 14 . A barra lateral ilustra os valores em pixels ao quadrado.

Figura 37: Tempo gasto no corregistro para vários valores de Default Step Length, Gradient Convergence Tolerance e Line Search Accuracy para um mapa de RF deformado de $2 \%$ pela equação 14. A barra lateral ilustra os valores em segundos.

Figura 38: Comparação entre os mapas de deformação lateral (parte superior) e axial (parte inferior) obtidos pelo modo B (lado esquerdo) e pelos mapas de RF (lado direito), para as imagens da Figura 19.

Figura 39: Processamento da fatia da posição de $5 \mathrm{~mm}$. A imagem superior esquerda é etapa 1, a imagem superior direita é a etapa 2, imagem inferior esquerda é a etapa 2 corregistrada e a imagem inferior direita é a etapa 1 com o mapa de deformação calculado.

Figura 40: Processamento da fatia da posição de 10mm. A imagem superior esquerda é etapa 1, a imagem superior direita é a etapa 2, imagem inferior esquerda é a etapa 2 corregistrada e a imagem inferior direita é a etapa 1 com o mapa de deformação calculado.

Figura 41: Processamento da fatia da posição de $14 \mathrm{~mm}$. A imagem superior esquerda é etapa 1, a imagem superior direita é a etapa 2, imagem inferior esquerda é a etapa 2 corregistrada e a imagem inferior direita é a etapa 1 com o mapa de deformação calculado.

Figura 42: Processamento da fatia da posição de $18 \mathrm{~mm}$. A imagem superior esquerda é etapa 1, a imagem superior direita é a etapa 2, imagem inferior esquerda é a etapa 2 corregistrada e a imagem inferior direita é a etapa $1 \mathrm{com}$ o mapa de deformação calculado. 
Figura 43: Processamento da fatia da posição de $23 \mathrm{~mm}$. A imagem superior esquerda é etapa 1, a imagem superior direita é a etapa 2, imagem inferior esquerda é a etapa 2 corregistrada e a imagem inferior direita é a etapa 1 com o mapa de deformação calculado.

Figura 44: Processamento da fatia de -16‥ A imagem superior esquerda é etapa 1, a imagem superior direita é a etapa 2, imagem inferior esquerda é a etapa 2 corregistrada e a imagem inferior direita é a etapa 1 com o mapa de deformação calculado.

Figura 45: Processamento da fatia de 18‥ A imagem superior esquerda é etapa 1, a imagem superior direita é a etapa 2, imagem inferior esquerda é a etapa 2 corregistrada e a imagem inferior direita é a etapa 1 com o mapa de deformação calculado.

Figura 46: Processamento da fatia da posição de $4 \mathrm{~mm}$. As imagens superiores da esquerda para a direita correspondem às etapas: 1, 2, 3, 4 e 5. As imagens inferiores da esquerda para a direita são as etapas 1, 2, 3 e 4, com a superposição do mapa deformação calculado que se aplicado leva a etapa posterior........................................................................ 77 Figura 47: Processamento da fatia da posição de $8 \mathrm{~mm}$. As imagens superiores da esquerda para a direita correspondem às etapas: 1, 2, 3, 4 e 5. As imagens inferiores da esquerda para a direita são as etapas 1, 2, 3 e 4, com a superposição do mapa deformação calculado que se aplicado leva a etapa posterior.

Figura 48: Processamento da fatia da posição de $12 \mathrm{~mm}$. As imagens superiores da esquerda para a direita correspondem às etapas: 1, 2, 3, 4 e 5. As imagens inferiores da esquerda para a direita são as etapas 1, 2, 3 e 4, com a superposição do mapa deformação calculado que se aplicado leva a etapa posterior.

Figura 49: Processamento da fatia da posição de $16 \mathrm{~mm}$. As imagens superiores da esquerda para a direita correspondem às etapas: 1, 2, 3, 4 e 5. As imagens inferiores da esquerda para a direita são as etapas 1, 2, 3 e 4, com a superposição do mapa deformação calculado que se aplicado leva a etapa posterior.

Figura 50: Processamento da fatia da posição de $20 \mathrm{~mm}$. As imagens superiores da esquerda para a direita correspondem às etapas: 1, 2, 3, 4 e 5. As imagens inferiores da esquerda para a direita são as etapas 1, 2, 3 e 4, com a superposição do mapa deformação calculado que se aplicado leva a etapa posterior.

Figura 51: Processamento da fatia de $-12^{\circ}$. As imagens superiores da esquerda para a direita correspondem às etapas: 1, 2, 3, 4 e 5. As imagens inferiores da esquerda para a direita são as etapas 1, 2, 3 e 4, com a superposição do mapa deformação calculado que se aplicado leva a etapa posterior.

Figura 52: Processamento da fatia de $8^{\circ}$. As imagens superiores da esquerda para a direita correspondem às etapas: 1, 2, 3, 4 e 5. As imagens inferiores da esquerda para a direita são as etapas 1, 2, 3 e 4, com a superposição do mapa deformação calculado que se aplicado leva a etapa posterior.

Figura 53: Processamento da fatia da posição de $2 \mathrm{~mm}$. As imagens superiores da esquerda para a direita correspondem às etapas: 1, 2, 3 e 4 . As imagens inferiores da esquerda para a direita são as etapas 1, 2 e 3, com a superposição do mapa deformação calculado que se aplicado leva a etapa posterior.

Figura 54: Processamento da fatia da posição de $6 \mathrm{~mm}$. As imagens superiores da esquerda para a direita correspondem às etapas: $1,2,3$ e 4 . As imagens inferiores da esquerda para a direita são as etapas 1, 2 e 3, com a superposição do mapa deformação calculado que se aplicado leva a etapa posterior.

Figura 55: Processamento da fatia da posição de $10 \mathrm{~mm}$. As imagens superiores da esquerda para a direita correspondem às etapas: 1, 2, 3 e 4. As imagens inferiores da esquerda para a direita são as etapas 1, 2 e 3, com a superposição do mapa deformação calculado que se aplicado leva a etapa posterior. 
Figura 56: Processamento da fatia da posição de $14 \mathrm{~mm}$. As imagens superiores da esquerda para a direita correspondem às etapas: 1, 2, 3 e 4. As imagens inferiores da esquerda para a direita são as etapas 1, 2 e 3, com a superposição do mapa deformação calculado que se aplicado leva a etapa posterior.

Figura 57: Processamento da fatia da posição de 18mm. As imagens superiores da esquerda para a direita correspondem às etapas: 1, 2, 3 e 4. As imagens inferiores da esquerda para a direita são as etapas 1, 2 e 3, com a superposição do mapa deformação calculado que se aplicado leva a etapa posterior.

Figura 58: Processamento da fatia de $-8^{\circ}$. As imagens superiores da esquerda para a direita correspondem às etapas: 1, 2, 3 e 4. As imagens inferiores da esquerda para a direita são as etapas 1, 2 e 3, com a superposição do mapa deformação calculado que se aplicado leva a etapa posterior. 86

Figura 59: Processamento da fatia da posição de $0 \mathrm{~mm}$. As imagens superiores da esquerda para a direita correspondem às etapas: 1, 2, 3, 4, 5 e 6. As imagens inferiores da esquerda para a direita são as etapas 1, 2, 3, 4 e 5, com a superposição do mapa deformação calculado que se aplicado leva a etapa posterior.

Figura 60: Processamento da fatia da posição de $3 \mathrm{~mm}$. As imagens superiores da esquerda para a direita correspondem às etapas: 1, 2, 3, 4, 5 e 6. As imagens inferiores da esquerda para a direita são as etapas 1, 2, 3, 4 e 5, com a superposição do mapa deformação calculado que se aplicado leva a etapa posterior.

Figura 61: Processamento da fatia da posição de $6 \mathrm{~mm}$. As imagens superiores da esquerda para a direita correspondem às etapas: 1, 2, 3, 4, 5 e 6 As imagens inferiores da esquerda para a direita são as etapas 1, 2, 3, 4 e 5, com a superposição do mapa deformação calculado que se aplicado leva a etapa posterior.

Figura 62: Processamento da fatia da posição de $9 \mathrm{~mm}$. As imagens superiores da esquerda para a direita correspondem às etapas: 1, 2, 3, 4, 5 e 6 As imagens inferiores da esquerda para a direita são as etapas 1, 2, 3, 4 e 5, com a superposição do mapa deformação calculado que se aplicado leva a etapa posterior 


\section{Lista de Tabelas}

Tabela 1: Algumas Transformações Rígidas disponíveis no ITK ..............................31

Tabela 2: Diferentes Fantomas de Parafina-Gel ................................................4 40 Tabela 3: Valores dos Parâmetros do Corregistro para Imagens em Modo B e mapas de RF 66 


\section{Lista de Abreviaturas}

Analyze - Formato de Imagem desenvolvido pelo Mayo Clinic's Biomedical Imaging Resource (BIR).

B-Splines - Basic splines (splines básicas ou simples)

DICOM - Digital Imaging and Communications in Medicine (Formato de imagem)

\section{DLT - Direct Linear Transform}

GIIMUS - Grupo de Inovação em Instrumentação Médica e Ultrassom

HSV - Sistema de cores formadas pelas componentes matiz (hue), saturação (saturation) e valor (value).

ICP - Iterative Closest Point, algoritmo para minimizar a diferença entre duas nuvens de pontos.

ITC - Imagens por tomografia computadorizada.

IRM - Imagens por ressonância magnética.

ITK - Insight Segmentation and Registration Toolkit.

JPEG ou JPG - Joint Photographic Experts Group (Formato de imagem).

LBFGS - Limited-memory Broyden-Fletcher-Goldfarb-Shanno, algortimo de minimização.

Modo B (B-Mode) - Imagem em modo brilho (Brightness Mode).

PET - Positron Emission Tomography

Pixel - Picture e Element, ponto da imagem.

RF - Response Field ou Radio Frequency.

RGB - Sistema de cores aditivas formado por vermelho (red), verde (green) e azul (blue).

PNG - Portable Network Graphics (Formato de imagem).

SPECT - Single Photon Emission Tomography.

SQD - Soma do quadrado das diferenças

VTK - Visualization Toolkit. 


\section{Sumário}

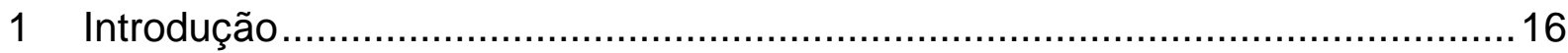

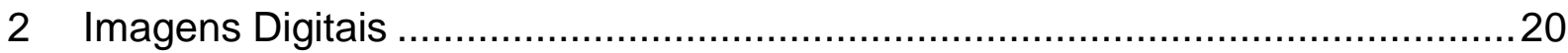

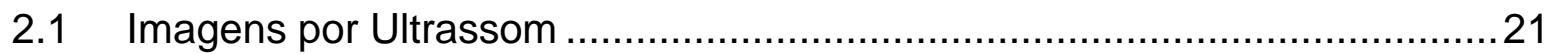

2.1.1 Imagens Modo B (Brightness Mode) ………..................................23

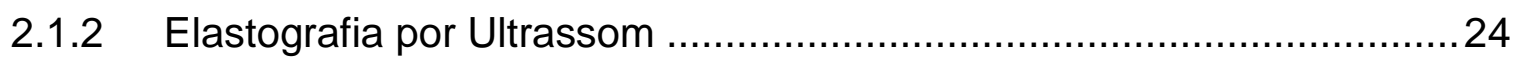

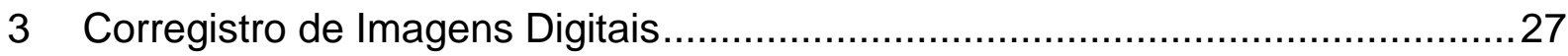

3.1 Insight Segmentation and Registration Toolkit (ITK) ...............................28

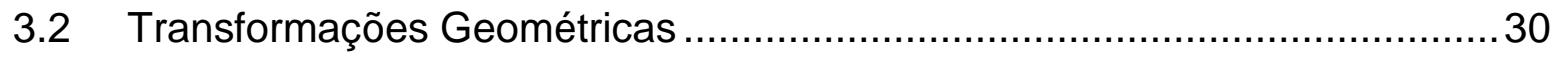

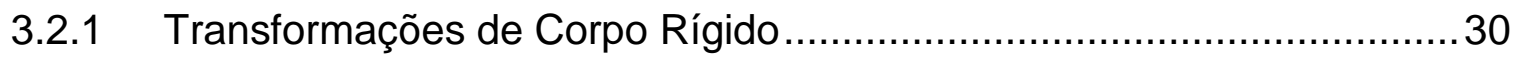

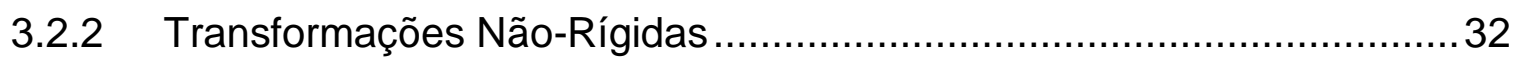

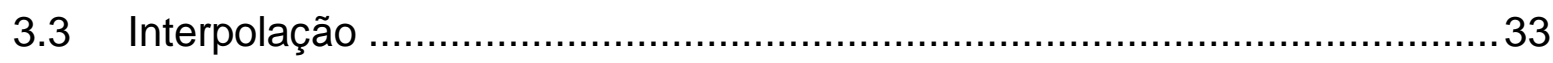

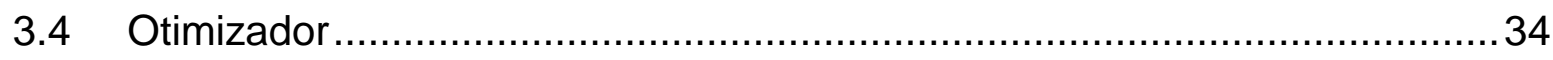

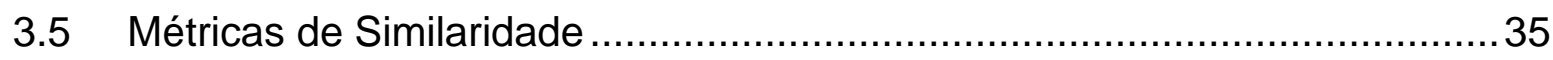

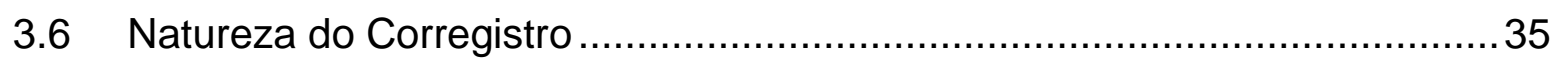

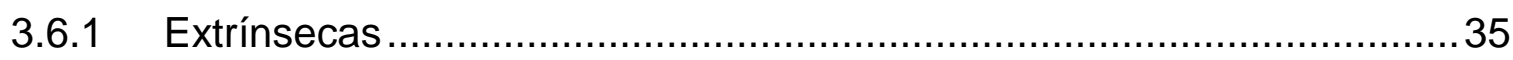

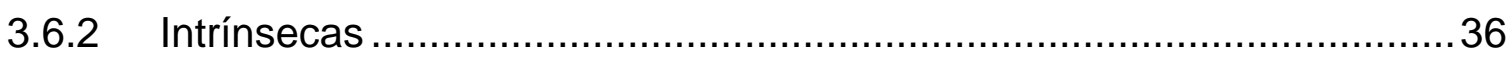

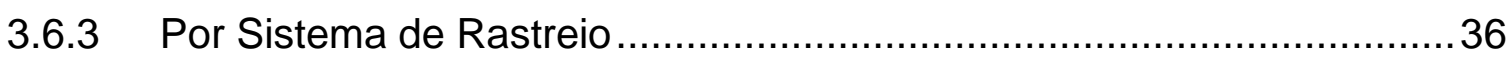

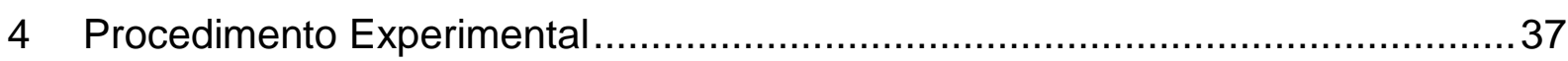

4.1 Sistema de Aquisição de Imagens no Espaço ……................................... 37

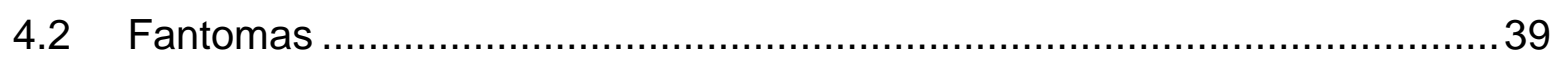

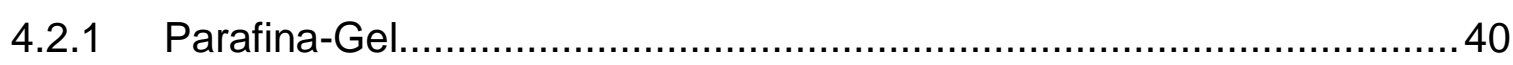

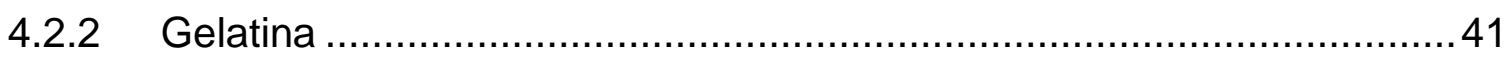

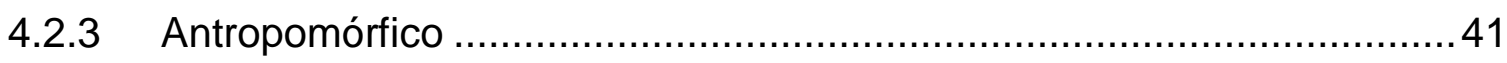

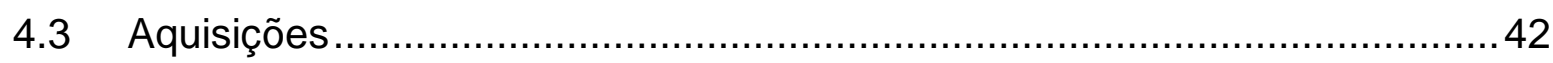

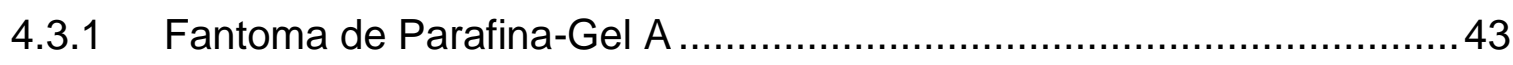

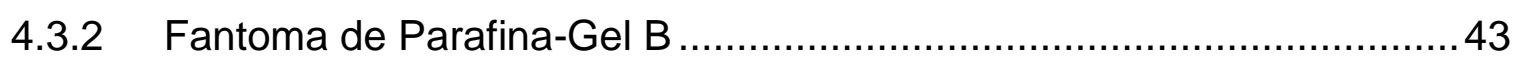

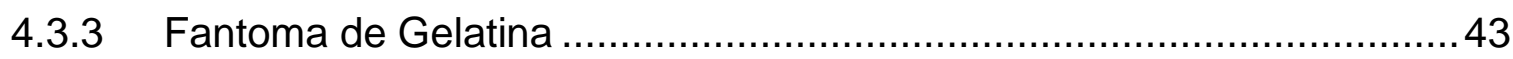

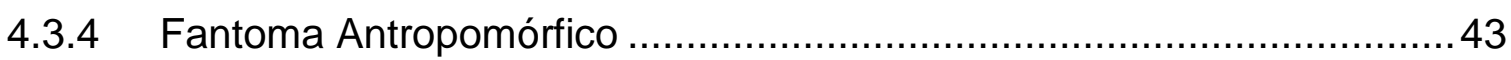

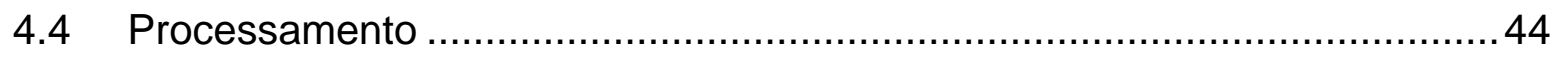

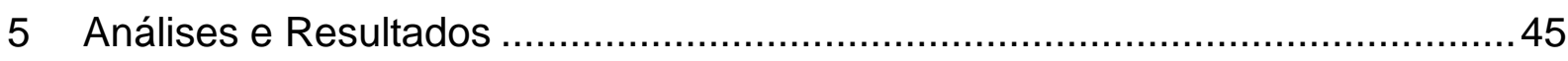

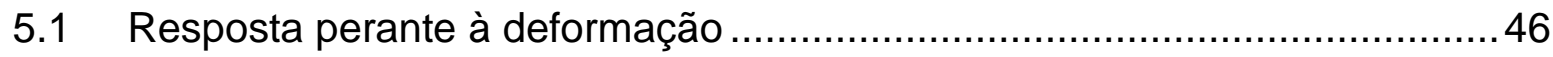

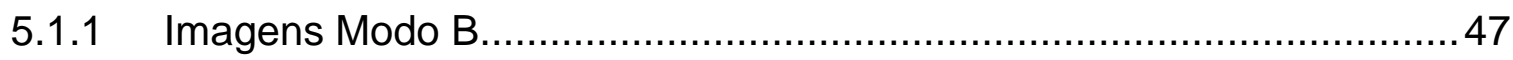




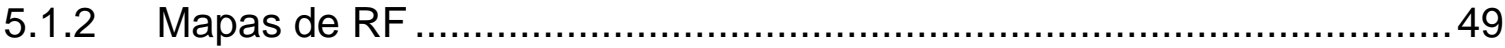

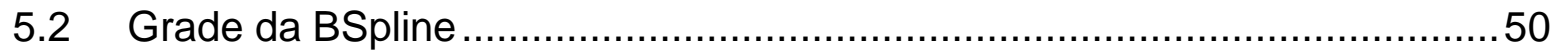

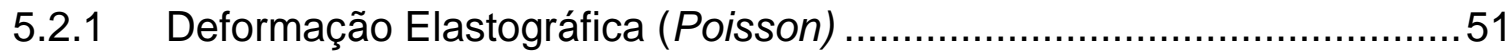

5.2.2 Deformação por Sucção (procedimento de retirada da inclusão) ...........55

5.3 Otimizador Limited-memory Broyden-Fletcher-Goldfarb-Shanno

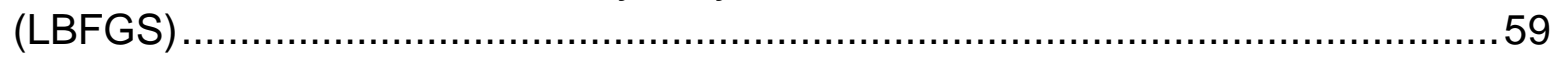

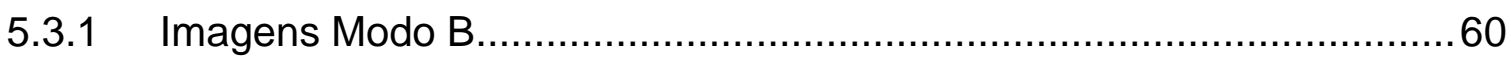

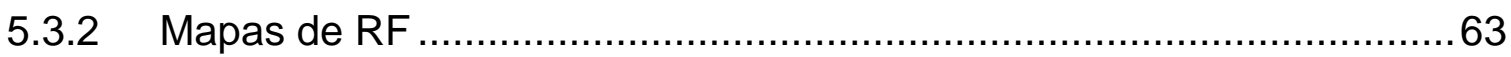

5.3.3 Comparação do Corregistro Entre Mapas RF e Imagens Modo-B ........66

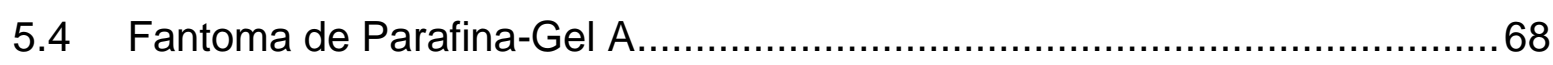

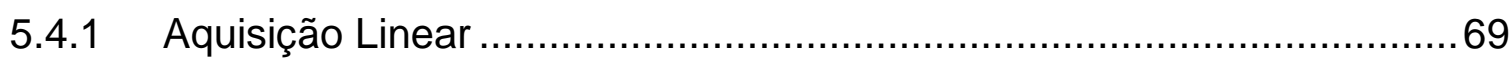

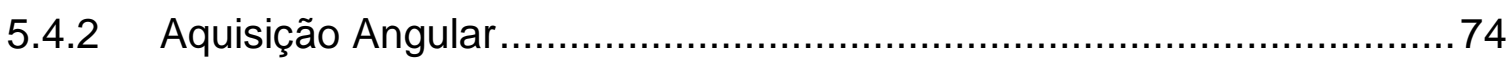

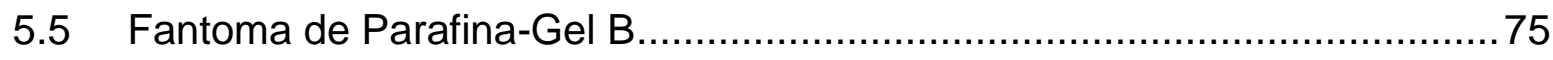

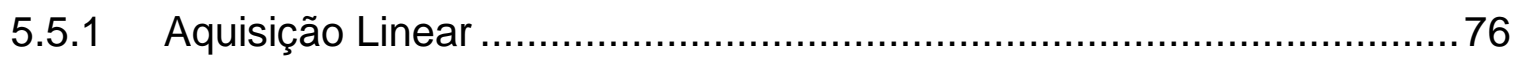

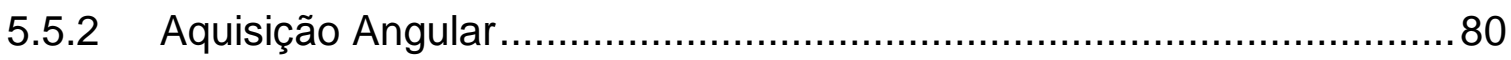

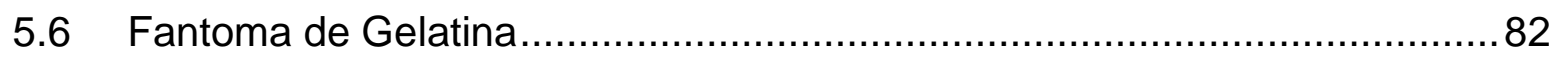

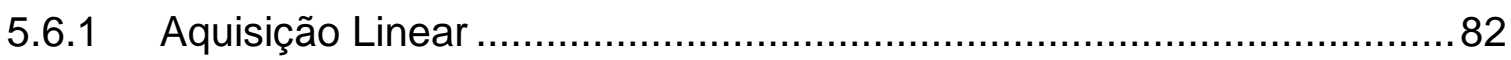

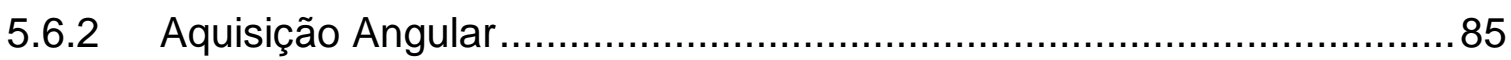

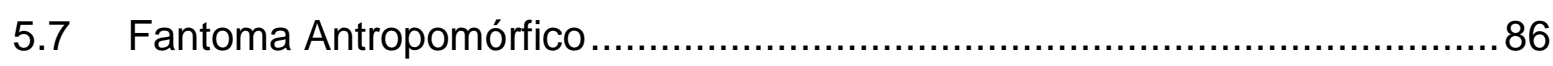

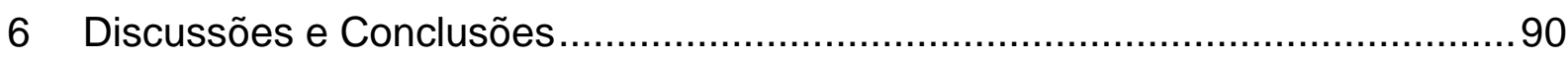

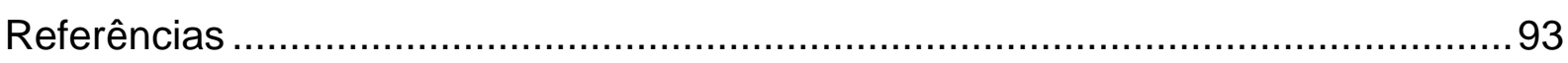




\section{Introdução}

A precisa localização espacial da lesão dentro do cérebro é extremamente importante para a cirurgia. Neste sentido a neurocirurgia guiada por imagem tem sido desenvolvida nos últimos 10 anos em centros cirúrgicos de vários países. Estes sistemas de neuronavegação auxiliam o cirurgião a aprimorar a neurocirurgia definida no planejamento pré-cirúrgico, permitindo a remoção da lesão com menor dano ao tecido sadio do cérebro [1]. O diagnóstico de um tumor (por uma aglomeração anormal de vasos sanguíneos) ou alguma outra lesão do cérebro normalmente é confirmado através de imagens por tomografia computadorizada (ITC) e/ou imagens por ressonância magnética (IRM). Reunindo as informações anatômicas com a investigação funcional da lesão, o neurocirurgião investigará e planejará a região cirúrgica efetiva, levando em consideração a minimização dos efeitos colaterais. Normalmente, a excisão deve iniciar em uma área do cérebro que é próxima a lesão, mas não parte dela e, no entanto, a remoção de uma grande área do cérebro provavelmente prejudicará as funções cerebrais. Se o neurocirurgião está considerando uma área maior que a lesão, primeiramente o paciente deverá passar por um mapeamento cuidadoso das regiões funcionais [2].

Uma parte dos candidatos a cirurgia são pacientes com epilepsia e embora a maior fração dentre estes possa ser tratada eficientemente com medicamentos, o procedimento cirúrgico é indicado numa importante parcela dos pacientes [3], [4]. Por isso um dos principais focos do projeto CInAPCe (Cooperação Interinstitucional de Apoio a Pesquisas sobre o Cérebro) da FAPESP (Fundação de Amparo à Pesquisa do Estado de São Paulo) é o desenvolvimento de novos métodos e técnicas para o tratamento de desordens epilépticas. A escolha da epilepsia como foco de estudo deve-se a sua importância como problema médico e psicossocial, e à existência de um número expressivo de diferentes grupos de pesquisa no país e no Estado de São Paulo com competência na área. Trata-se, pois, de uma iniciativa para integrar o Brasil nos grandes movimentos internacionais para tratamento da condição neurológica. Nosso projeto está inserido ao subprojeto CInAPCe: Neuronavegação com ultrassonografia intra-operatória e correlação com ressonância magnética de alto campo na cirurgia da epilepsia na infância (FAPESP: 04/14004-9). 
O uso da imagem nos planejamentos cirúrgicos, principalmente durante 0 ato, é fundamental para o sucesso do mesmo. Com o advento da tecnologia na instrumentação digital e no processamento de dados, o uso de duas ou mais modalidades de imagens para diagnosticar a mesma região, tem se tornado uma prática de grande interesse nos centros clínicos. Normalmente a neuronavegação é baseada em imagens pré-operatórias, sendo portanto, sujeita a um erro de localização das estruturas. Isto ocorre porque a imagem é adquirida do encéfalo, enquanto este permanece estático, ou seja, sem mudança de posição. Após a abertura do crânio e da dura-máter, e com saída de fluido cerebroespinhal, ocorrem mudanças da posição e no volume do encéfalo (Figura 1). A partir deste momento o cirurgião pode ser induzido ao erro, pois está sendo guiado por uma imagem que já não corresponde à realidade. Esta mudança do posicionamento do encéfalo durante a cirurgia é chamado de "Brain Shift" e ocorre, principalmente, por causa das diferenças entre a pressão interna e a pressão externa ao cérebro e, também à elasticidade do tecido cerebral que varia entre os indivíduos [5].
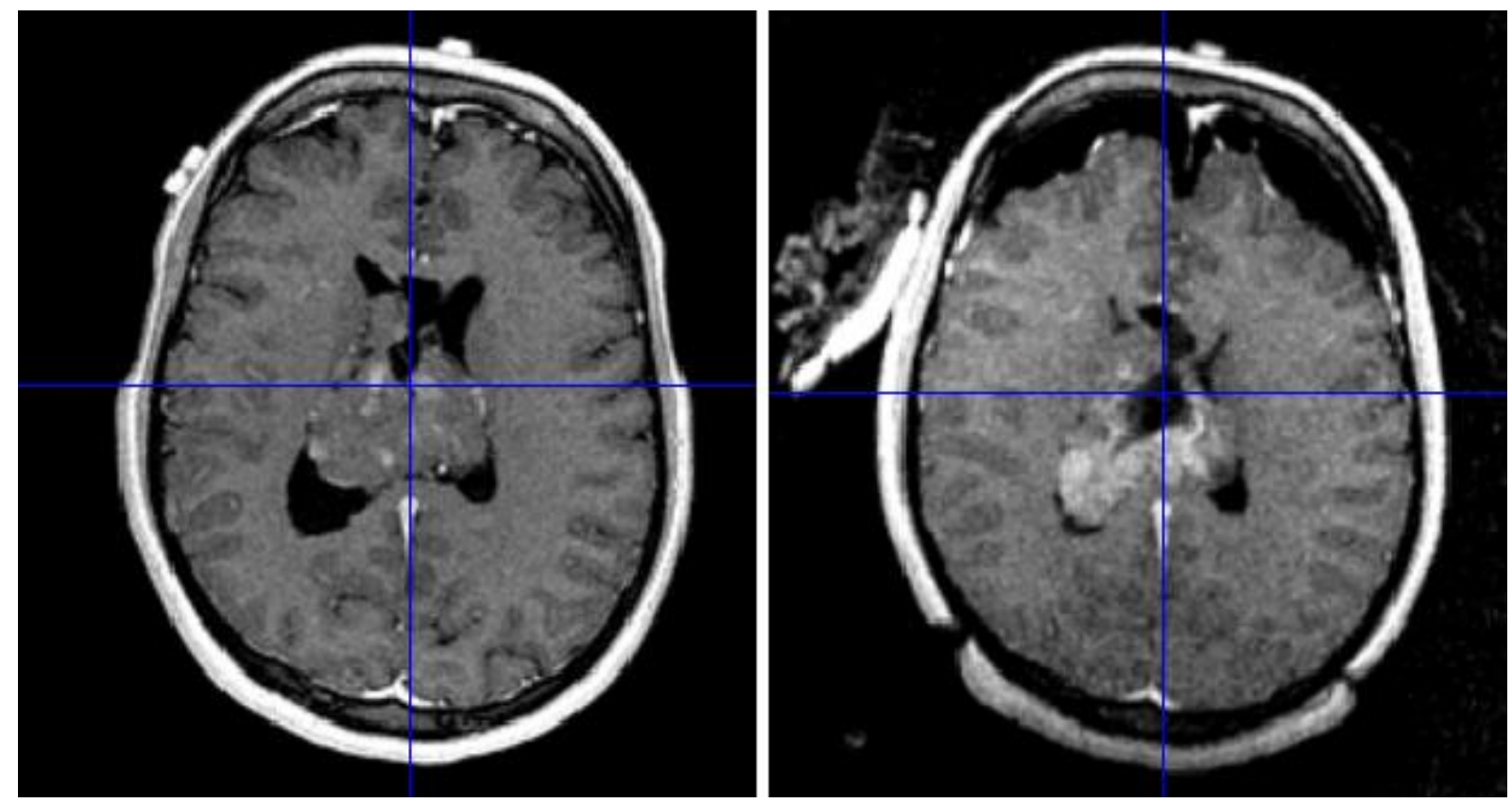

Figura 1: Imagens de ressonância magnética pré-operatória (esquerda) e intra-operatória (direita) demonstrando o Brain Shift.

A melhor solução para este problema é a utilização de imagens adquiridas em tempo real por ressonâncias magnéticas intra-operatórias. Mas como o custo desta solução ainda é muito alto, ela é utilizada apenas em poucos lugares. A ressonância magnética é o exame de escolha na definição das lesões epileptogênicas enquanto a ultrassonografia é um método comumente usado na avaliação intra-operatória [6], 
principalmente em casos de monitoramento em tempo real: na aspiração de fluidos, colocação de cateteres, na localização e avaliação de massas, bem como na confirmação da remoção completa das mesmas. Modalidades de imagens como: PET (Positron Emission Tomography), SPECT (Single Photon Emission Tomography) e mesmo a ITC [7] também podem ser usadas na avaliação pré-operatória, assim como, a modalidade Color Doppler tem sido usada durante a neurocirurgia [8].

As informações fundamentais obtidas deste corregistro multimodalidade são a deformação e o deslocamento das regiões cerebrais e, o "Brain Shift" é um problema tipicamente não-rígido e não-linear, cuja solução mais adequada é o corregistro nãorígido (deformável) [9]. A mesma situação é encontrada no processamento de imagens elastográficas [10], no qual as propriedades elásticas dos tecidos derivam, justamente da deformação e deslocamento das estruturas histológicas e isto demonstra que nosso estudo também pode se estender a esta modalidade de imagem. Por isso, através destas técnicas, este projeto tem o diferencial de integrar as informações mecânicas dos tecidos cerebrais na neuronavegação, fornecendo uma nova forma diagnóstica intra-operatória.

O uso da ultrassonografia intra-operatória como guia cirúrgico e para correção das imagens pré-operatórias pode ser utilizado através do corregistro rígido realizado entre um sistema de rastreio e as imagens pré-operatórias tornando possível a visualização das diferenças entre as condições [8]. No entanto há poucos trabalhos na literatura propondo o corregistro entre as imagens de ultrassom durante o procedimento cirúrgico de forma a acompanhar a evolução e as mudanças dos tecidos. Nos estudos in vivo, devido à natureza do problema, nem sempre é viável a quantidade de testes e o controle necessário para os estudos de corregistro nãorígido. Por isso o uso de fantomas, que são objetos que simulam tecidos para um ou mais tipos de imagens [11], possibilitam o estudo destas imagens em neurocirurgia. Com a retirada de uma inclusão há um deslocamento das estruturas próximas e o corregistro de uma imagem no mesmo local permite quantificar este deslocamento.

O objetivo deste trabalho é um estudo do corregistro livre não-rígido a partir de um modelo in vitro experimental que simule uma situação cirúrgica de retirada de uma inclusão líquida, de forma controlada, para medir os deslocamentos das estruturas próximas, utilizando imagens de ultrassom. Alguns fantomas que simulam o tecido humano nas imagens de ultrassom, feitos de gelatina e parafina [12], forma escolhidos como modelo. Para realizar o corregistro foi escolhida a transformação geométrica por 
splines simples (B-Splines), o otimizador Limited-memory Broyden-FletcherGoldfarb-Shanno (LBFGS) e a métrica de similaridade soma do quadrado das diferenças (SQD) e, utilizada a biblioteca Insight Segmentation and Registration Toolkit (ITK), assim como o estudo dos parâmetros adequados para a nossa tarefa. 


\section{Imagens Digitais}

As imagens digitais usadas em medicina são do tipo raster, que são formadas por matrizes de pontos chamados pixels, diferentemente das imagens vetoriais que são descritas por equações matemáticas e são muito usadas em artes gráficas, arquitetura e engenharia. Comumente cada pixel pode armazenar um valor (para imagens de um único tom ou coloridas do tipo indexada) ou três valores (RGB ou HSV) inteiros, e cada um destes pode assumir valores que dependem da quantidade de níveis de cor utilizada. Imagens médicas tipicamente utilizam tons de cinza e uma escala de 8 bits (ultrassom e ressonância magnética por exemplo) ou 16 bits (raios-X e tomografia computadorizada). Abaixo segue uma ilustração de uma imagem de tons de cinza [13].
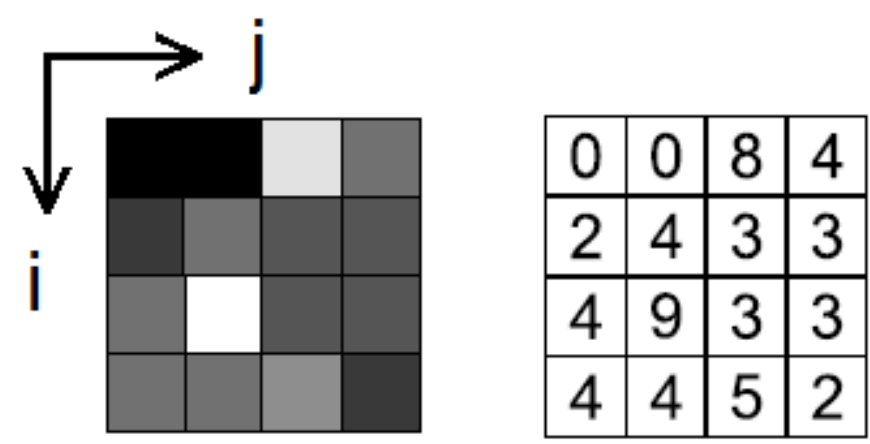

Figura 2: Imagem tipo raster de Tons de Cinza. Fonte: [14].

A escolha da escala de cor depende do equipamento que produz as imagens, do nível de detalhe desejado e do custo e capacidade de armazenamento destas. Imagens com maior discretização de cor precisam de mais espaço computacional para armazenamento e, assim como as com maior resolução espacial (número de pontos por unidade de comprimento). Uma imagem de alta resolução espacial possui muitos pixels e demanda mais armazenamento.

Como são matrizes o acesso aos valores dos pixels é feito pelo sistema de coordenadas matricial linha (i) e coluna (j). No caso de volumes de imagens é adicionada uma terceira dimensão, conhecida como folha $(\mathrm{k})$, para localizar as imagens. A origem se localiza no primeiro pixel e as coordenadas somente podem assumir valores inteiros positivos e, isto se configura em uma restrição às transformações geométricas, que mais adiante será demostrado como contorná-las. 


\subsection{Imagens por Ultrassom}

A imagem por ultrassom é uma técnica amplamente utilizada para a visualização de estruturas internas do corpo, tais como tendões, músculos, articulações, vasos e órgãos internos, na busca de eventual enfermidade e/ou de lesões. Essa técnica utiliza ondas acústicas com frequência acima da faixa audível do ouvido humano (por isso chamada de ultrassom), ou seja, com frequências superiores a 20 quilohertz. Os equipamentos de imagens por ultrassonografia possuem transdutores formados por vários elementos capazes de emitir e captar ondas mecânicas. Essas são emitidas por pulsos mecânicos na superfície do corpo (ou na superfície do órgão, no caso do uso como guia cirúrgico), sendo parcialmente refletidas nas interfaces dos tecidos, enquanto a parte não refletida continua se propagando, podendo ser refletida novamente caso encontre outra interface (Figura $3)$.

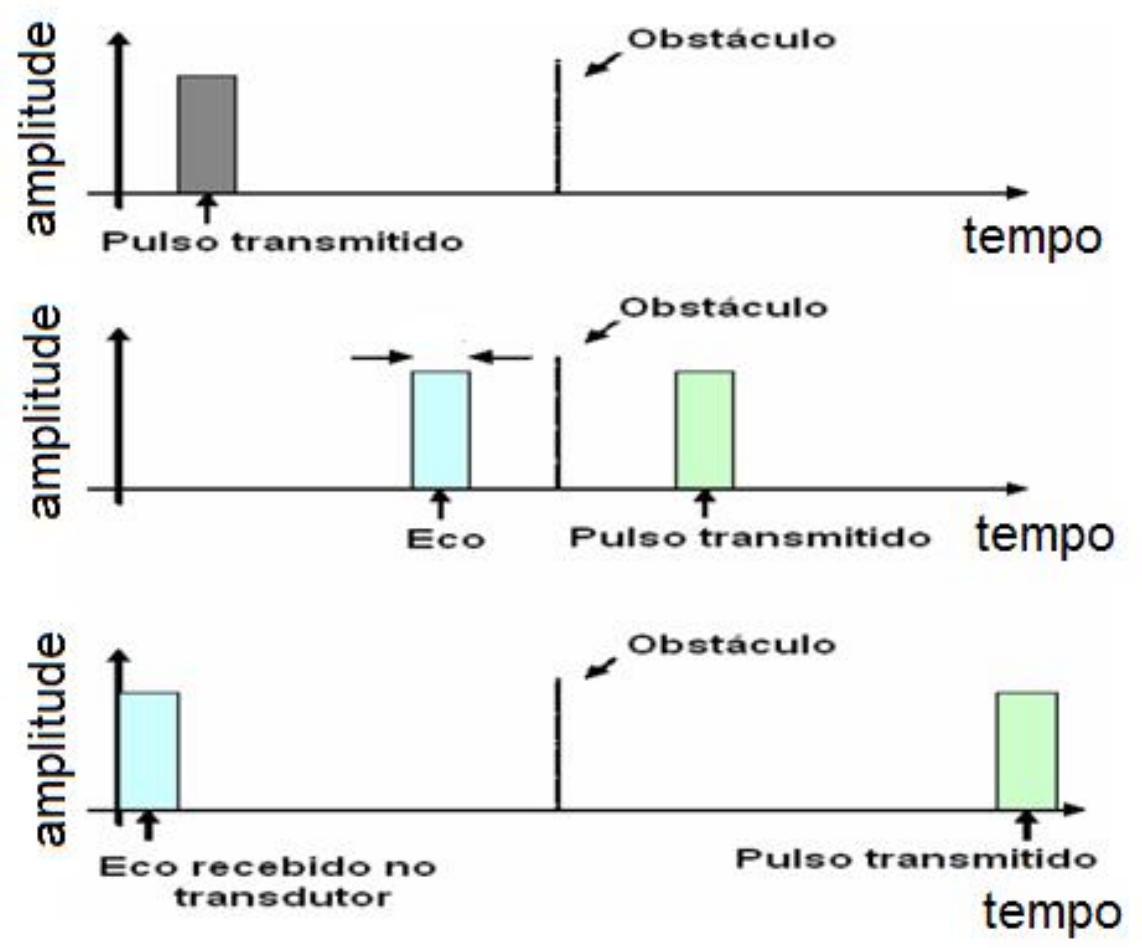

Figura 3: Esquema de Pulso Eco utilizado para a geração de sinais de ultrassom. Fonte: [12]

O fato que define a reflexão e a transmissão da onda ultrassonográfica é o de ter impedâncias acústicas específica (Z) diferentes em cada lado da interface. A impedância acústica específica é uma grandeza que depende da densidade $(\rho)$ e da velocidade de propagação da onda ultrassônica no meio (c), cujo valor médio para 
tecidos moles é aproximadamente $1540 \mathrm{~m} / \mathrm{s}$ [15]. Para uma onda acústica plana temos a seguinte equação:

$$
Z=\rho c
$$

A reflexão e a transmissão das ondas sonoras se dão da mesma forma que as ondas eletromagnéticas. Quanto maior a diferença entre as impedâncias das estruturas, maior é a amplitude do eco gerado na interface das estruturas e, por consequência, maior será o brilho da imagem. A geração dos pulsos e a captura dos ecos são realizadas com os mesmos elementos piezoelétricos que compõem o transdutor de ultrassom, sendo que, este controle de geração e detecção é feito eletronicamente por comandos temporizados [15]. Cada subconjunto de elementos que captura um eco forma uma linha de RF (Response Field ou Radio Frequency) e o conjunto destas forma o mapa de RF que é a base para todas as modalidades de imagens de ultrassom. A figura a seguir ilustra a linha de RF.

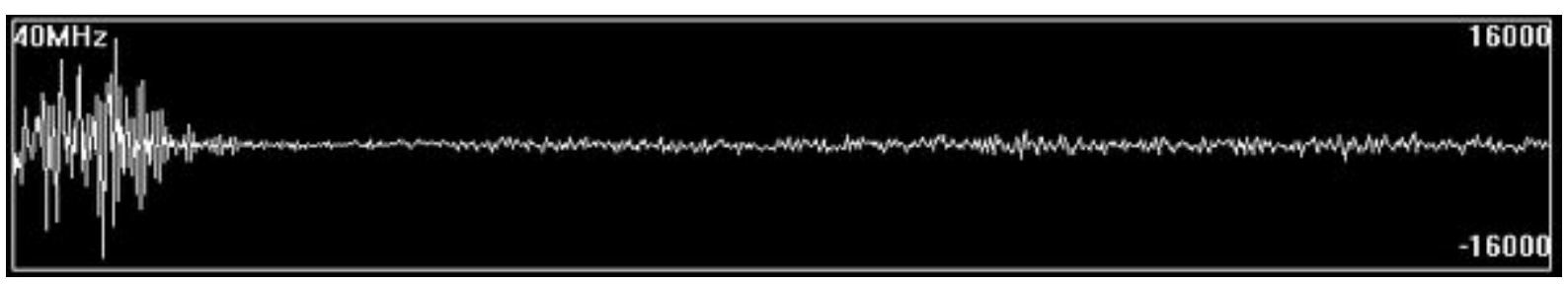

Figura 4: Linha de RF. Fonte: [16].

Os modernos aparelhos de ultrassom contemplam sistemas de geração de pulso-eco com o processamento dos dados em tempo real, tornando a técnica de ultrassom uma ferramenta com potencial para diagnóstico anatômico e quantitativo sobre o funcionamento dos órgãos. Além disso, é muito usado como guia não invasivo nos processos cirúrgicos [5]. As principais modalidades são: modo-B, modo-M, modo Doppler e o modo Elastográfico. Este último ainda está sendo implementado nos equipamentos modernos e é uma das áreas de pesquisa do Grupo de Inovação em Instrumentação Médica e Ultrassom (GIIMUS) da Universidade de São Paulo Campus de Ribeirão Preto. Para cada uma dessas modalidades de imagens existe um protocolo específico para o sistema de geração pulso-eco. Pode-se citar como vantagens da ultrassonografia:

- São métodos não invasivos ou minimamente invasivos;

- Imagens seccionais que podem ser adquiridas em qualquer orientação espacial; 
- Não possuem efeitos nocivos significativos para o uso em diagnóstico médico;

- Não utilizam radiação ionizante;

- Permitem a aquisição de imagens dinâmicas, em tempo real, possibilitando estudos de movimento das estruturas corporais;

- O modo Doppler possibilita o estudo não invasivo da hemodinâmica corporal;

- O equipamento e o custo do exame são muito mais baratos comparados à ressonância.

De posse das diferentes modalidades, das múltiplas aplicações clínicas e das características citadas acima, o ultrassom se tornou uma das técnicas de imagens mais usadas no diagnóstico clínico.

\subsubsection{Imagens Modo B (Brightness Mode)}

As linhas de RF são dados com alta resolução espacial (da ordem de décimos de micrômetros) e alta frequência (devido à frequência do sinal emitido). A resposta de uma interface no caminho de propagação do sinal é representada por muitos pontos com alta frequência o que faz que cada linha possua muitos pontos comparado com o número de linhas do transdutor (10 a 15 vezes mais). Desta forma a detecção do envelope do sinal melhor representa a amplitude espalhada deste. Este processamento é obtido através da transformada de Hilbert $\left(\mathrm{f}_{\mathrm{H}}\right)$ de cada linha [15]:

$$
f_{H}(t)=\frac{1}{\pi} \int_{-\infty}^{+\infty} \frac{f(\tau)}{\tau-t} d \tau
$$

Onde t é uma variável de tempo. Isto é feito em todas as linhas e, subsequentemente, é aplicada uma compressão logarítmica na escala de valores. Por fim é obtido a imagem modo $B$ que é a mais usada e conhecida. A figura a seguir ilustra um linha de RF e o seu envelope obtido pela transformada de Hilbert. 


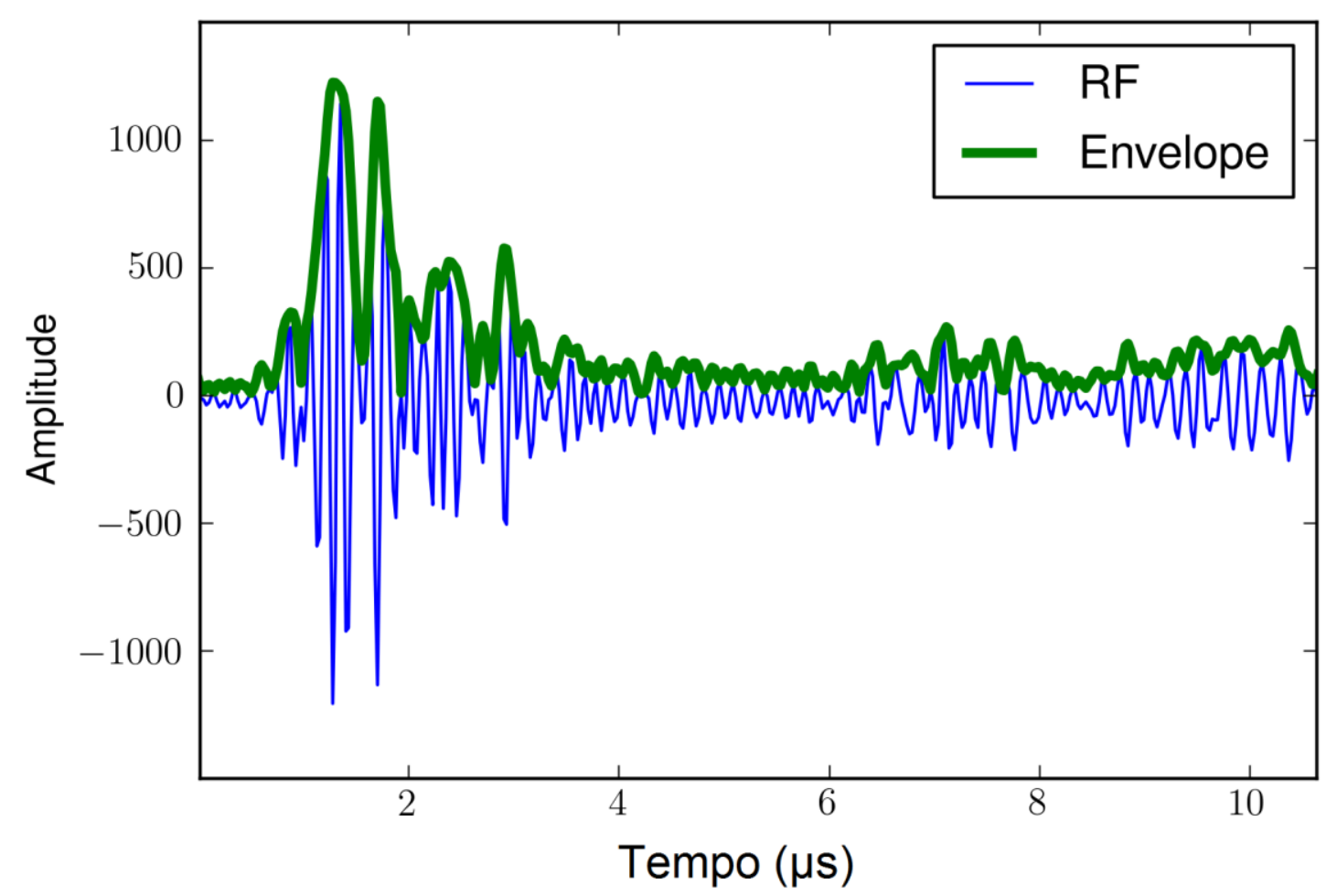

Figura 5: Sinal linha de RF e o modo B (Envelope). Fonte: [17]

\subsubsection{Elastografia por Ultrassom}

As mudanças nas propriedades elásticas dos tecidos estão geralmente relacionadas com seu estado patológico, portanto técnicas de imagens que detectem estas propriedades são altamente desejadas [18]. Nos últimos anos, técnicas elastográficas por ultrassom [19], por ressonância magnética nuclear [20] ou por métodos ópticos [21] têm sido amplamente pesquisadas.

Elastogramas podem mostrar a deformação no interior da região de interesse. Esta deformação geralmente é feita por forças externas aplicadas ao tecido, as quais podem ser estáticas ou dinâmicas [10]. No caso da elastografia por ultrassom esta medida é encontrada comparando os mapas de RF da região de interesse adquiridos antes $\left(p_{i}\right)$ e após a deformação $\left(p_{f}\right)$ (Figura 6). 


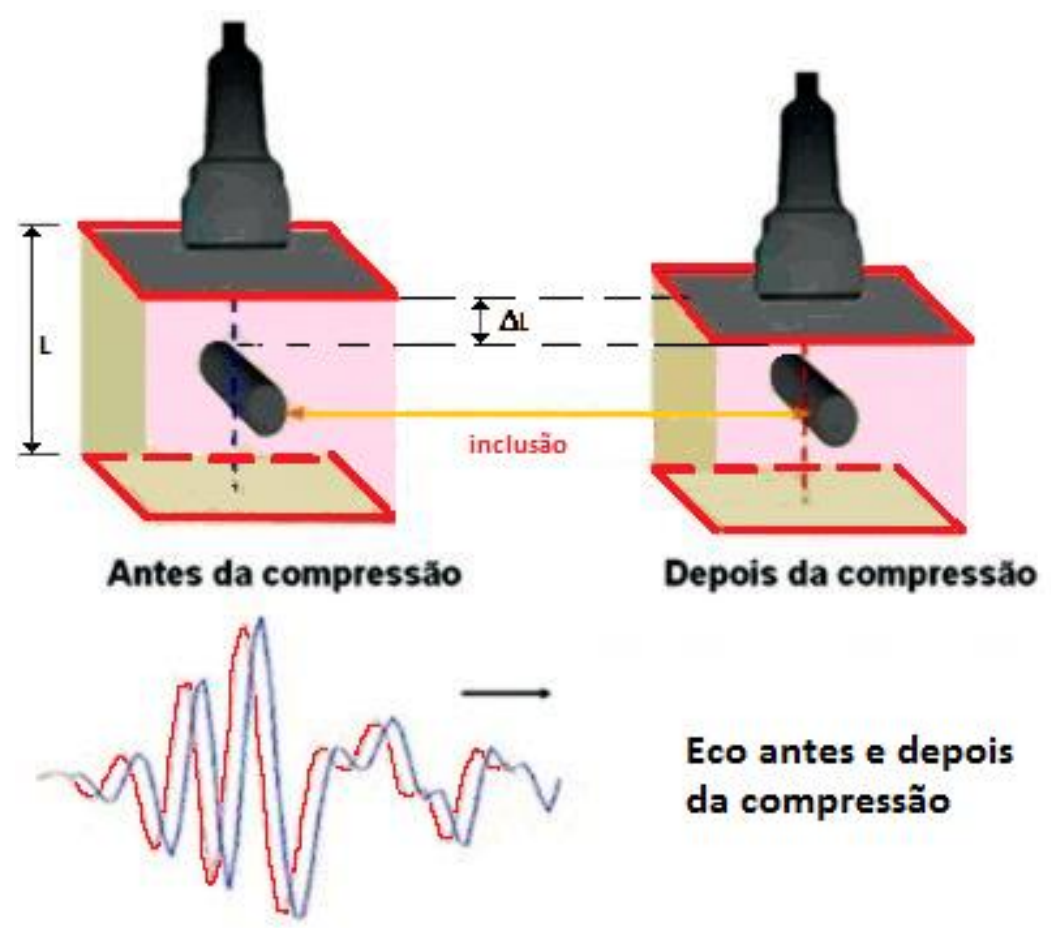

Figura 6: Eco adquirido antes e após a deformação da amostra. Fonte: [22]

O deslocamento das estruturas internas dos tecidos é monitorado através de mudanças de fase nos sinais de eco e através do gradiente do mapa de deslocamento a imagem de deformação é estimada [23], [24]. Esta imagem é denominada de mapa de deformação (s) e representa a taxa percentual de deformação dos tecidos póscomprimidos em relação aos pré-comprimidos. Com o conhecimento adicional do mapa de tensão $(\sigma)$ das imagens, podemos calcular o módulo elástico $(E)$, ou seja, a elastografia.

$$
\begin{gathered}
s=\frac{p_{f}-p_{i}}{p_{i}} \\
E=\frac{\sigma}{s}
\end{gathered}
$$

Normalmente os níveis médios de deformação produzidos no tecido são muito pequenos (entre 1 e 5\%) [25] e frequentemente, são usados métodos que utilizam uma fonte externa para produzir a distribuição força sobre toda a sua superfície (tensão). Para certos valores da razão entre profundidade e a largura da área de aplicação da força externa, pode-se afirmar que a tensão é aproximadamente constante com a profundidade [26], deste modo somente o mapa de deslocamento já é a própria elastografia. 
É importante salientar que para esta análise são necessários os mapas de RF que são obtidos no estágio de pré-processamento do equipamento de ultrassom, sendo necessário que a máquina os disponibilize, o que acontece somente em modelos específicos como a Ultrasonix Sonix RP que utilizamos no seguinte trabalho.

A qualidade de uma imagem elastográfica depende da exatidão e precisão das estimativas de deslocamento. Trabalhos recentes desenvolvidos pelo GIIMUS e outros pesquisadores observaram que os esforços para melhorar os algoritmos de rastreamento de movimento e reduzir a variância na estimativa de deslocamento são essenciais para fornecer imagens de elasticidade mais confiáveis [27]-[30]. A qualidade da imagem elastográfica do tecido também é afetada por outros fatores, tais como os parâmetros do sistema de ultrassom (frequência central, largura de banda e razão sinal-ruído de dados ultrassonográficos) e os parâmetros de processamento do mapa de deslocamento [31]. 


\section{Corregistro de Imagens Digitais}

O corregistro de imagens é um procedimento iterativo feito entre duas imagens, no qual são encontrados os parâmetros de uma transformação geométrica que alinhe morfologicamente uma das imagens em relação a outra. Por se tratar de um processo iterativo esta busca é feita através de uma função para comparar o quão similar as imagens estão, conhecida como função custo ou métrica de similaridade, e um otimizador que guie esta busca. As transformações geométricas são operações matemáticas que alteram as posições dos pixels e trabalham com números reais, diferentemente do sistema discreto de coordenadas da imagem, o que demanda um método de interpolação para definir as novas coordenadas. A figura abaixo exemplifica o procedimento de corregistro [32].

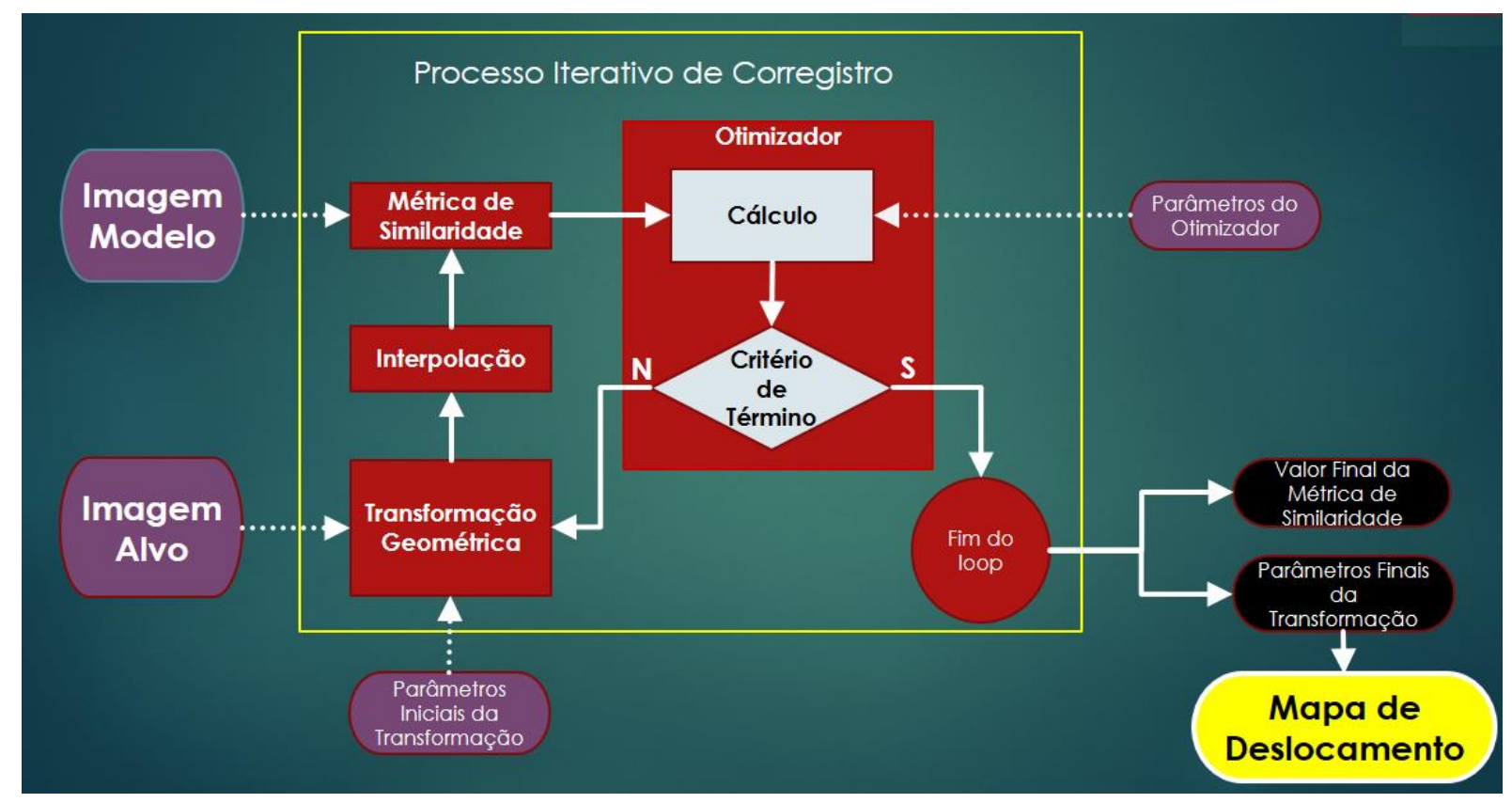

Figura 7: Diagrama do corregistro

Desta forma o que desejamos é encontrar a transformação geométrica que se aplicada à imagem alvo fará com que se torne morfologicamente igual a imagem modelo. Na próxima subseção os conceitos serão descritos de acordo com filosofia do ITK. 


\subsection{Insight Segmentation and Registration Toolkit (ITK)}

O ITK é um conjunto de bibliotecas, de código aberto e multiplataforma (Windows, Linux e Mac OSX), focado em segmentação e corregistro de imagens [33]. É implementado na linguagem $\mathrm{C}++$ e também pode ser utilizado nas linguagens $\mathrm{Tcl}$, Python, Java e C\#. Possui grande variedades de templates de classes de leitura de arquivos de imagens, processamento de intensidade de pixels (escala de tons, suavização, erosão, dilatação, etc...), transformações geométricas e, principalmente corregistro e segmentação. $\mathrm{O}$ conceito de template em $\mathrm{C}++$ permite criar classes genéricas que podem ser adaptadas conforme a necessidade. Por exemplo, o template Image é a base para criar uma classe de imagens e possui todas as características necessárias para uma imagem no âmbito do ITK, e para utiliza-lo devemos informar o tipo do pixel e a dimensão da imagem. Assim a instrução Image <float, $3>$ no código indica uma classe onde os pixels tem valores do tipo ponto flutuante (decimais) e possui 3 dimensões (trata- se de um volume de imagens). No lugar do float, poderia ser utilizado um vetor de duas ou três dimensões (o que significaria que cada pixel tem 2 ou 3 valores que poderiam ser do tipo float ou inteiro) ou ainda poderia ser um número complexo. No lugar do 3 poderia ser qualquer valor inteiro positivo (2 seria uma imagem e 4 um conjunto de volumes ao longo do tempo). Toda esta flexibilidade permite carregar ou criar os mais diferentes tipos de dados dependendo da situação abordada.

Além disso alguns conceitos geométricos associados às imagens foram ampliados, de modo a facilitar as operações geométricas. Uma arquivo de imagem Joint Photographic Experts Group (JPEG ou JPG) ou Portable Network Graphics (PNG), amplamente utilizados em fotografias ou em páginas da internet, não possui informação de origem geométrica, pois quando estes formatos foram propostos não havia aplicação para tal. A informação de espaçamento nem sempre está presente, apesar de descrever a resolução espacial da imagem. Já em um arquivo tipo DICOM (Digital Imaging and Communications in Medicine) ou Analyze, todas estas informações estão presentes, permitindo que imagens geradas por equipamentos diferentes possam compartilhar o mesmo espaço geométrico. A Figura 8 a seguir ilustra estes conceitos. 

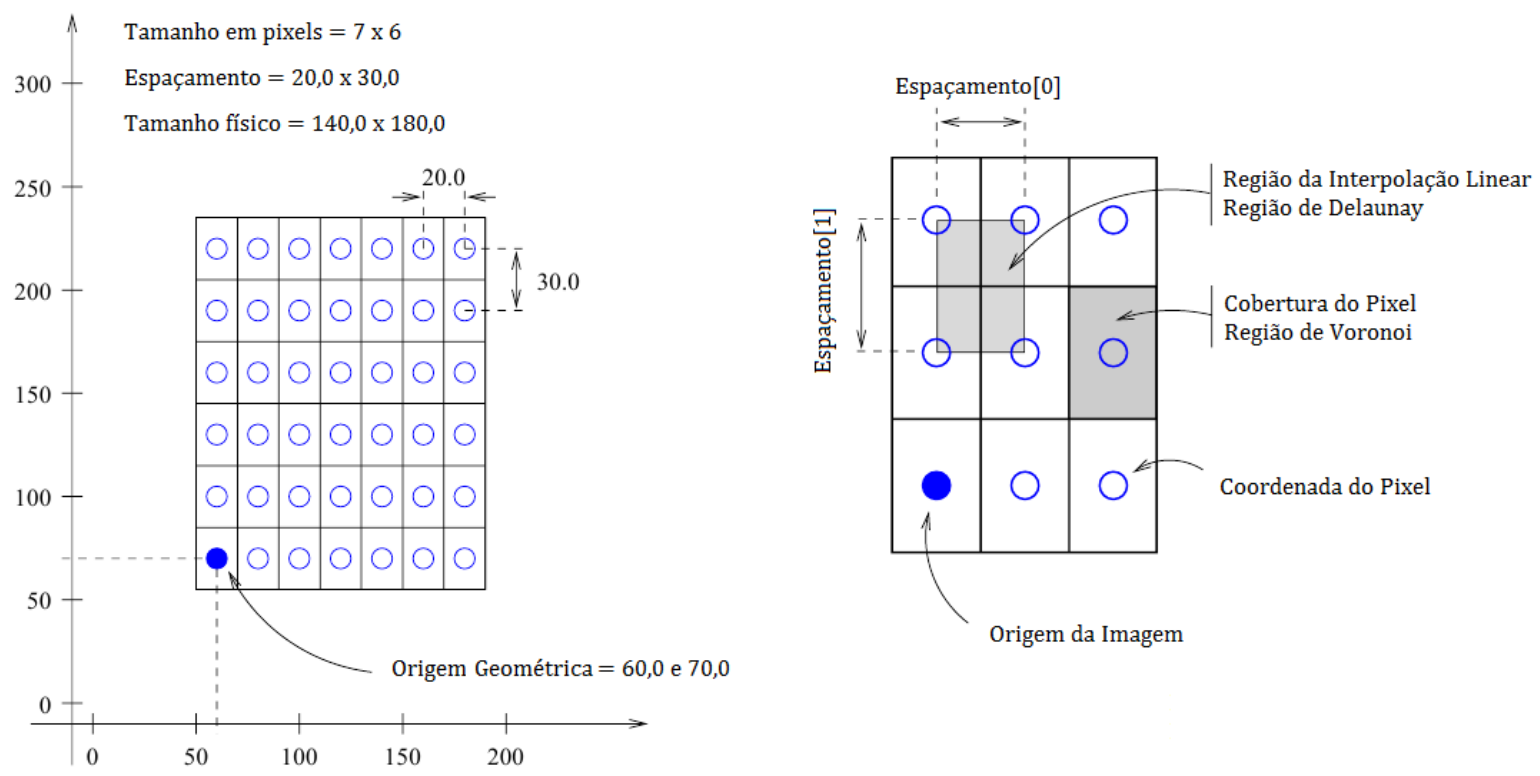

Figura 8: Conceitos geométricos associados com a imagem no ITK. Fonte: [33].

Por fim existe também a informação da orientação da imagem no espaço. Abaixo a figura ilustra duas imagens com tamanhos, espaçamento, tamanho físico, origem e orientação geométrica diferentes, no entanto pode se tratar do mesmo objeto.
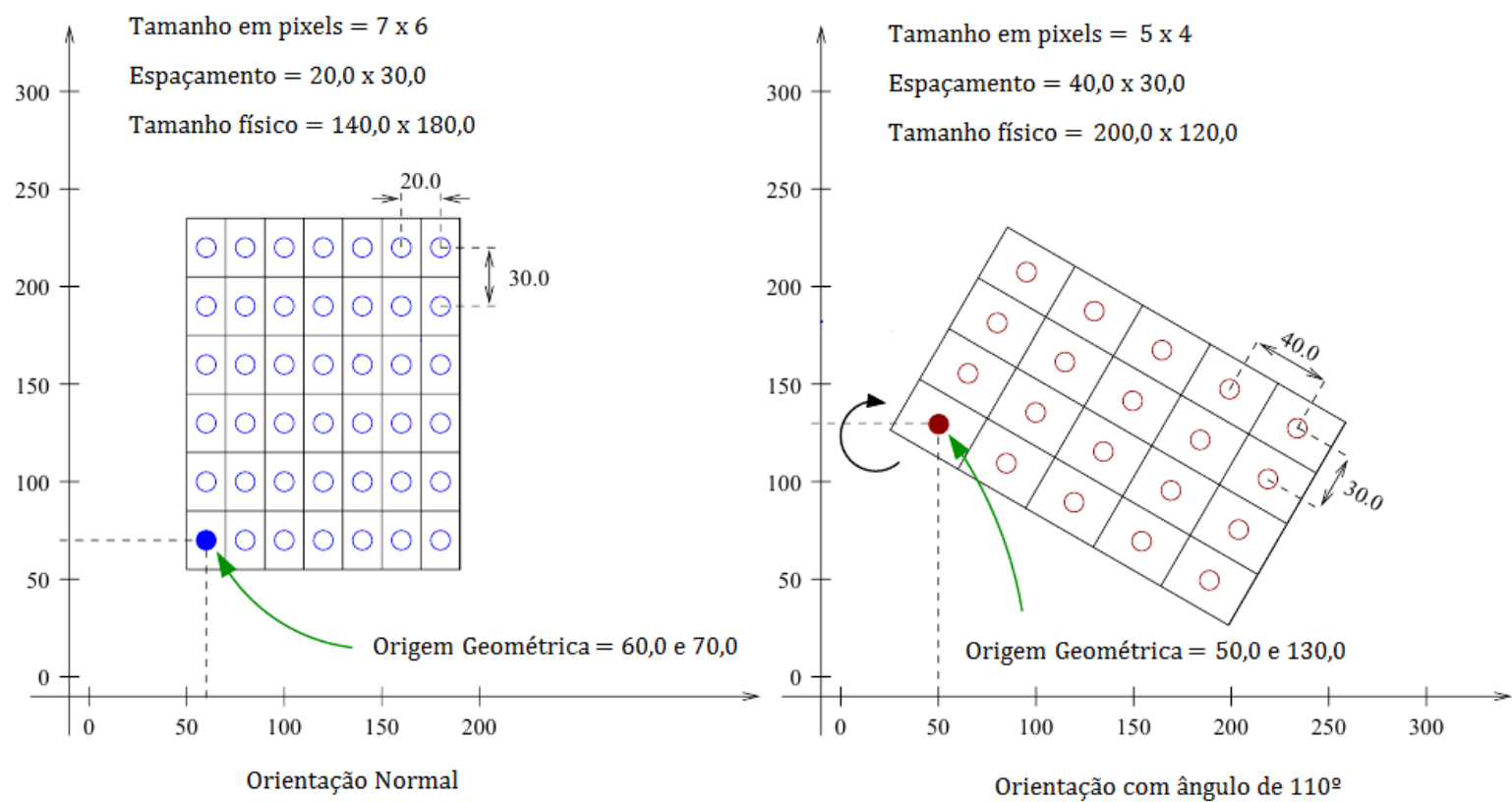

Figura 9: Imagens com todos os conceitos geométricos diferentes, mas pode se tratar do mesmo objeto. Fonte: [33].

Esses conceitos do espaço geométrico permite que as transformações possam ocorrer sem problemas e, por conseguinte, o corregistro. Desta forma, em relação à 
dimensionalidade, existem os corregistros 2D/2D (entre imagens), 3D/3D (entre volumes) - e 2D/3D - que ocorre quando se deseja correlacionar uma imagem com uma fatia de um volume, o que ocorre tipicamente entre uma imagem intra-operatória (IUS ou Raios-X) e um volume pré-operatório (IRM ou ICT), inclusive quando esta fatia representa um corte oblíquo do volume (situação desejada no procedimento cirúrgico guiado por ultrassom) e, todos estes tipos estão contemplados no ITK. Além disto, também é possível corregistrar uma imagem ou volume em relação a marcadores espaciais (um conjunto de pontos). O template do ITK que realiza o corregistro é o ImageRegistrationMethod.

\subsection{Transformações Geométricas}

As transformações geométricas são operações matemáticas aplicadas às coordenadas dos pixels, de forma a calcular as novas posições destes. As transformações podem ser globais (quando aplicada sobre a imagem toda) ou locais (quando aplicada sobre determinadas regiões). Pode-se ainda, dividir estas como rígidas e não-rígidas. A primeira é caracterizada por preservar as distâncias e os ângulos da imagem e a segunda é bem mais geral e envolve transformações elásticas [34]. É importante salientar que é sempre útil concatenar-se várias transformações para produzir um resultado composto, como a translação seguida de uma rotação ou outras transformações espaciais, por isto se utiliza matrizes quadradas chamadas de coordenadas generalizadas. Isto simplifica consideravelmente uma transformação geométrica múltipla, pois para obtê-la basta multiplicar as matrizes de transformações geométricas mais simples. Nas equações a seguir consideremos o vetor $(x, y, z)$ como a antiga posição e o vetor $\left(x^{\prime}, y^{\prime}, z^{\prime}\right)$ como a nova posição do pixel no espaço.

\subsubsection{Transformações de Corpo Rígido}

São constituídas por rotações, translações e mudança de escala [32]. Para o caso de rotações no espaço existem três planos ortogonais, nos quais o objeto da imagem pode ser rotacionado, expressos em torno dos eixos $X, Y$ e Z. A rotação de $\alpha$ radianos em torno do eixo $X$ é normalmente chamada de pitch, é realizada pela seguinte operação: 


$$
\left[\begin{array}{c}
x^{\prime} \\
y^{\prime} \\
z^{\prime} \\
1
\end{array}\right]=\left[\begin{array}{cccc}
1 & 0 & 0 & 0 \\
0 & \cos \alpha & \operatorname{sen} \alpha & 0 \\
0 & -\operatorname{sen} \alpha & \cos \alpha & 0 \\
0 & 0 & 0 & 1
\end{array}\right] \times\left[\begin{array}{c}
x \\
y \\
z \\
1
\end{array}\right]
$$

Da mesma forma, rotações em torno dos eixos $Y$ e $Z$, respectivamente chamadas de rolß $(\beta)$ e yaw $(\theta)$, são efetuadas pelas seguintes matrizes:

$$
\left[\begin{array}{cccc}
\cos \beta & 0 & \operatorname{sen} \beta & 0 \\
0 & 1 & 0 & 0 \\
-\operatorname{sen} \beta & 0 & \cos \beta & 0 \\
0 & 0 & 0 & 1
\end{array}\right] e\left[\begin{array}{cccc}
\cos \beta & \operatorname{sen} \beta & 0 & 0 \\
-\operatorname{sen} \beta & \cos \beta & 0 & 0 \\
0 & 0 & 1 & 0 \\
0 & 0 & 0 & 1
\end{array}\right]
$$

A operação de translação por um vetor té descrita da seguinte forma:

$$
\left[\begin{array}{c}
x^{\prime} \\
y^{\prime} \\
z^{\prime} \\
1
\end{array}\right]=\left[\begin{array}{lllc}
0 & 0 & 0 & t_{x} \\
0 & 0 & 0 & t_{y} \\
0 & 0 & 0 & t_{z} \\
0 & 0 & 0 & 1
\end{array}\right] \times\left[\begin{array}{c}
x \\
y \\
z \\
1
\end{array}\right]
$$

As transformações de escala são necessárias para alterar o tamanho de uma imagem, o que inclui transformações para trabalhar com imagens num espaço isotrópico. Isto é feio pela multiplicação de um fator $\mathrm{C}_{\mathrm{i}}$ para cada eixo:

$$
\left[\begin{array}{c}
x^{\prime} \\
y^{\prime} \\
z^{\prime} \\
1
\end{array}\right]=\left[\begin{array}{cccc}
C_{x} & 0 & 0 & 0 \\
0 & C_{y} & 0 & 0 \\
0 & 0 & C_{z} & 0 \\
0 & 0 & 0 & 1
\end{array}\right] \times\left[\begin{array}{l}
x \\
y \\
z \\
1
\end{array}\right]
$$

O ITK possui diversos templates para transformações rígidas dentre as quais podemos citar:

Tabela 1: Algumas Transformações Rígidas disponíveis no ITK

\begin{tabular}{|c|c|}
\hline Template & Tipo de Transformação \\
\hline IdentityTransform & Identidade \\
\hline TranslationTransform & Translação \\
\hline ScaleTransform & Escala \\
\hline Euler2DTransform & Rotação entorno da origem seguida de translação (somente em \\
\hline CenteredRigid2DTransform & Rotação entorno do centro seguida de translação (somente em 2D) \\
\hline QuaternionRigidTransfom & Transformação geral de corpo rígido utilizando quaternions \\
\hline Euler3DTransform & Versão para volumes da Euler2DTransform \\
\hline AffineTransform & $\begin{array}{c}\text { Transformação Geral de corpo rígido e perspectiva (engloba todas } \\
\text { as outras citadas) }\end{array}$ \\
\hline
\end{tabular}




\subsubsection{Transformações Não-Rígidas}

As transformações não-rígidas são as mais gerais, incluem as transformações rígidas como seu subconjunto assim como, os termos referentes às deformações elásticas determinados por modelos físicos. Deformação (tipo cisalhante), utilizando os parâmetros $S_{i j}$ pode ser realizada pela seguinte matriz:

$$
\left[\begin{array}{c}
x^{\prime} \\
y^{\prime} \\
z^{\prime} \\
1
\end{array}\right]=\left[\begin{array}{cccc}
S_{x x} & S_{x y} & S_{x z} & 0 \\
S_{y x} & S_{y y} & S_{y z} & 0 \\
S_{z x} & S_{z y} & S_{z z} & 0 \\
0 & 0 & 0 & 1
\end{array}\right] \times\left[\begin{array}{c}
x \\
y \\
z \\
1
\end{array}\right]
$$

Os parâmetros $S_{x x}$, $S_{y y}$ e $S_{z z}$ são referentes às deformações normais (fatores de escala com $S_{x x}=C_{x}, S_{y y}=C_{y}$ e $S_{z z}=C_{z}$ ). Os outros parâmetros são as deformações cisalhantes [35].

Para a situação de transformações não-rígidas o ITK possui alguns templates como: FEM (elementos finitos), BSplineDeformableTransform[36], DemonsRegistrationFilter[37] e outros baseados em kernels (por exemplo a ElasticBodySplineKernelTransform). A transformação adotada neste trabalho foi a BSplineDeformableTransform, por ser inédita a aplicação nas imagens de ultrassom e que consiste em construir uma grade esparsa e regular de pontos de controle. Cada ponto da grade funciona como um ponto de atração ou repulsão e a transformação $T(x, y, z)$ é obtida pela interpolação BSplines sobre os pontos de controle (Ф) [36]:

$$
T(x, y, z)=\sum_{l=0}^{3} \sum_{m=0}^{3} \sum_{n=0}^{3} B_{l}(u) B_{m}(v) B_{n}(w) \phi_{i+l, j+m, k+n}
$$

Onde $\quad i=\left\lfloor x / n_{x}\right\rfloor-1, j=\left\lfloor y / n_{y}\right\rfloor-1, \quad k=\left\lfloor z / n_{z}\right\rfloor-1, \quad u=x / n_{x}-\lfloor x\rfloor$ $\left.n_{x}\right\rfloor, \quad v=y / n_{y}-\left\lfloor y / n_{y}\right\rfloor, w=z / n_{z}-\left\lfloor z / n_{z}\right\rfloor$ e Bı representa a I-nézima função base da B-Spline:

$$
\begin{gathered}
B_{0}(u)=(1-u)^{3} / 6 \\
B_{1}(u)=\left(3 u^{3}-6 u^{2}+4\right) / 6 \\
B_{2}(u)=\left(-3 u^{3}+3 u^{2}+u+1\right) / 6 \\
B_{3}(u)=u^{3} / 6
\end{gathered}
$$

No corregistro os pontos de controle da imagem a ser transformada são iterativamente alterados até que a função custo seja minimizada. A figura a seguir ilustra a grade deformada obtida. 


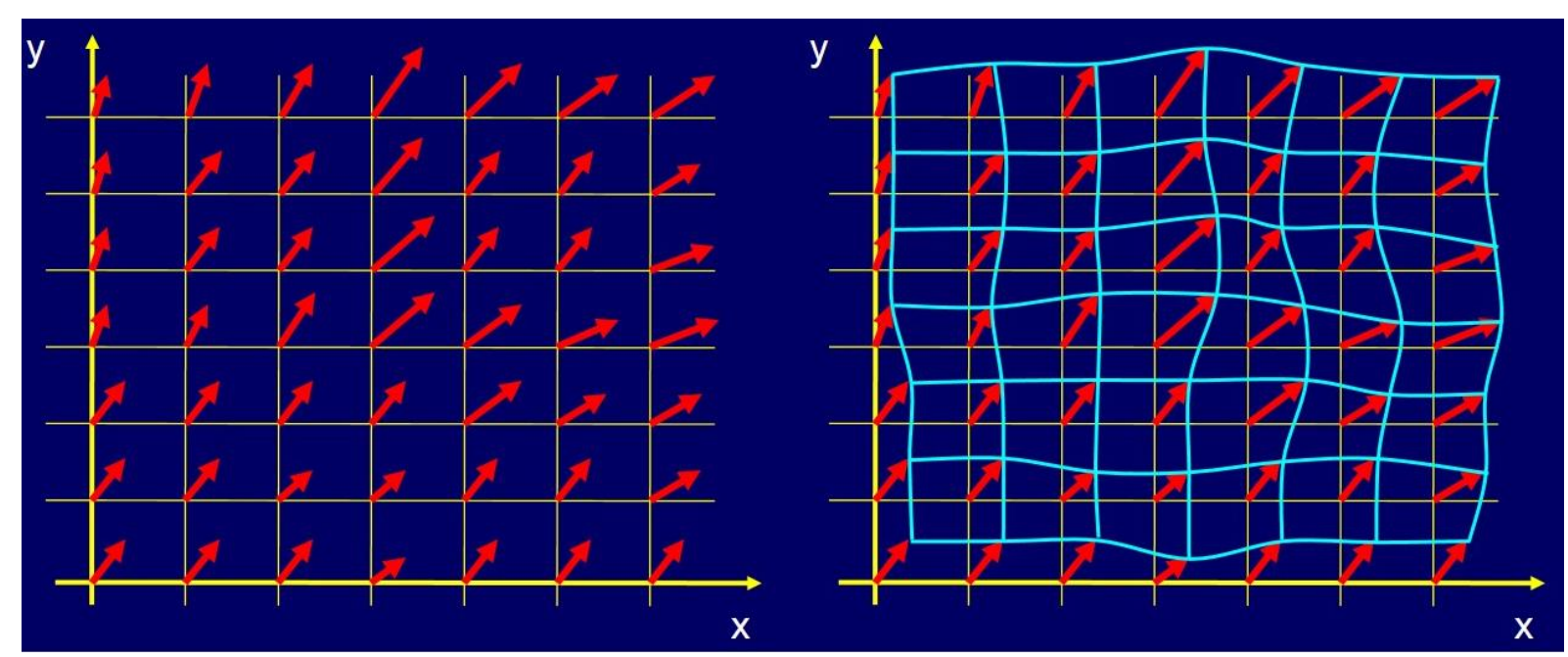

Figura 10: Mapa de deslocamento por grade de BSpline. Fonte: [33]

\subsection{Interpolação}

Devido à natureza da imagem digital os valores de posição i e j são discretos. No entanto em muitas aplicações surge a necessidade de trabalhar com valores de posição contínuos. A solução para este problema consiste em aproximar o valor no ponto por um valor de um ponto da vizinhança mais próximo possível ou buscar um método de interpolação. Isto significa encontrar um valor para um novo ponto entre pontos já existentes. Os métodos de interpolação mais utilizados são: por vizinhos mais próximos, linear, por splines e por função sinc. A Figura 11 ilustra a situação de uma transformação geométrica cujos pontos assumem valores contínuos.

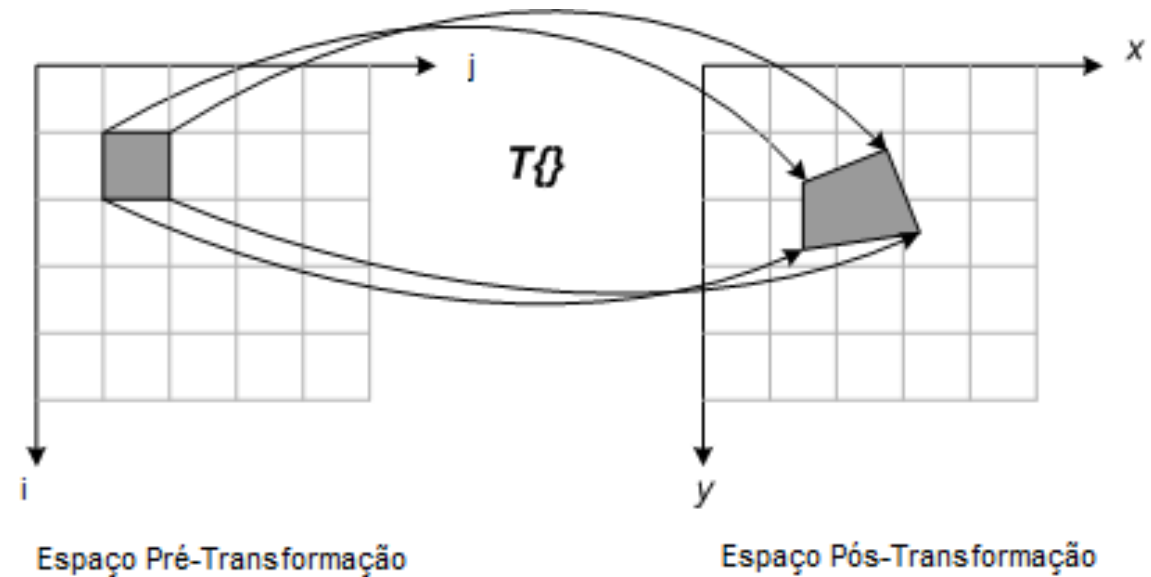

Figura 11: Transformação geométrica cujo as coordenadas dos pixels assumem valores contínuos. 
Os templates disponíveis no ITK para interpolação são: NearestNeighborlnterpolatelmageFunction (vizinhos mais próximos), LinearInterpolatelmageFunction (linear), BSplinelnterpolatelmageFunction (splines) e WindowedSincInterpolatelmageFunction (função sinc).

\subsection{Otimizador}

O otimizador é um algoritmo que busca minimizar ou maximizar uma determinada função e no contexto do corregistro é utilizado para guiar a busca pelos melhores parâmetros para a transformação geométrica. Existem na literatura diversos otimizadores como o método de Newton, o algoritmo de Levenberg-Marquardt, método gradiente descendente, simplex downhill e muitos outros derivados destes. No ITK estão disponíveis o AmoebaOptimizer (tipo de simplex), GradientDescentOptimizer (gradiente descendente), LBFGSOptimizer (tipo de quaseNewton) e outros. Neste trabalho adotamos o Limited memory Broyden, Fletcher, Goldfarb and Shannon minimization (LBFGSOptimizer) por ser adequado para problemas de otimização multidimensional como o corregistro não rígido [38].

O LBFGS é a versão com restrições de memória do BFGS que se baseia na derivada da expansão de Taylor de $2^{\mathrm{a}}$ ordem como a seguir para uma função de uma variável:

$$
\begin{gathered}
f(x)=f\left(x_{0}\right)+f^{\prime}\left(x_{0}\right)\left(x-x_{0}\right)+\frac{1}{2} f^{\prime \prime}\left(x_{0}\right)\left(x-x_{0}\right)^{2} f^{\prime}(x) \\
=f^{\prime}\left(x_{0}\right)+f^{\prime \prime}\left(x_{0}\right)\left(x-x_{0}\right)=0 \\
x_{n+1}=x_{n}-\frac{f^{\prime}\left(x_{n}\right)}{f^{\prime \prime}\left(x_{n}\right)}
\end{gathered}
$$

Para um caso de uma função de várias variáveis $x_{n+1}$ e $x_{n}$ são vetores, a primeira derivada é substituída pela matriz Jacobiana e a segunda derivada por uma matriz que é uma aproximação da matriz Hessiana. A ideia é atualizar a inversa da matriz aproximada da Hessiana de maneira simples a cada iteração, usando informação de curvatura obtida na iteração atual e na anterior [38]. O parâmetros sugeridos para o LBFGSOptimizer [33] são:

- GradientConvergenceTolerance =0.05; 
- LineSearchAccuracy = 0.9;

- DefaultStepLength = 1.5;

- MaximumNumberOfFunctionEvaluations = 1000;

\subsection{Métricas de Similaridade}

Os algoritmos de otimização das transformações geométricas buscam otimizar uma função custo, também chamada de métrica de similaridade, de forma a buscar uma transformação geométrica que maximize a similaridade entre duas imagens, ou entre duas regiões destas. As diferentes métricas representam formas de medir o quão similares são as imagens ou regiões. No ITK estão disponíveis várias métricas de similaridade como soma das diferenças quadráticas (MeanSquaresImageTolmageMetric), a correlação cruzada normalizada (NormalizedCorrelationlmageTolmageMetric), informação mútua (MutuallnformationImageTolmageMetric) [39], distância de Kullback-Leibler (KullbackLeiblerCompareHistogramlmageTolmageMetric), etc...

Neste trabalho adotamos a soma das diferenças quadráticas (SQD) que é uma métrica simples e amplamente utilizada como fator de otimização, que consiste na diferença ao quadrado do valor dos pixels das imagens [14], [33], [40]:

$$
S Q D=\sum \sum\left[I_{\text {modelo }}(i, j)-I_{\text {transformada }}(i, j)\right]^{2}
$$

\subsection{Natureza do Corregistro}

Para realizar a transformação espacial em uma imagem é necessária uma referência de corregistro, que pode ser extrínseca, intrínseca ou por sistema de rastreio.

\subsubsection{Extrínseca}

São realizadas por algum objeto externo acoplado ao paciente. Este objeto deve ser bem visível às modalidades de imagem escolhidas. Em geral são rápidos e automatizados, não sendo necessária uma otimização complexa. Como exemplos 
temos: parafusos fixados ao crânio, marcadores fiduciais colados sobre a pele e, principalmente o sistema estereotáxico (Figura 12), que é o mais utilizado em neurocirurgias[41].
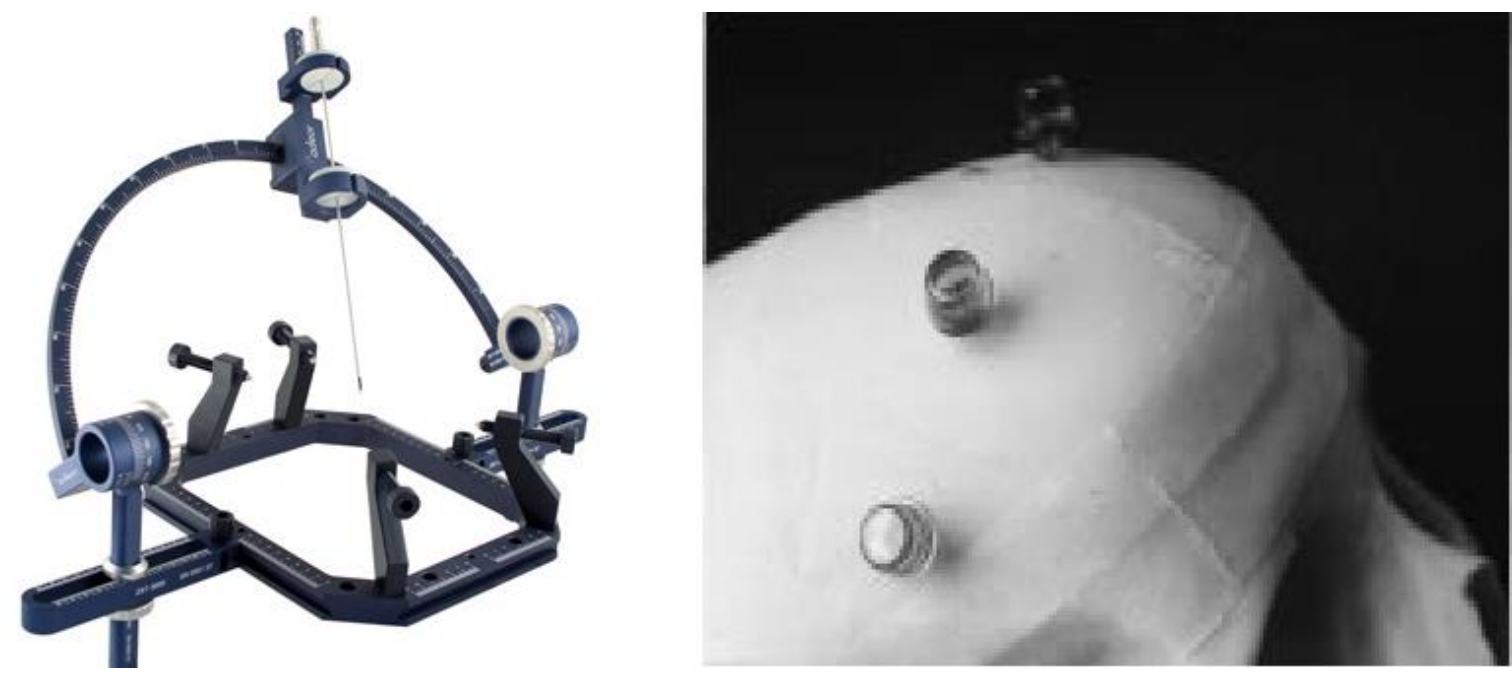

Figura 12: Sistema Estereotáxico (esquerda) e parafusos fixados ao crânio - Fiduciais - (direita)

\subsubsection{Intrínseca}

Neste caso a referência está contida nas próprias imagens a serem corregistradas. O mais comum é a escolha de pontos anatômicos bem definidos, como, no caso das imagens cerebrais, os pontos pré-auriculares e o nasion. Um outra maneira intrínseca é o uso de segmentação, de modo a corregistrar somente as bordas do objeto que consta na imagem. O corregistro monomodalidade (utilizando somente um tipo de imagem) e o processamento elastográfico se inserem nesta classificação [27].

\subsubsection{Por Sistema de Rastreio}

Nesta situação a referência é fornecida por um sistema de rastreamento espacial tridimensional. Transdutores de posição 3D medem em tempo real, a posição e orientação angular de objetos no espaço (três translações e três rotações). Os dois principais tipos de transdutores de posição são os magnéticos e os ópticos.

O primeiro é baseado na técnica de indução magnética constituído de um transmissor (bobinas excitadoras), um receptor (bobinas sensoras) e uma unidade de controle, como é, por exemplo, o Polhemus Patriot ${ }^{\mathrm{TM}}$ (Figura 13 - esquerda). O segundo tipo utiliza duas ou mais câmeras (Figura 13 - centro) para detectar radiação infravermelha provida por marcadores (Figura 13 - direita). Existem dois tipos de marcadores que podem ser usados no rastreamento óptico: marcadores ativos (emissores de infravermelho que são alimentados por energia elétrica) e marcadores passivos (são marcadores esféricos que refletem luz infravermelha, emitida por 
iluminadores sobre 0 transdutor de posição). $O$ transdutor calcula a posição e orientação dos marcadores baseado nas imagens captadas dos marcadores.
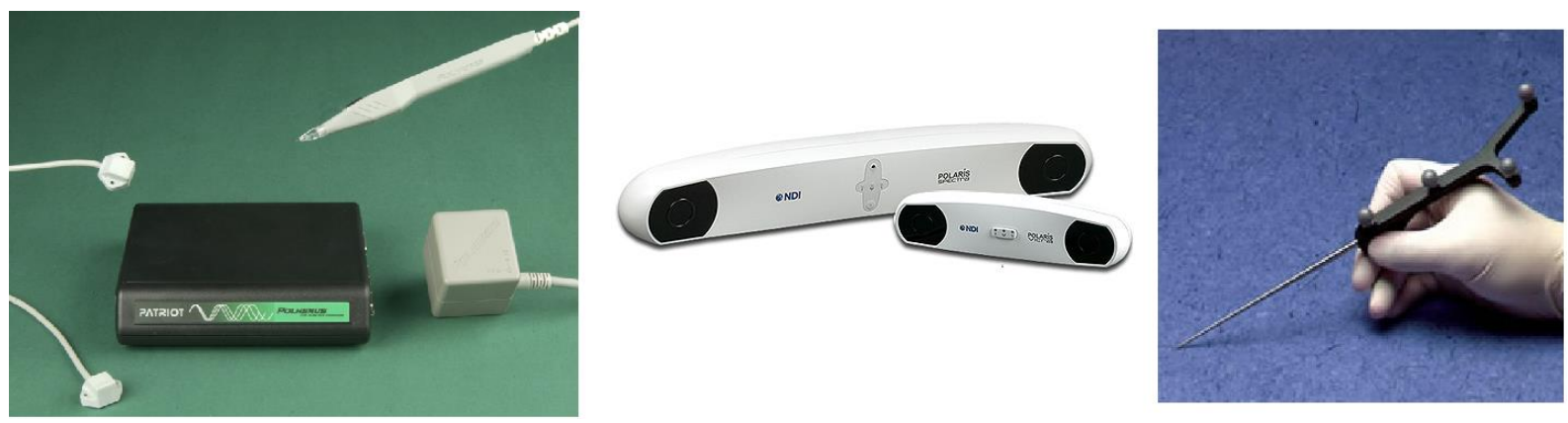

Figura 13: Polhemus Patriot ${ }^{\mathrm{TM}}$ (esquerda), os Polaris Spectra ${ }^{\mathrm{TM}}$ e Polaris Vicra ${ }^{\mathrm{TM}}$ (centro) e as NDI Passive Spheres ${ }^{\mathrm{TM}}$ fixadas em um objeto de metal (direita).

Ambos necessitam, para o uso em sistemas de neuronavegação, de um algoritmo de corregistro rígido como o Iterative Closest Point (ICP) ou Direct Linear Transform (DLT), para sistemas eletromagnéticos e ópticos, respectivamente.

\section{Procedimento Experimental}

\subsection{Sistema de Aquisição de Imagens no Espaço}

Em algumas modalidades de imagens, em geral nas tomográficas (ressonância magnética, SPECT, PET ou tomografia computadorizada), os equipamentos geradores capturam um volume de imagens e determinam uma referência espacial (sistema intrínseco). Desta forma os arquivos de imagens gerados possuem a informação de origem e orientação espacial em relação a tal referência. Isto facilita o corregistro de imagens realizadas em um mesmo equipamento (uma vez que qualquer imagem adquirida possui o mesmo sistema de coordenadas) e também entre equipamentos diferentes (através de uma mudança de base geométrica).

No caso do equipamento de ultrassom temos imagens que são geradas com um sistema de coordenadas móvel, uma vez que o transdutor pode ser colocado em qualquer lugar do espaço. Esta flexibilidade facilita aquisição da imagem em qualquer orientação desejada, como no guia cirúrgico, mas torna o corregistro uma tarefa muito complexa e computacionalmente muito custosa. Desta forma é necessário utilizar algum sistema de coordenadas fixo para que a aquisição das imagens no espaço seja conhecida (intrínseco, extrínseco ou utilizar algum sistema de rastreio). 
Para o propósito deste projeto foi utilizado um sistema extrínseco mecânico composto de três carrinhos que se movimentam ortogonalmente nas nos três eixos com a precisão de $0,1 \mathrm{~mm}$, um eixo com suporte para um transdutor de ultrassom para movimentos angulares com um goniômetro acoplado, permitindo movimentos com precisão de $0,25^{\circ}$ e uma placa acoplada a um dos carrinhos para fixação da amostra (Figura 14: Sistema de Rastreio utilizado para aquisição das imagens.Figura 14).

Com este sistema é possível a aquisição de imagens em planos paralelos (para formar um volume) e ou em um ângulo conhecido entre as superfícies do transdutor e do objeto de interesse (como acontece nas cirurgias guiadas por imagens), que garante a aquisição de imagens num mesmo lugar geométrico, minimizando o número de transformações geométricas (translações e rotações) e resumindo somente ao corregistro não rígido, uma vez que é humanamente impossível adquirir imagens exatamente nas mesmas posições.

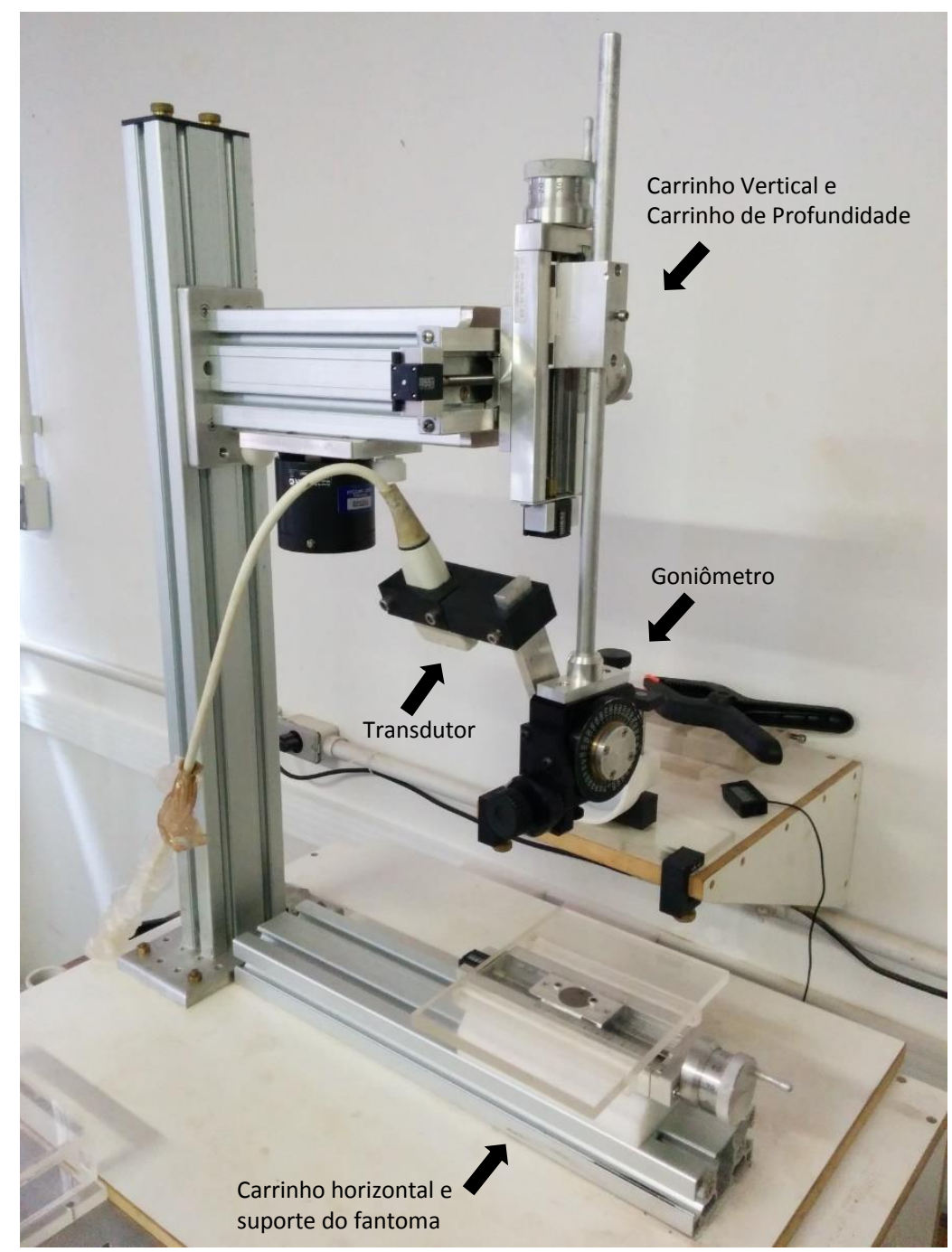

Figura 14: Sistema de Rastreio utilizado para aquisição das imagens. 
Inicialmente iríamos utilizar um sistema de rastreio Polhemus Patriot ${ }^{\circledR}$, que possuímos em nosso laboratório. No entanto a criação de volumes à mão livre demanda uma interpolação por grades esparsas que não estão inclusas no ITK e que poderia ser resolvido com uma outra ferramenta computacional como Visualization Toolkit (VTK) mas isto extrapolava o intuito deste trabalho.

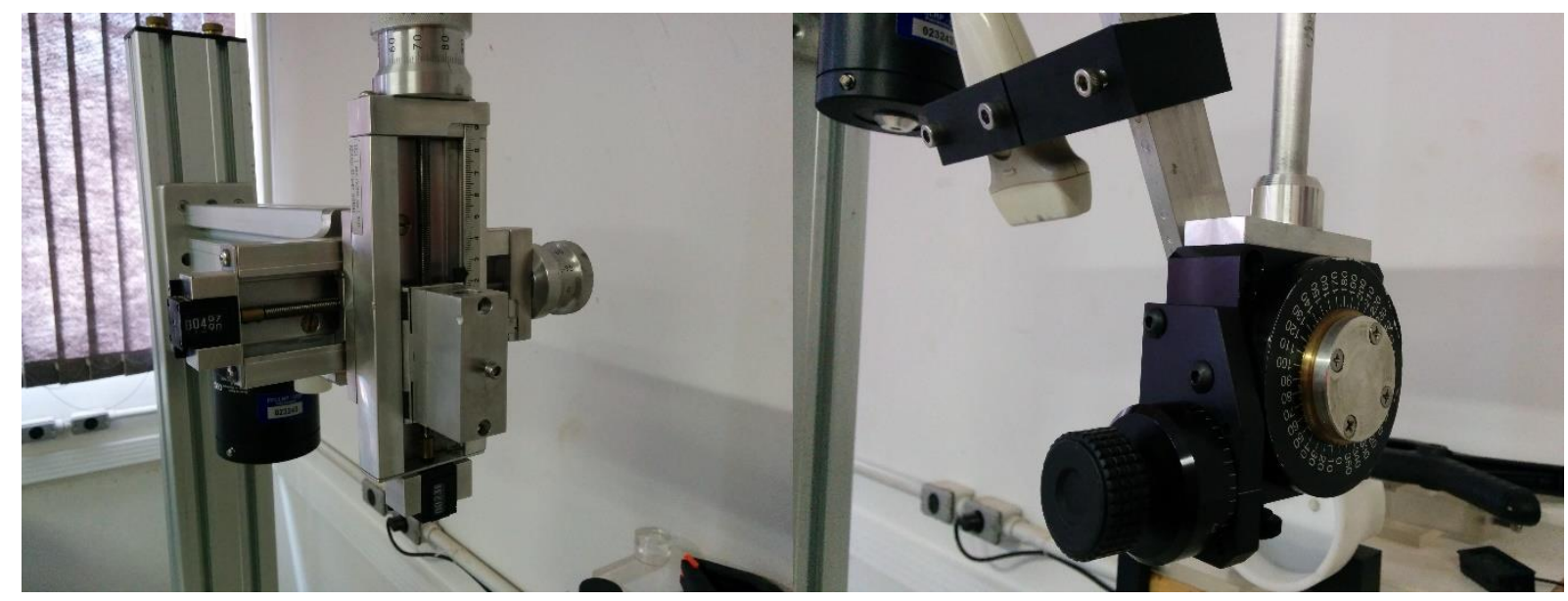

Figura 15: Detalhes do carrinho e do goniômetro do sistema de rastreio.

\subsection{Fantomas}

O uso de materiais simuladores de tecidos (fantomas) são fundamentais no estudos de ferramentas antes de qualquer estudo in vivo. Neste trabalho construímos fantomas de parafina [12] e gelatina [11], com e sem inclusão, para simular um procedimento cirúrgico de retirada desta. Foram utilizados dois formato: cúbico e o outro com a morfologia do cérebro humano (antropomórfico). Os de formato cúbico foram construídos dentro de uma caixa de acrílico, de dimensões $10 \times 10 \times 10 \mathrm{~cm}$, com um suporte para inserção de uma agulha veterinária de aço inox acoplada a uma seringa de volume $10,0 \pm 0,2 \mathrm{ml}$, utilizados para simular a retirada da inclusão por sucção sem danificar o fantoma (Figura 16). O fantoma antropométrico foi construído sobre uma estrutura óssea equivalente a de um crânio humano e seus detalhes estão descritos na subseção correspondente. Em todos os fantomas foi usado pó de vidro, com diâmetro de médio de $40 \mu \mathrm{m}$, como espalhador acústico. 


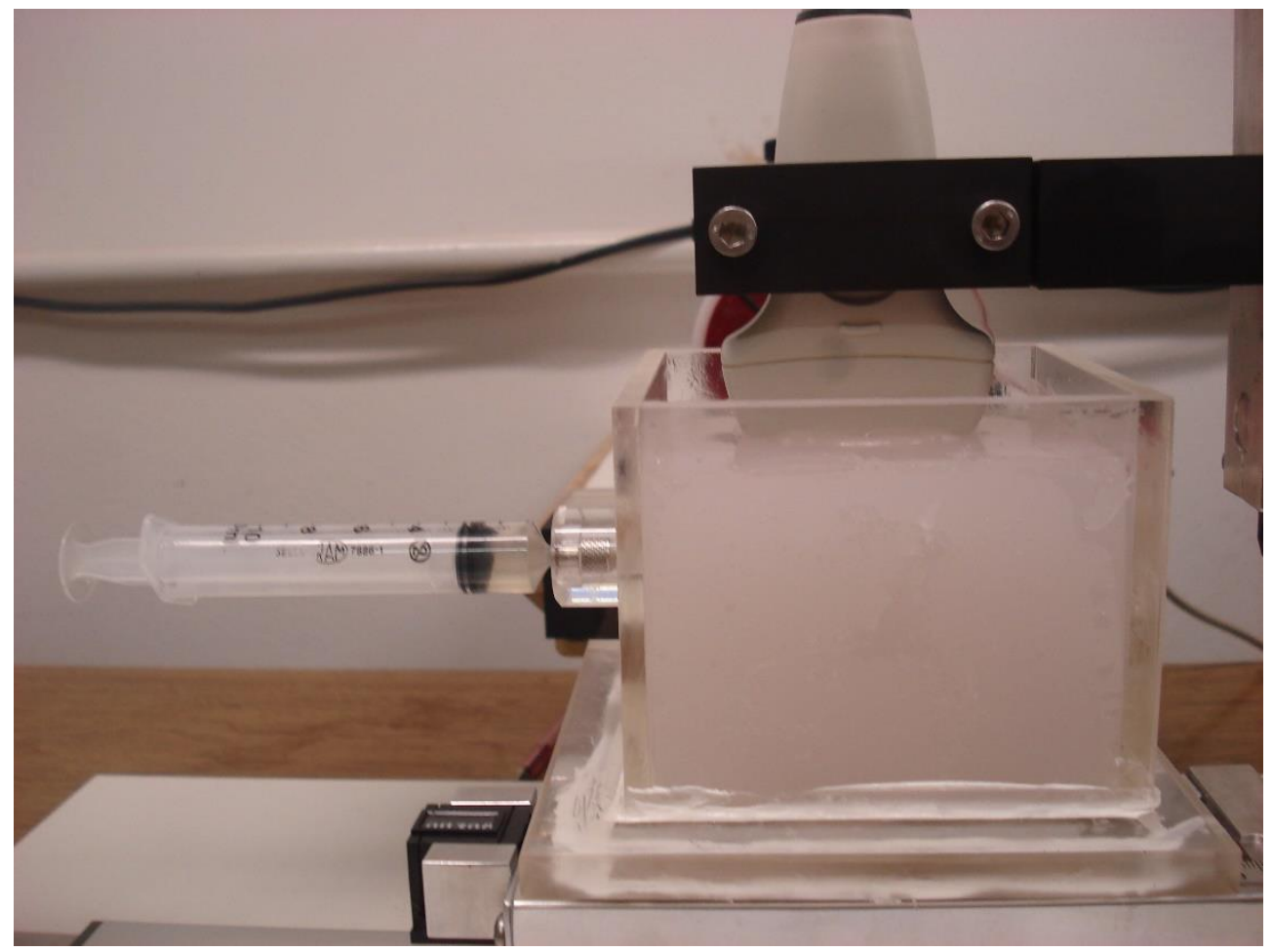

Figura 16: Fantoma cúbico dentro da caixa de acrílico com o suporte para a agulha.

\subsubsection{Parafina-Gel}

Para alguns experimentos foram construídos alguns fantomas com um material constituído de parafina-gel e pó vidro (0,5\% em massa) [6]. Este material possui boa estabilidade térmica, resistência a ataques de fungos e bactérias (mantendo as suas características ultrassônicas), elasticidade e é fácil manuseio, inclusive podendo ser reutilizado várias vezes. Foram construídos no formato cúbico e para simular uma região líquida, como um cisto, foi colocada uma inclusão de óleo de soja, que representa uma estrutura anecóica na imagem de ultrassom modo-B. O inconveniente da parafina é a velocidade do som, que é de aproximadamente $1480 \mathrm{~m} / \mathrm{s}$, abaixo dos $1540 \mathrm{~m} / \mathrm{s}$ que é o padrão dos equipamentos de ultrassom diagnóstico. Foram feitos 2 fantomas diferentes:

Tabela 2: Diferentes Fantomas de Parafina-Gel

\begin{tabular}{|c|c|c|}
\hline Fantoma & Diferenças & Volume da Inclusão $(\mathrm{ml})$ \\
\hline Tipo A & Normal & $2,2 \pm 0,1$ \\
\hline Tipo B & $\begin{array}{c}\text { Sem material } \\
\text { absorvedor }\end{array}$ & $4,2 \pm 0,1$ \\
\hline
\end{tabular}

O tipos A foi montado com uma placa de silicone no fundo da caixa cúbica para absorver e não provocar reverberação. $\mathrm{O}$ tipo $\mathrm{B}$, como não possui a placa, simula a reverberação provocada por alguma estrutura óssea. 


\subsubsection{Gelatina}

Outro material utilizado é feito à base de gelatina animal, que consiste na confecção de um gel utilizando a gelatina Bloom 250 da Gelitaß e pó de vidro. Este material tem a vantagem de possuir a velocidade acústica adequada (1540 m/s), mas possui a desvantagem de ser perecível, mesmo com o uso de formaldeído para evitar os ataques biológicos. O material é composto por água, gelatina 7,5 \%, ágar 2,3\%, formaldeído ( $\mathrm{HCHO}$ ) 0,24\% e pó de vidro 0,5\% em massa. A inclusão é formada por uma casca esférica de parafina-gel (capsula) preenchida com óleo de soja com volume de $4,8 \mathrm{ml}$.

\subsubsection{Antropomórfico}

Este fantoma foi construído com gelatina e segue a mesma receita descrita na subseção anterior. Para possuir a morfologia de um encéfalo humano este material foi montado em moldes, construídos com silicone e com um encéfalo modelo de plástico de oito peças. Foram moldadas 8 partes independentes, sendo quatro pares simétricos formando o lado esquerdo e direito do encéfalo, representando as seguintes partes do encéfalo: o cérebro (divido em quatro partes), o tálamo unido ao hipotálamo (duas peças) e o hipocampo (duas peças). Todas estas partes foram fundidas e montadas dentro de um crânio humano real.

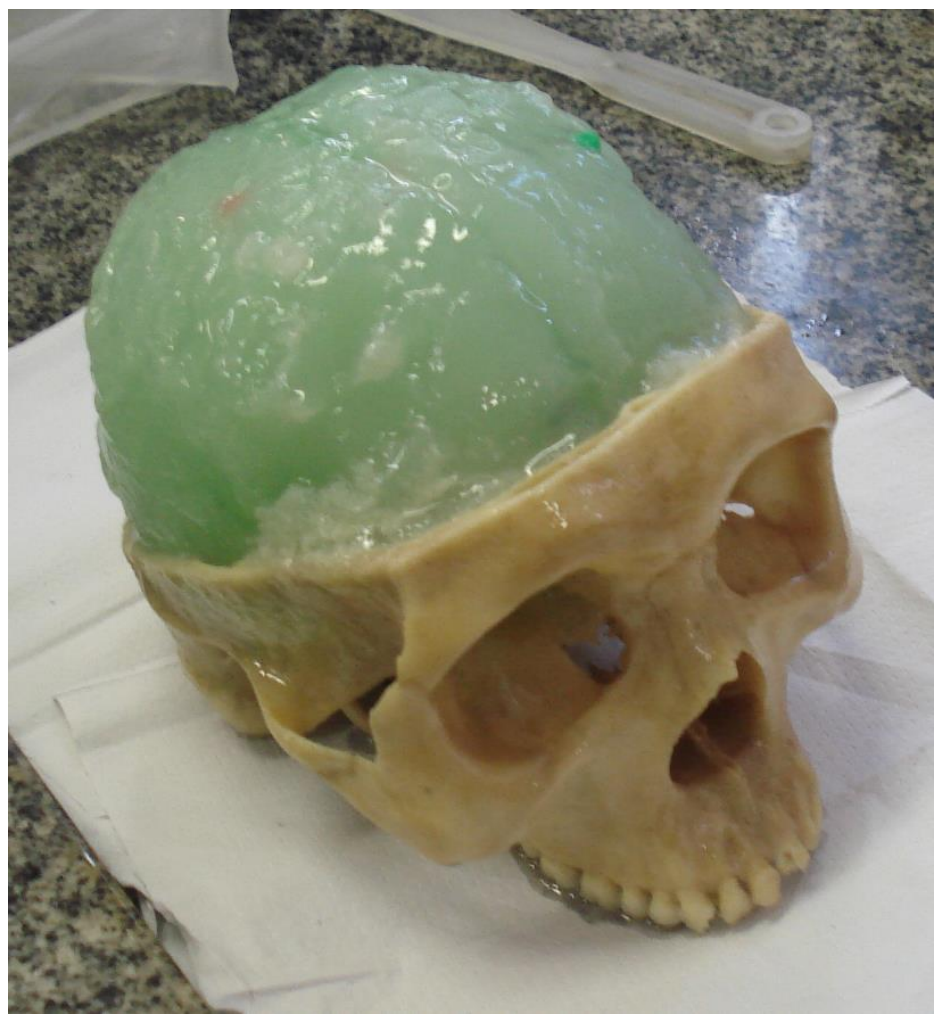

Figura 17: Fantoma Antropomórfico a base de gelatina animal Bloom 250 e composto de 8 partes montado em um crânio humano. 


\subsection{Aquisições}

Todas as aquisições foram feitas utilizando o equipamento de ultrassom modelo Sonix RP da empresa Ultrasonix. Este modelo possui uma interface de pesquisa e desenvolvimento que permite configurações de baixo nível em relação ao modo clínico, o que possibilita a modelagem do feixe ultrassônico (Beamforming) de emissão e recepção, a aquisição de imagens no modo RF, além das modalidades convencionais de imagens de diagnósticos. O transdutor utilizado foi o modelo L 14$5 / 38$ de 38 milímetros de largura (linear) e todas as aquisições foram com frequência central do sinal de ultrassom de $10 \mathrm{MHz}$ e a temperatura foi constante à $24{ }^{\circ} \mathrm{C}$.

As aquisições das imagens foram divididas em etapas de forma a simular um procedimento cirúrgico, assim foi feita sempre uma aquisição antes da intervenção (pré-cirúrgico) e outras conforme a retirada da região de interesse. Em cada etapa foi feita a aquisição de um conjunto de imagens em duas formas:

- Linear - o transdutor foi posicionado perpendicularmente à superfície do fantoma (goniômetro em zero graus) e deslocado ortogonalmente ao plano da imagem de forma a varrer um volume (Figura 18-esquerda).

- Angular - inicialmente o transdutor foi posicionado perpendicularmente à superfície do fantoma (goniômetro em zero graus), e as imagens foram adquiridas fazendo uma varredura angular no sentido anti-horário e horário (Figura 18-direita).

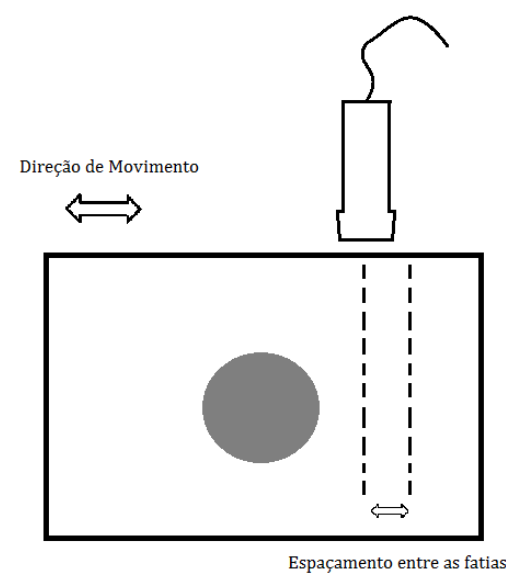

Linear

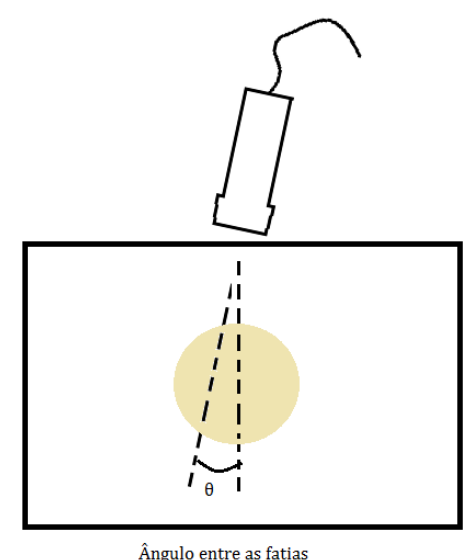

Ângulo entre as fatias

Angular

Figura 18: Aquisições Linear (direita) e Angular (esquerda) 


\subsubsection{Fantoma de Parafina-Gel A}

- Modos de Imagens: modo B.

- Etapas: 1 e 2 (retirada de 1,6 ml da inclusão).

- Profundidade: $40 \mathrm{~mm}$

- Tamanho em pixels: 439 colunas x 491 linhas, o que corresponde a um espaçamento entre os pixels de $(0,087 \mathrm{~mm})$.

- Aquisição Linear: 27 fatias com espaçamento de $1 \mathrm{~mm}$ entre as fatias.

- Angular: 33 fatias de $\left(-32^{\circ}\right.$ a $32^{\circ}$ de espaçamento de $\left.2^{\circ}\right)$

\subsubsection{Fantoma de Parafina-Gel B}

- Modos de Imagens: modo B e RF.

- Etapas: 1, 2 (retirada de $1 \mathrm{ml}$ da inclusão), 3 (2,8 ml), 4 (3,2 ml) e 5 (4 ml acumulados).

- Profundidade: $50 \mathrm{~mm}$

- Tamanho em pixels

- Modo B: 351 colunas x 462 linhas, o que corresponde a um espaçamento entre os pixels de $(0,108 \mathrm{~mm})$.

- RF: 256 colunas x 3120 linhas, o que corresponde a um espaçamento entre os pixels de 0,148 $\mathrm{mm}$ e 0,01602 $\mathrm{mm}$

- Aquisição Linear: 12 fatias com espaçamento de $2 \mathrm{~mm}$ entre as fatias.

- Angular: 20 fatias de $\left(-20^{\circ}\right.$ a $18^{\circ}$ de espaçamento de $\left.2^{\circ}\right)$

\subsubsection{Fantoma de Gelatina}

- Modos de Imagens: modo B.

- Etapas: 1, 2 (retirada de 1,4 ml da inclusão), $3(2,4 \mathrm{ml})$ e 4 (4,0 ml acumulados).

- Profundidade: $60 \mathrm{~mm}$

- Tamanho em pixels: 217 colunas x 340 linhas, o que corresponde a um espaçamento entre os pixels de $(0,176 \mathrm{~mm})$.

- Aquisição Linear: 21 fatias com espaçamento de $1 \mathrm{~mm}$ entre as fatias.

- Angular: 27 fatias de (-26ำ a $26^{\circ}$ de espaçamento de $\left.2^{\circ}\right)$.

\subsubsection{Fantoma Antropomórfico}

- Modos de Imagens: modo B e RF.

- Etapas: 1, 2, 3, 4, 5 e 6.

- Profundidade: $70 \mathrm{~mm}$ 
- Tamanho em pixels: 185 colunas x 342 linhas, que corresponde a um espaçamento entre os pixels de $(0,2046 \mathrm{~mm})$.

- Aquisição Linear: 13 fatias com espaçamento de $1 \mathrm{~mm}$ entre as fatias.

\subsection{Processamento}

As imagens modo $\mathrm{B}$ adquiridas pelo equipamento Sonix $R P$ são salvas como arquivos na extensão b8 e os mapas de RF na extensão rf. Como estes formatos não são compatíveis com o ITK, foi necessário desenvolver uma rotina em Matlab para fazer a leitura destes arquivos e converter para algum formato adequado sem a perda de informação. Nos arquivos b8 o valor de intensidade do pixel está armazenado pelo tipo unsigned char (8 bits) que possui valores de 0 a 255 e nos arquivos if o tipo utilizado é o short (16 bits) que possui valores de -32767 a 32767 . O formato de imagem adotado para conversão para ambos os casos foi o PNG (Portable Network Graphics) que é um tipo de compressão sem perda e que aceita os tipos unsigned char e unsigned short. Para os arquivos b8 a conversão é natural, mas para os arquivos rf é necessário um ajuste, pois o tipo unsigned short armazena valores de 0 a 65536.

Para a construção do programa de corregistro foi utilizada a biblioteca ITK versão 3.2, mais especificamente os templates de transformação por BSplines (BSplineDeformableTransform), o otimizador LBFGS (LBFGSOptimizer), a métrica de diferença quadrática média (MeanSquaresImageTolmageMetric) e o interpolador linear (LinearInterpolatelmageFunction). O projeto foi montado utilizando a ferramenta $\mathrm{CMake}^{\mathrm{TM}}$, compilado com o gcc versão $4.9 .1 \mathrm{e}$, como foram feitos muitos processamentos, foram utilizados scripts em bash para automatizar os procedimentos.

Os mapas de deslocamento foram salvos no formato Metalmage do ITK (extensão mhd ou mha) e para visualização destes foi utilizado o programa VV 4D Slicer ou Matlab (a partir da conversão para Analyze 7.5).

Todos os processamentos de corregistro foram realizados em um computador com processador Intel Core i7 com a 3,2 GHz e memória RAM de 6 GB DDR3 a 1066 $\mathrm{MHz}$ com sistema operacional Linux, distribuição Knoppix com kernel 64 bits versão 3.2. 


\section{$5 \quad$ Análises e Resultados}

Não há referências na literatura que indique quais parâmetros devem ser utilizados no corregistro não-rígido feito pela transformação por BSplines e o otimizador LBFGS. O tamanho da grade da transformação indica a quantidade de pontos de controle e portanto o grau de resolução da transformação e, isto é diretamente proporcional ao tempo computacional. Já o otimizador depende parcialmente da função de custo. $O$ guia do ITK arbitrariamente utiliza grades de BSpline de $5 \times 5$ e para o LBFSG com a função custo de diferenças quadráticas os parâmetros

DefaultStepLength, LineSearchAccuracy

e GradienteConvergenceTolerance com os valores 0,9, 1,5 e 0,05 respectivamente [33], para o corregistro intramodalidade de imagens de ressonância magnética de 8 bits, aproximadamente quadradas e sem especificar o grau de deformação. Portanto não há nenhum indicativo que tais parâmetros funcionariam para as nossas imagens de modo $\mathrm{B}$ e os mapas de RF e, caso funcionasse, também não indicaria que estes seriam os que proveriam melhor performance. Portanto a investigação do grau de deformação o qual é possível corregistrar utilizando o nosso programa e a busca por parâmetros que melhor respondem à nossa situação se faz necessária.

Este capítulo está divido em duas partes:

- Otimização: as seções 5.1, 5.2 e 5.3 se referem aos testes com os parâmetros do corregistro e para isto foi escolhida uma imagem aleatoriamente de um dos volumes adquiridos (no caso foi um corte angular à -18 graus do Fantoma de Parafina-Gel B após a remoção parcial da inclusão, conforme a Figura 19). Foram aplicadas deformações conhecidas.

- Aplicação: as demais seções se referem ao uso do corregistro nos dados das aquisições com os fantomas simulando uma intervenção cirúrgica utilizando os parâmetros determinados anteriormente. Os resultados estão nas seções 5.4, 5.5, 5.6 e 5.7.

Vale ressaltar que em nenhum processamento durante todo o projeto foi alcançado o número de máximo de iterações (fixado em 1000). Os pontos hiperecoicos na imagem modo B (Figura 19) são devido a bolhas de ar presente no fantoma. 

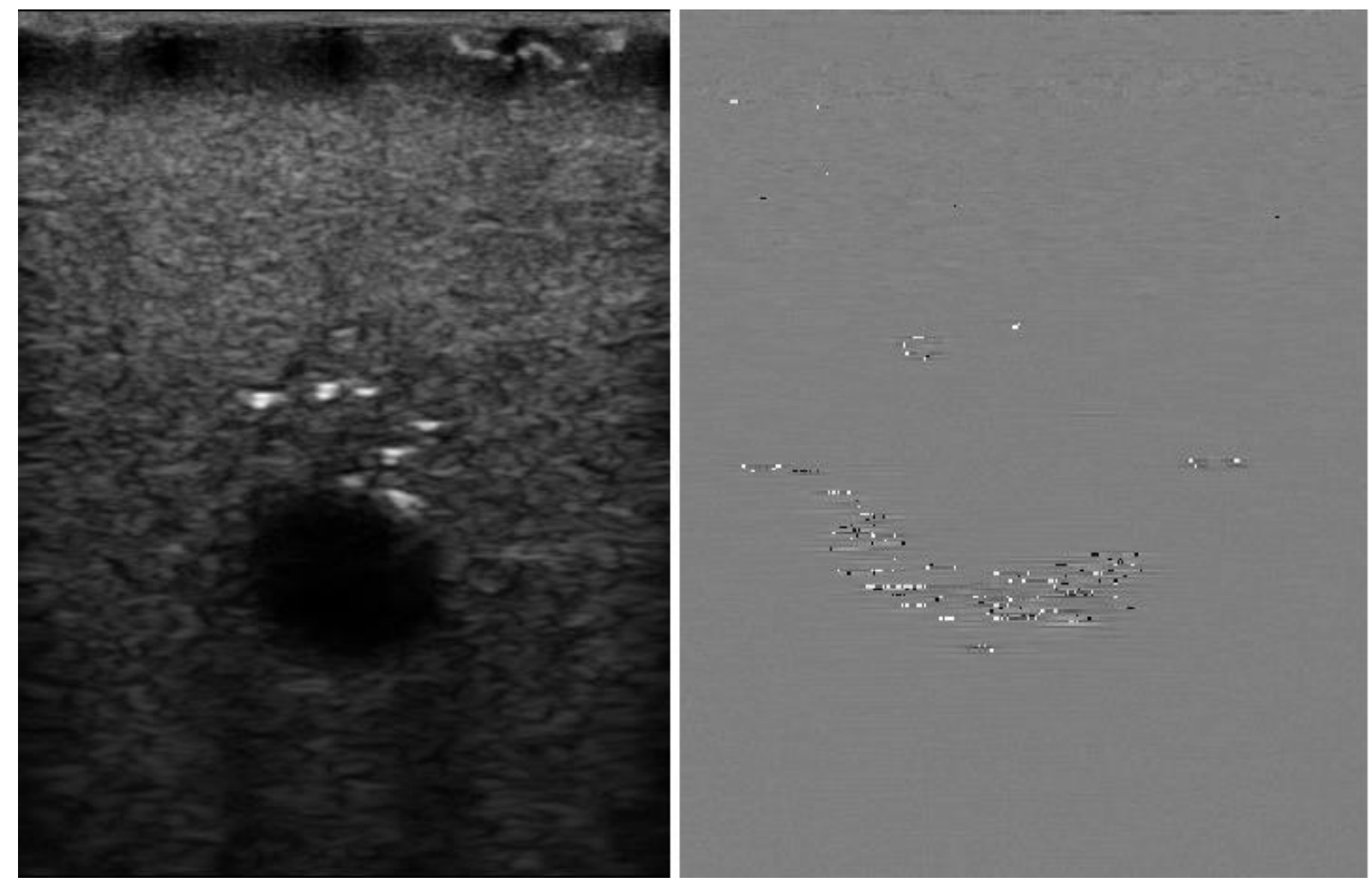

Figura 19: Imagem em Modo-B (esquerda) e o seu respectivo mapa de RF(direita) do fantoma de parafina Gel-B utilizada para os estudos dos parâmetros do Corregistro (Seções 5.1, 5.2 e 5.3).

\subsection{Resposta perante à deformação}

Para avaliar a influência do grau de deformação no algoritmo de corregistro, foi aplicada uma transformação geométrica na imagem da Figura 19. Esta transformação está descrita na equação (13, na qual x' e y' são as posições finais dos pixels, $x$ e y são as iniciais e s é a deformação dada em valores decimais. A origem do sistema de coordenadas é deslocada no eixo lateral $(x)$ para o ponto médio (as imagens tem $38 \mathrm{~mm}$ de largura) e desta forma a fórmula provoca a contração axial em relação à superfície superior e a expansão lateral em relação ao centro, com aproximadamente a metade do valor axial (razão de Poisson) [26], que é a típica da elastografia cuja deformação é provocada pela compressão de um objeto na superfície, como o transdutor de ultrassom.

$$
\left[\begin{array}{l}
x^{\prime} \\
y^{\prime}
\end{array}\right]=\left[\begin{array}{cc}
\frac{1}{1-s / 2} & 0 \\
0 & 1-s
\end{array}\right] \times\left[\begin{array}{c}
x-19 \\
y-0
\end{array}\right]
$$


Os valores de s utilizados variam de 0,005 a 0,1 com passos de 0,005 tanto na imagem modo-B quanto para o mapa de RF e que isto corresponde a contração axial (y) variando de $0,5 \%$ até $10 \%$ da profundidade (Figura 6). Para realizar esta transformação foi utilizado um programa desenvolvido no ITK com o template ImageResample.

\subsubsection{Imagens Modo B}

As imagens a seguir ilustram os resultados da transformação aplicadas às imagens em Modo B (para melhor visualização foram suprimidas algumas imagens).

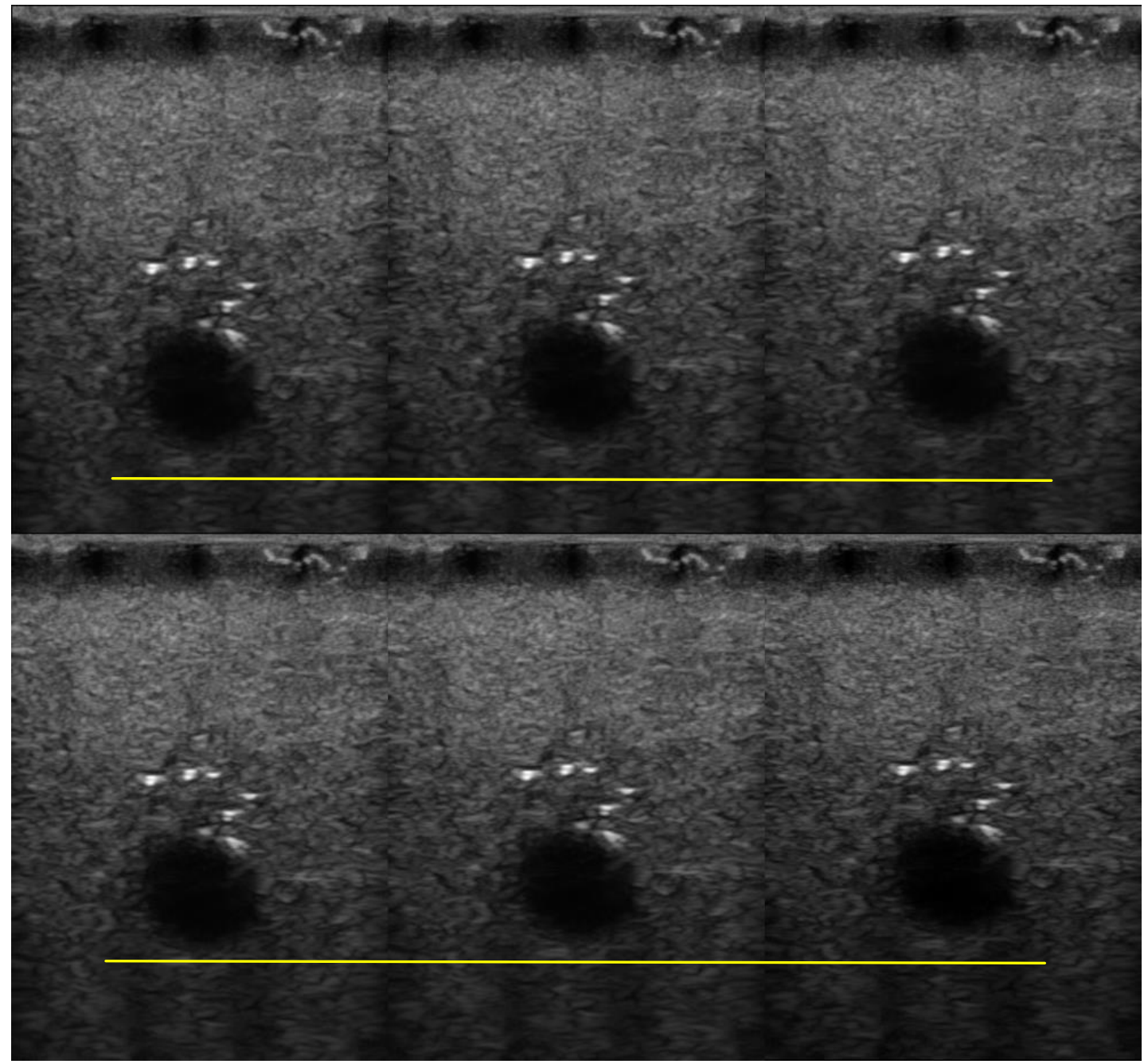

Figura 20: Imagens em Modo B deformadas, conforme a equação (13. As imagens superiores correspondem à deformação de $0 \%$ (original), $2 \%$ e $4 \%$ e, as inferiores à $6 \%, 8 \%$ e $10 \%$. A linha amarela auxilia a visualização da deformação.

O programa de corregistro foi aplicado utilizando os parâmetros sugeridos no início deste capítulo [33] e como a imagem modelo a imagem original (Figura 19 esquerda. As imagens deformadas $(0,5 \%$ a $10 \%)$ foram consideradas como as imagens alvo (Figura 20, exceto a imagem superior esquerda), o que configura em 20 
procedimentos de corregistro e cada um destes segue o esquema da Figura 7. As imagens resultantes do corregistro estão na Figura 21.

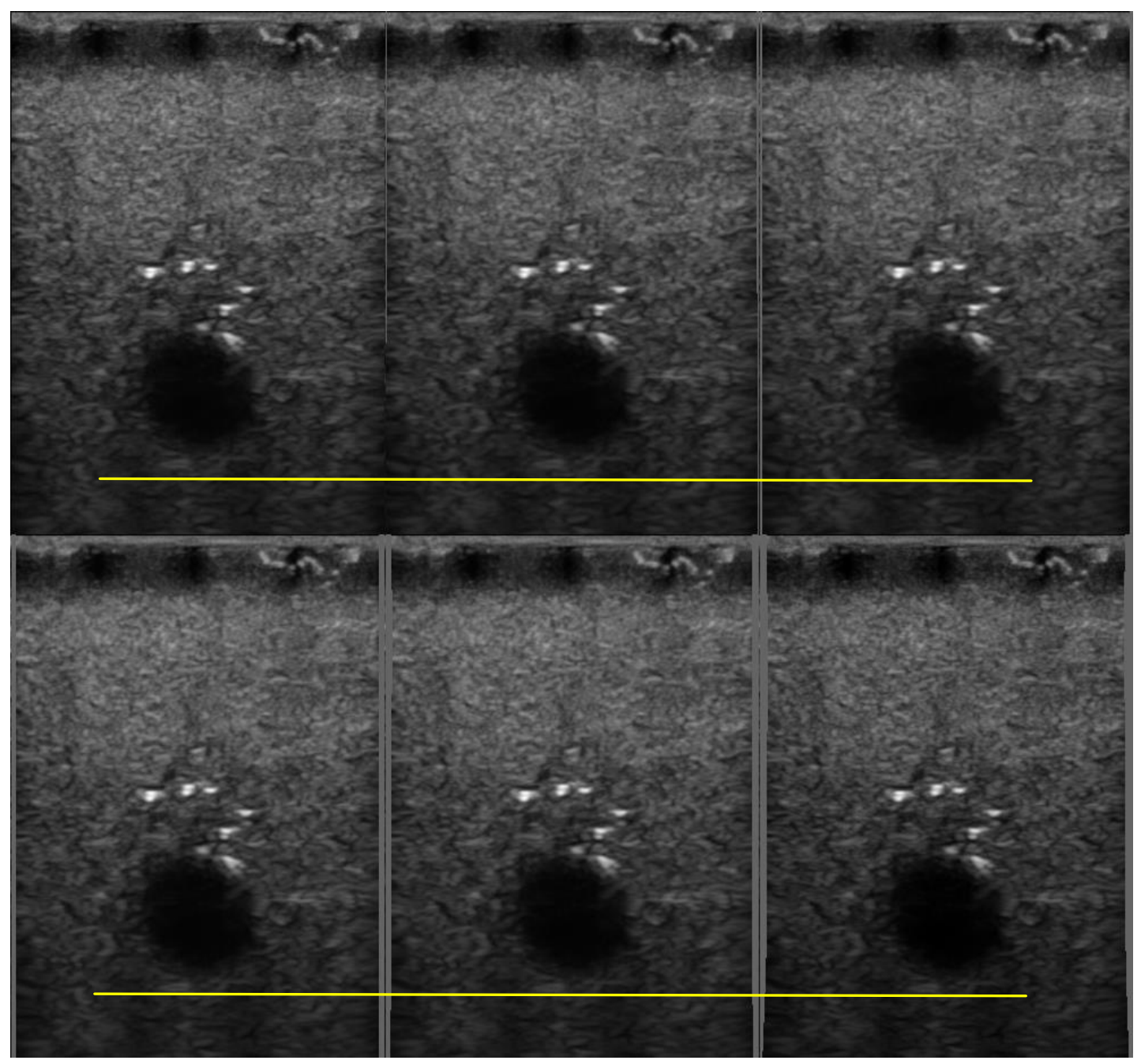

Figura 21: Imagens em Modo $B$ corregistradas. As imagens superiores correspondem à deformação de $0 \%$ (original), $2 \%$ e $4 \%$ e, as inferiores à $6 \%, 8 \%$ e 10\%. A linha amarela auxilia a visualização do corregistro

A inspeção visual das imagens corregistradas demonstra que o programa é capaz de corregistrar com deformação até $10 \%$. O otimizador fornece o valor da função custo inicial (no início do processo iterativo) e final que são calculadas sobre as imagens. O que determina o erro do corregistro é a variação da função custo (diferença entre os valores iniciais e finais). Os gráficos a seguir ilustram o comportamento do programa em relação à deformação. 

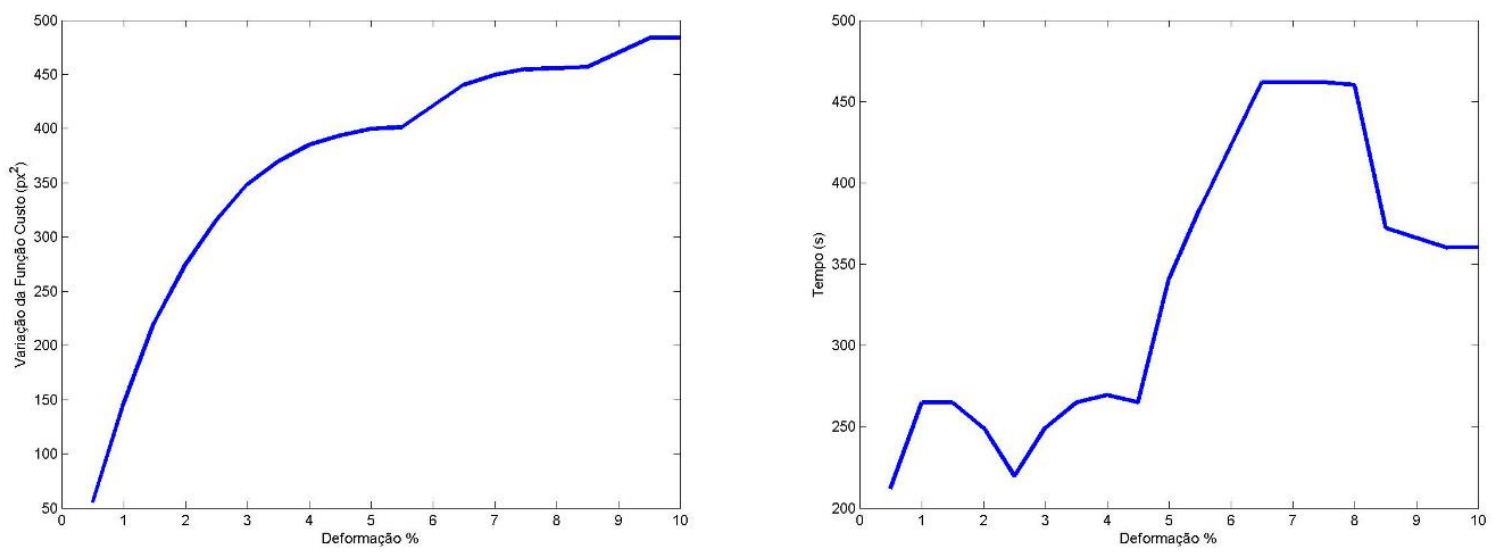

Figura 22: Gráficos da Variação da Função Custo por deformação (esquerda) e do Tempo Gasto pelo algoritmo por deformação (direita) para imagem modo B.

$\mathrm{Na}$ análise do gráfico de tempo (Figura 22-direita) as deformações até $5 \%$ se mantém na mesma faixa de tempo e no caso do gráfico de variação da função custo (Figura 22-esquerda) o valor desta aumenta menos a partir de $5 \%$. Portanto os gráficos, principalmente o de tempo, indicam que com os parâmetros sugeridos 0 corregistro de imagens em modo $B$ com até $5 \%$ de deformação é confiável sem gasto excessivo de tempo computacional.

\subsubsection{Mapas de RF}

Neste caso não utilizamos a inspeção visual pois, conforme a Figura 19 os mapa de RF são de difícil visualização. A análise gráfica também é baseada na variação da função custo e no tempo gasto para efetuar o corregistro.
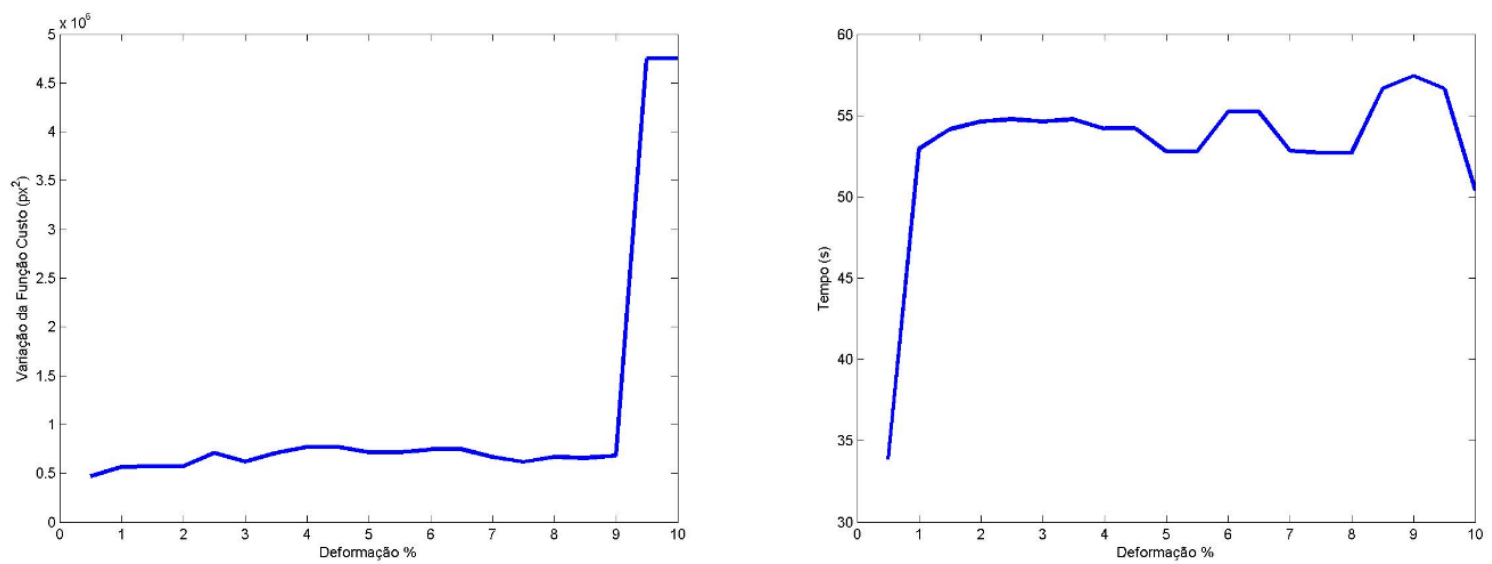

Figura 23: Gráficos da Variação da Função Custo por deformação (esquerda) e do Tempo Gasto pelo algoritmo por deformação (direita) para mapas de RF.

Algumas diferenças em relação ao modo B devem ser explicitadas. Primeiro é a ordem de grandeza da variação da função que decorre da natureza do mapa de RF 
(16 bits). Segundo é o tempo computacional ser bem menor mesmo utilizando uma imagem com uma quantidade bem maior de dados, mas isto é explicado que o tempo depende do tamanho da grade e não da imagem e neste caso o algoritmo convergiu mais rapidamente para os mapas de RF.

Os valores de variação da função custo permanecem aproximadamente constantes até $9 \%$ de deformação e o tempo oscilou em torno de 55 segundos. Desta forma, assim como no modo B, é possível o corregistro até $9 \%$ com os parâmetros sugeridos. Este nível de deformação, é muito maior que o observado nas aplicações elastográficas $(<2 \%)[10]$, [42].

\subsection{Grade da BSpline}

Conforme citado no início deste capítulo, o tamanho da grade de transformação indica o número de pontos de controle e que isto corresponde à resolução do corregistro. Na maioria do estudos de corregistro, geralmente é usada uma grade $5 \times 5$ para imagens quadradas e no presente trabalho as imagens são retangulares. Os mapas de RF, por exemplo, são muito alongados quando comparados com o modo B. Por conseguinte, avaliar o tamanho e a forma da grade é importante para o desempenho do corregistro.

Nesta análise não há diferenças significativas entre imagens 8 bits e 16 bits, portanto utilizamos somente a imagem modo $B(50 \times 38 \mathrm{~mm})$ da Figura 19 e o template ImageResample para criar imagens de tamanho lateral de 330 pixels e tamanho axial diferentes: 330, 660, 1320, 1980, 2640, 3300 e 3960, o que corresponde a uma fator de proporção axial-lateral de 1, 2, 4, 6, 8,10 e 12 vezes.

Cada imagem gerada foi deformada utilizando duas fórmulas diferentes: uma típica de elastografia, Poisson - equação (13, que foi utilizada na seção anterior e uma outra que simule a sucção de uma região. Após isto foi feito o corregistro par a par (original-deformada) para cada fórmula mantendo os valores do otimizador (DefaultStepLength $=0,9$, LineSearchAccuracy $=1,5$ e GradienteConvergenceTolerance $=0,05$ ) . 


\subsubsection{Deformação Elastográfica (Poisson)}

A aplicação da transformação geométrica conforme a equação (13, para cada imagem, com o valor de $\mathrm{s}$ em $2 \%$ é suficiente para a situação dos experimentos em fantomas realizados neste trabalho.

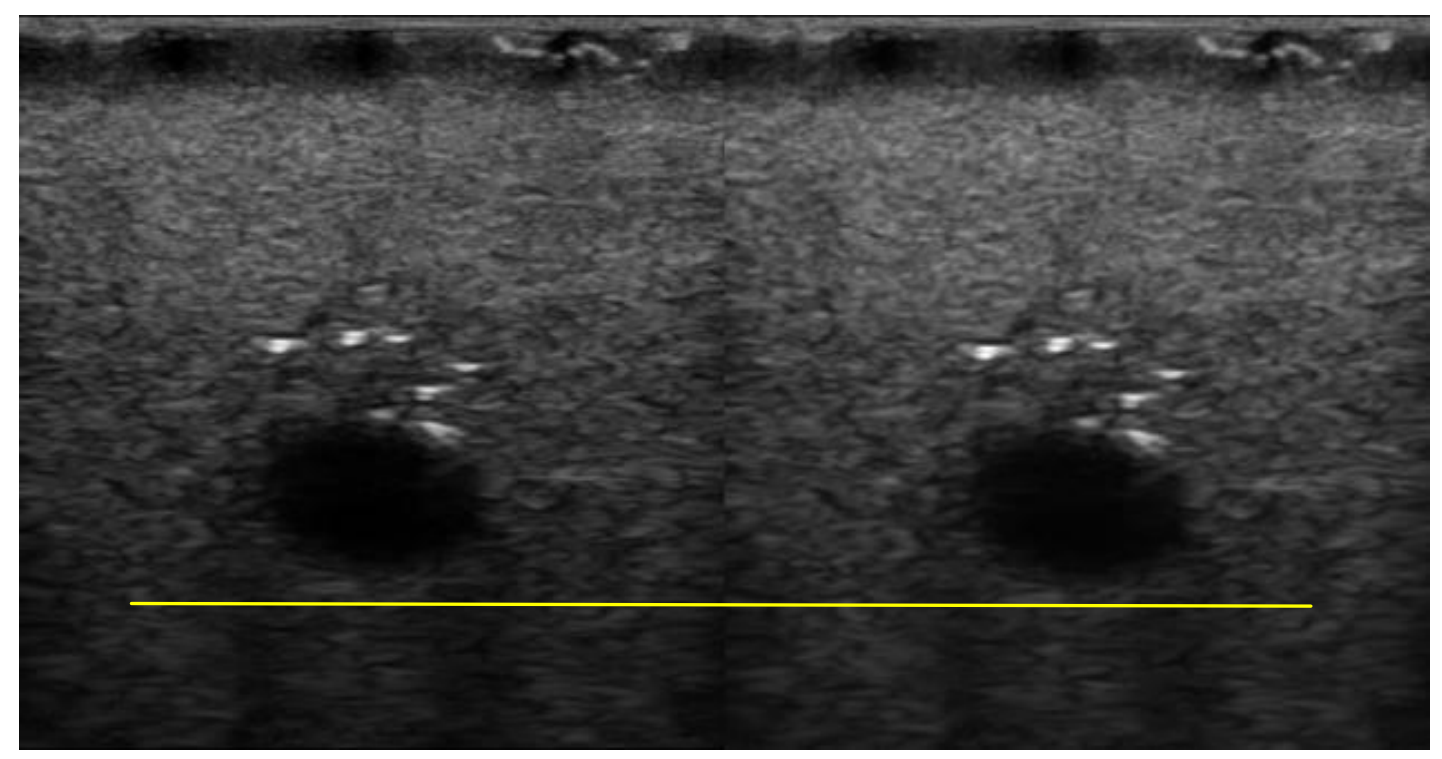

Figura 24: Imagens em modo B quadradas (Fator 1). A imagem à esquerda é a original e à direita foi deformada em $2 \%$ utilizando a equação (13).

O corregistro foi aplicado a cada par de imagens de tamanhos diferentes, variando o tamanho da grade de $3 \times 3$ até $20 \times 20$ e os resultados foram analisados a partir da variação da função custo e do tempo gasto pelo processamento. A Figura 25 ilustra os resultados para a imagem quadrada (Fator 1) para a variação da função custo.

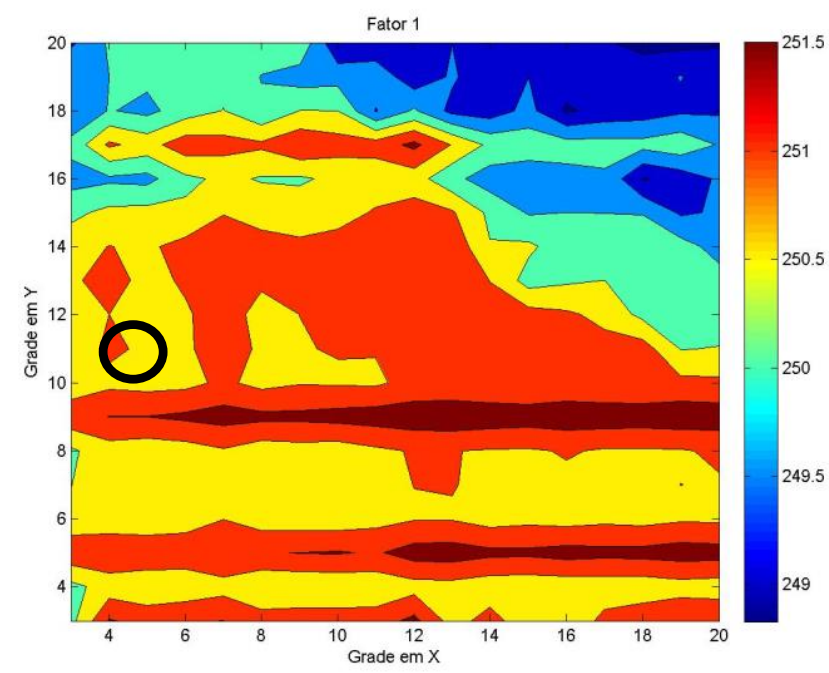

Figura 25: Variação da Função Custo para uma Imagem Quadrada (Fator 1) transformada pela equação (13) com deformação de $2 \%$. A barra lateral ilustra os valores em pixels ao quadrado. 
A análise das cores da figura e de sua barra de valores demonstra que os valores de erro variam de 249 a 251,5 pixels ao quadrado, ou seja, uma diferença de 2,5 que equivale a uma variação de aproximadamente $1 \%$. Podemos concluir em relação ao erro em uma imagem quadrada o tamanho da grade é indiferente no intervalo estudado. A figura a seguir ilustra o tempo gasto pelo programa de corregistro.

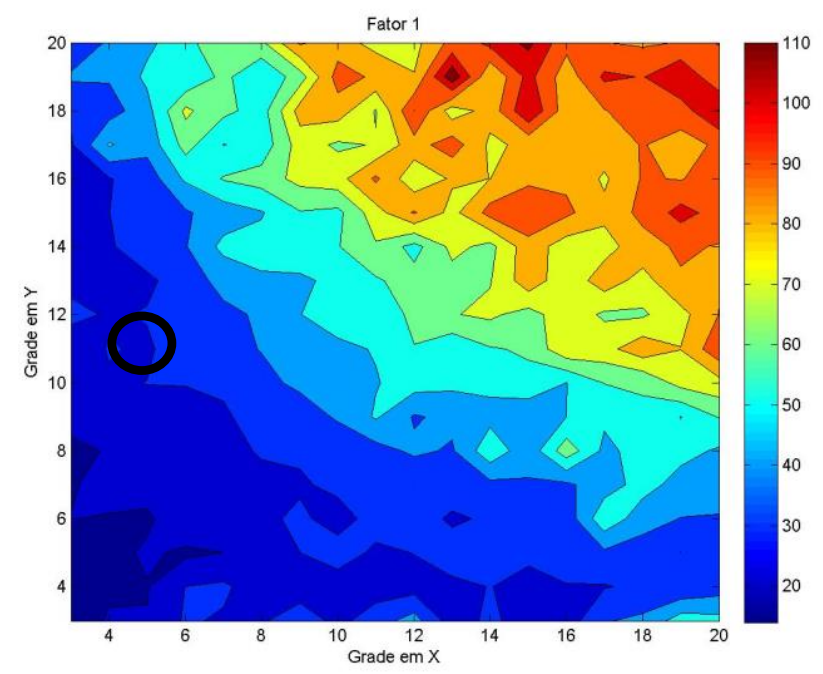

Figura 26: Tempo de processamento para uma Imagem Quadrada (Fator 1) transformada pela equação (13) com deformação de $2 \%$. A barra lateral ilustra os valores em segundos.

A análise das cores da figura e de sua barra de valores demonstra que os melhores valores estão entre um triângulo como vértices formados pelas grades de tamanho $3 \times 3$, $3 \times 20$ e $20 \times 3$ e que o tempo aumenta com o tamanho da grade, em qualquer dimensão. Assim escolhemos o valor de grade de $5 \times 11$ que representa um baixo tempo de processamento (que é de aproximadamente 30 segundos). É importante ressaltar a escolha de uma grade retangular com relação aproximadamente de 1:2 como acontece com transformação estudada nesta secção.

A Figura 27 a seguir ilustra os resultados para a variação da função custo para os demais fatores de proporção axial-lateral. 

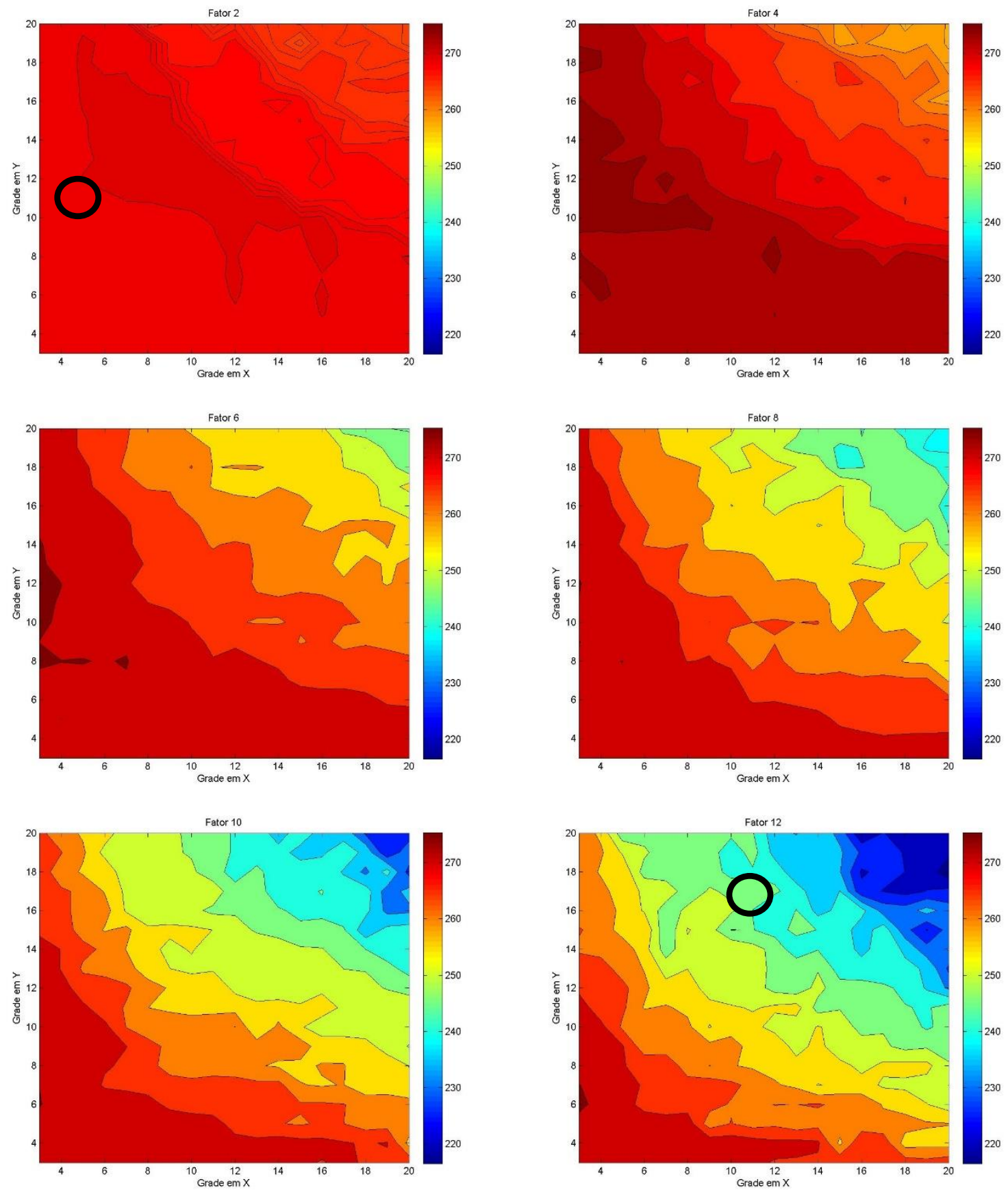

Figura 27: Variação da Função Custo em função do tamanho da grade para imagens deformadas pela equação (13. Cada fator indica uma proporção axial-lateral. A barra lateral ilustra os valores em pixels ao quadrado.

Para os outros fatores é notável que os piores valores são aqueles mais próximos ao eixo $\mathrm{X}$ e os melhores os mais distantes deste eixo. $\mathrm{E}$ ainda que as melhores opções são para valores de $Y$ maiores que os de X. É importante salientar que o aumento indefinido do tamanho da grade passa a diminuir o erro, mas como indica a imagem a seguir, o tempo aumenta também. 

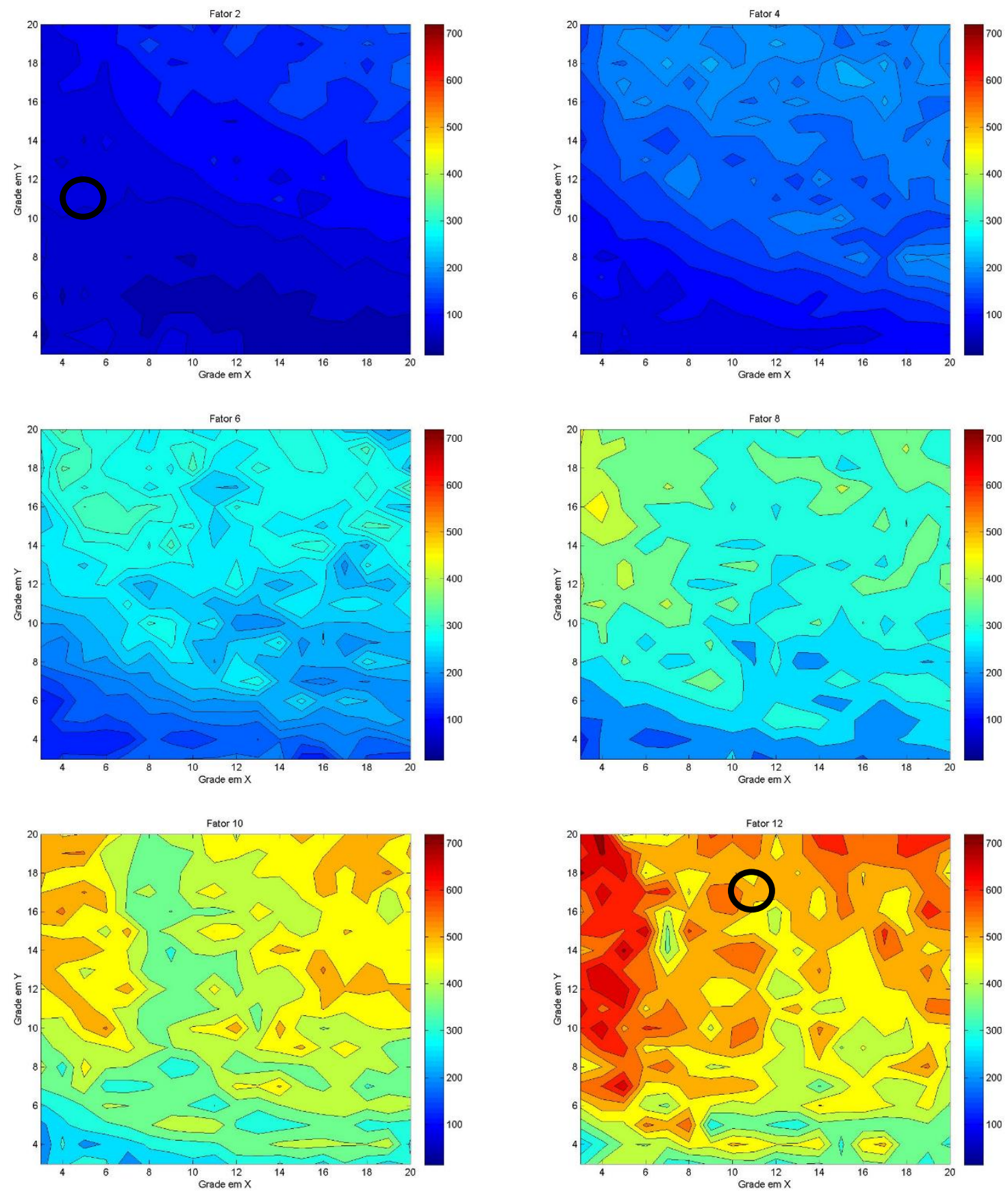

Figura 28: Tempo de processamento em função do tamanho da grade para imagens deformadas pela equação (13. Cada fator indica uma proporção axial-lateral. A barra lateral ilustra os valores em segundos

Os tempos se comportam de uma maneira complexa formando alguns sítios de menor valor e a dependência com as dimensões da imagem indicam que os valores de extremos para $X$ ( 3 e 20) são os piores e os valores melhores para Y estão de 3 a 14 , o que resume em valores mais centrais para $X$ e baixos para $Y$. As imagens que foram adquiridas durante este trabalho tem basicamente os seguintes fatores: 1 (Modo B), 2 (Modo B) e 12 (mapas de RF). O erro para a imagem de fator 2 varia de 264 a 
269 o que mostra que a escolha de qualquer grade equivale a um erro máximo de $2 \%$ e permite que a escolha somente se baseie pelo tempo de processamento. Para simplificação e sem abrir mão de valores satisfatórios a escolha para este fator foi mantida em $5 \times 11$ (aproximadamente 55 segundos). Para o fator 12 (mapas de RF) o erro tem uma variação de até $30 \%$ o que inviabiliza a análise somente por tempo. Assim a escolha comparando erro com tempo foi a grade $11 \times 17$ que possui um erro de $10 \%$ e um tempo de 450 segundos. Desta forma para a deformação utilizada nesta seção a grade adotadas para modo B foi a $5 \times 11$ e para os mapas de RF foi a $11 \times 17$.

\subsubsection{Deformação por Sucção (procedimento de retirada da inclusão)}

Este experimento é idêntico ao anterior, exceto pela transformação geométrica aplicada. Esta consiste em duas contrações com proporções diferentes (14), onde a contração lateral é $80 \%$ da contração axial e a transformação como um todo está centrada $\left(x_{c}\right.$ e $\left.y_{c}\right)$ na inclusão, e portanto, foi necessário determinar o ponto central da inclusão. O valor de s adotado foi $2 \%$ o que perfaz um fator contração de $98 \%$ do eixo Y(axial) e $98,4 \%$ no eixo $X$ (lateral).

$$
\left[\begin{array}{l}
x^{\prime} \\
y^{\prime}
\end{array}\right]=\left[\begin{array}{cc}
(1-0,8 \times s) & 0 \\
0 & 1-s
\end{array}\right] \times\left[\begin{array}{l}
x-x_{c} \\
y-y_{c}
\end{array}\right]
$$

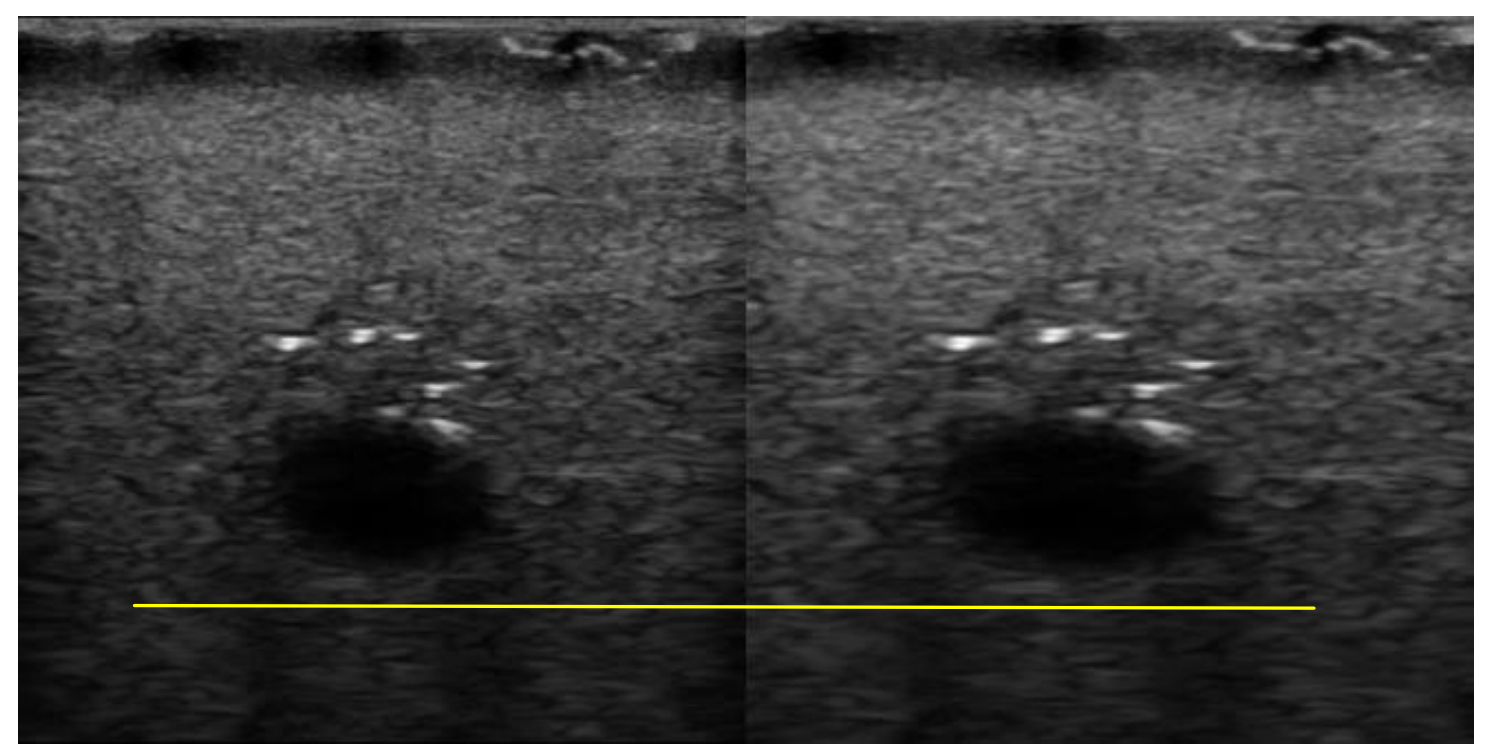

Figura 29: Imagens em modo B quadradas (Fator 1). A imagem à esquerda é a original e à direita foi deformada em $2 \%$ utilizando a equação (14.

O corregistro foi aplicado a cada par de imagens de tamanhos diferentes, variando o tamanho da grade de $3 \times 3$ até $20 \times 20$ e os resultados foram analisados a partir da variação da função custo e do tempo gasto pelo processamento. A Figura 30 ilustra os resultados para a imagem quadrada (Fator 1) para a variação da função custo. 


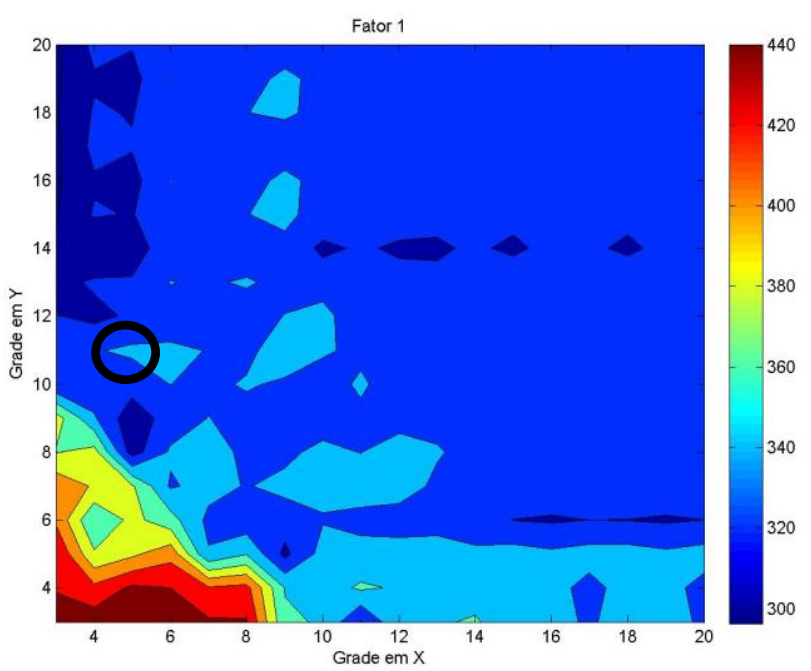

Figura 30: Variação da Função Custo para uma Imagem Quadrada (Fator 1) transformada pela equação (14 com deformação de $2 \%$. A barra lateral ilustra os valores em pixels ao quadrado.

A análise das cores da figura e de sua barra de valores mostra que há uma grande variação do erro (> 40\%), mas os piores valores estão entre um triângulo como

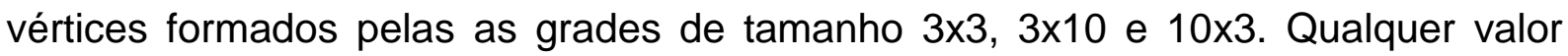
externo a região citada pode ser considerado satisfatório. A figura a seguir ilustra o tempo gasto pelo programa de corregistro.

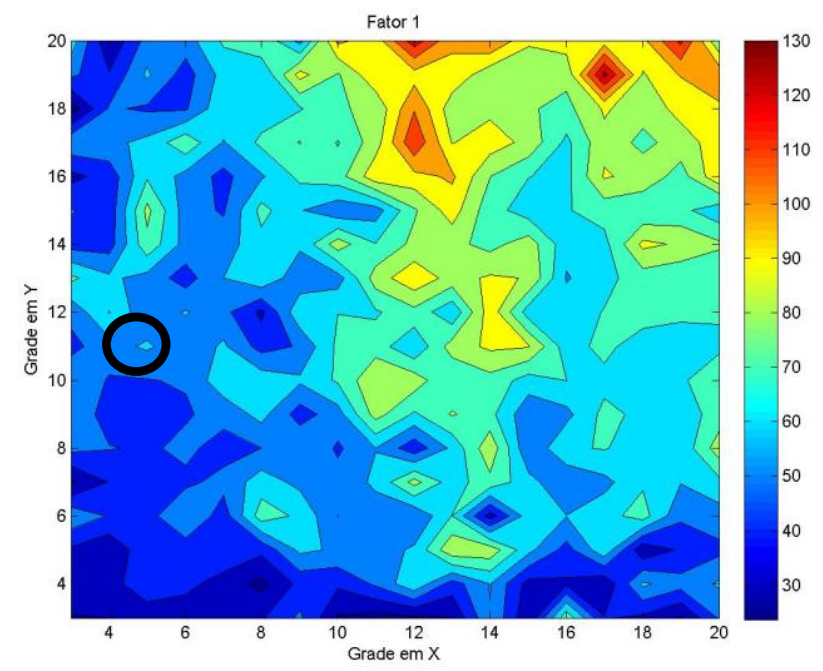

Figura 31: Tempo de processamento para uma Imagem Quadrada (Fator 1) transformada pela equação (14 com deformação de $2 \%$. A barra lateral ilustra os valores em segundos.

A distribuição do tempo para esta transformação em função da grade é bem complexa, mas podemos nos limitar à região triangular inferior $(3 \times 3,3 \times 18$ e $18 \times 3)$ onde os menores valores são predominantes. A Figura 32 a seguir ilustra os resultados para cada fator (proporção axial-lateral). 

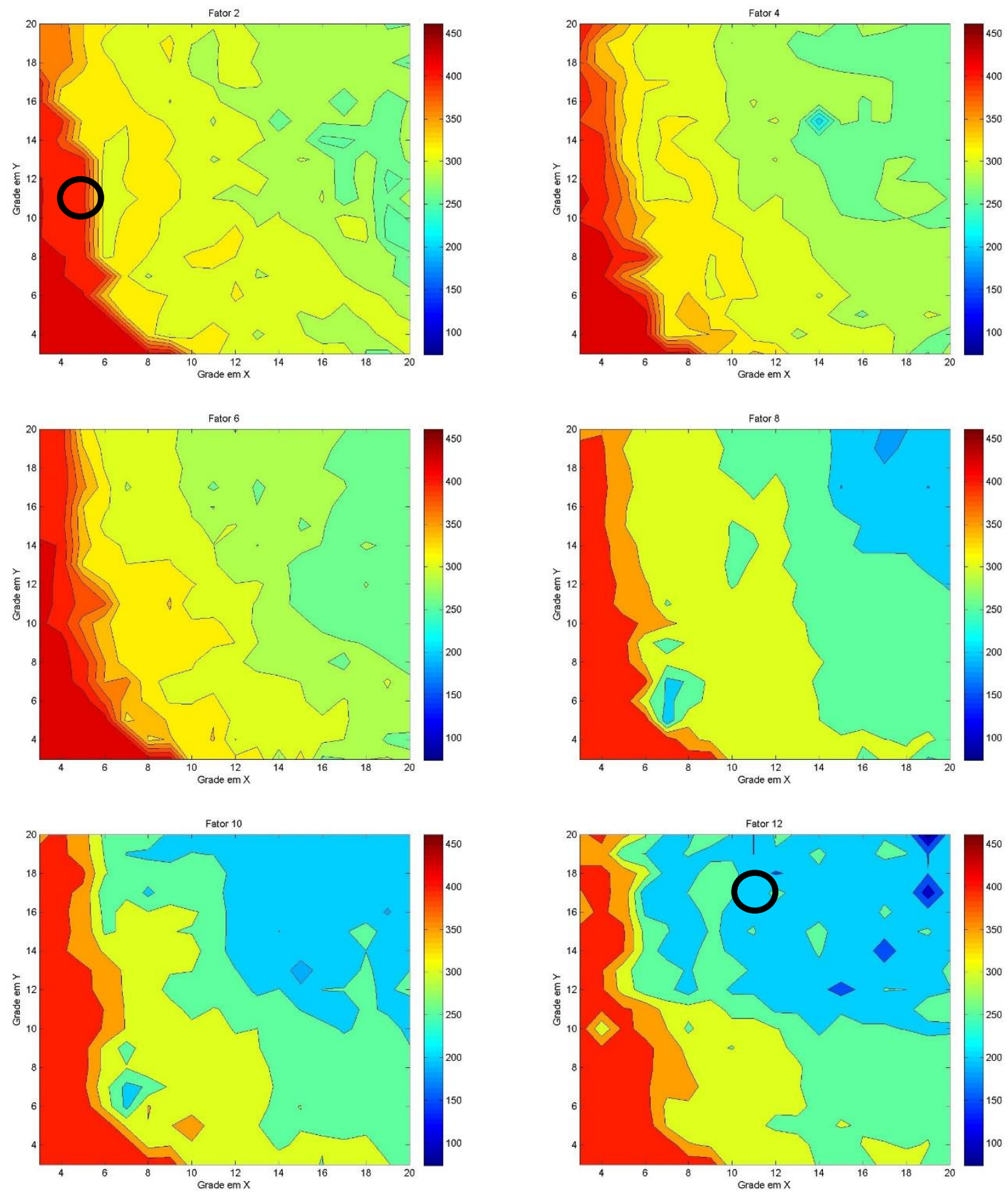

Figura 32: Variação da Função Custo em função do tamanho da grade para imagens deformadas pela equação (14). Cada fator indica uma proporção axial-lateral. A barra lateral ilustra os valores em pixels ao quadrado.

Nesta transformação os piores valores são aqueles mais próximos ao eixo $Y$ (menores valores de $\mathrm{X}$ ) e os melhores os mais distantes deste eixo. 

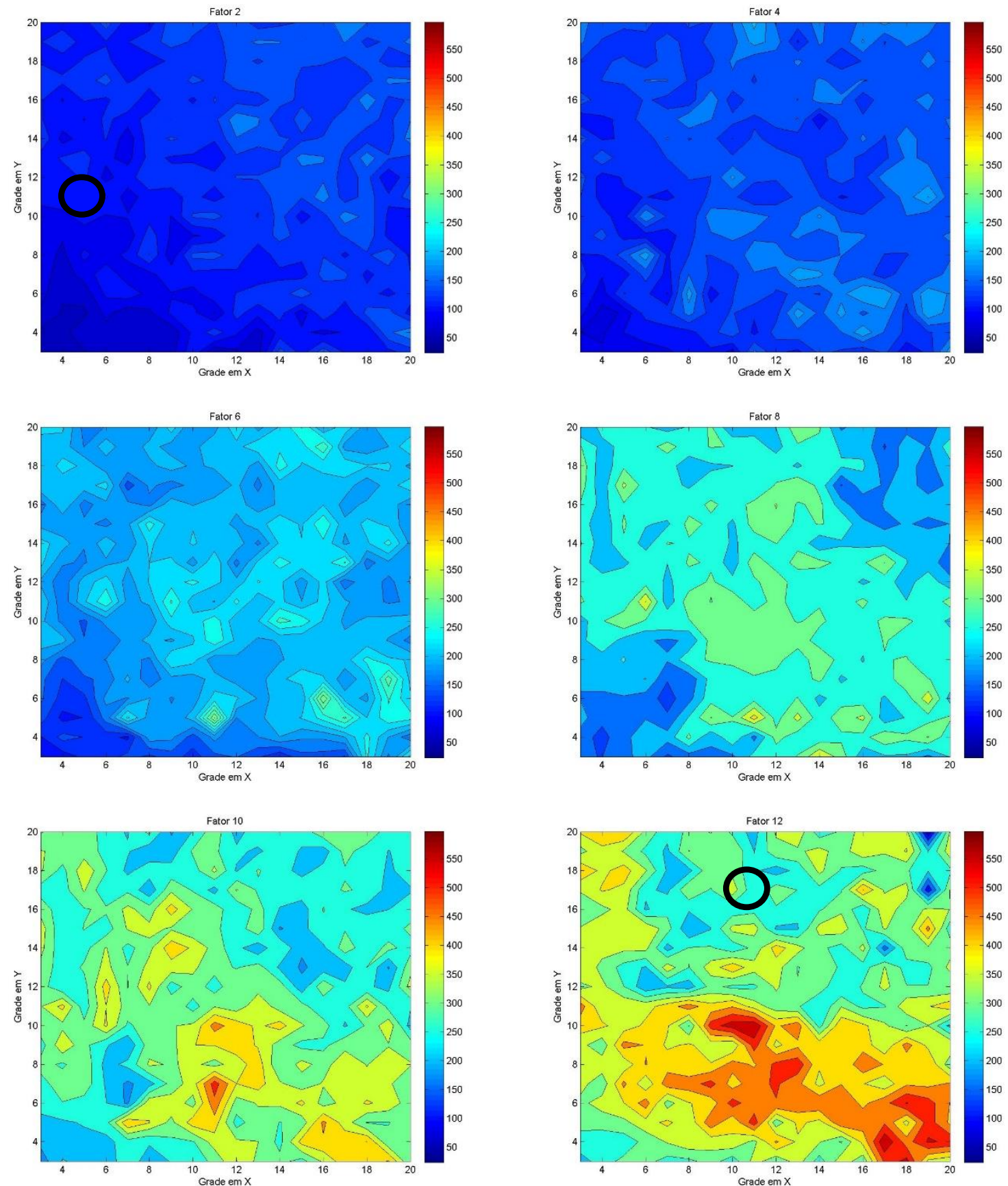

Figura 33: Tempo de processamento em função do tamanho da grade para imagens deformadas pela equação (14. Cada fator indica uma proporção axial-lateral A barra lateral ilustra os valores em segundos.

Os tempos, como na transformação anterior, se comportam de uma maneira complexa formando alguns sítios de menor valor mas, sem indicar nenhum tipo de tendência relacionada ao fator de proporção. Especificamente para as imagens adquiridas neste projeto seria conveniente a escolha de grades iguais as da

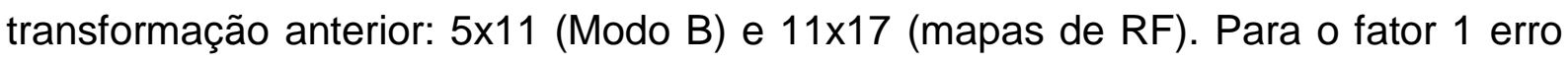
desta grade é de aproximadamente 320 ( 6\%) e o tempo de 40 segundos, e para o 
fator 2 o erro é 290 ( 10\%) e o tempo de 70 segundos, deste modo a escolha da grade $5 \times 11$ é satisfatória para as duas transformações para as imagens em modo $B$ deste trabalho. Para o fator 12 (mapas de RF) a escolha da grade $11 \times 17$ equivale a um erro de $175(\sim 75 \%)$ o que aparenta ser um erro inapropriado, mas ao observar a imagem somente algumas pequenas regiões possuem o valor mínimo (em azul e equivalente ao valor 100), o que faria a escolha ser muito localizada. O tempo para esta grade é de aproximadamente 300 segundos e neste gráfico acontece a mesma situação que na análise de erro: apenas algumas pequenas regiões possuem o tempo mínimo (em azul e equivalente ao valor $100 \mathrm{~s}$ ) mesmo. Desta forma fica definida a escolha da grade para os mapas de RF como $11 \times 17$ que configura na melhor escolha perante a distribuição de valores de erro e tempo.

\subsection{Otimizador Limited-memory Broyden-Fletcher-Goldfarb-Shanno (LBFGS)}

Uma vez definidas as grades para cada modalidade de imagem (modo $\mathrm{B} e$ mapas de RF) foi necessário ajustar o otimizador. Este experimento consiste em investigar quais valores dos parâmetros DefaultStepLength, LineSearchAccuracy e GradientConvergenceTolerance são mais adequados ao nosso propósito. Os valores sugeridos inicialmente são: 0,05, 0,9 e 1,5, respectivamente [33].

As imagens utilizadas são as da Figura 19 (tanto modo B e mapa de RF) e foi aplicada a transformação da equação (14) com a deformação (s) a $2 \%$. Foi aplicado o programa de corregistro em cada modalidade de imagem, utilizando as grades encontradas na seção anterior, e os valores dos parâmetros de otimização foram variados na seguintes extensões:

- DefaultStepLength: de 1,0 a 1,9

- LineSearchAccuracy: de 0,6 a 1,2

- GradientConvergenceTolerance: de 0,02 a 0,08.

Para os dois primeiros parâmetros o passo utilizado foi de 0,1 e no último o passo foi de 0,01. A escolha destes limites de valores foi feita de forma a fazer a busca a partir dos valores sugeridos, os quais, inclusive estão incluídos. Avaliamos o erro do otimizador pelo valor final da função custo, uma vez que o valor inicial neste 
experimento é sempre o mesmo, para cada conjunto de parâmetros, assim como o tempo gasto para o processamento.

\subsubsection{Imagens Modo B}

No modo B a grade utilizada foi a 5x11, conforme justificada na seção anterior. A Figura 34 é formada por várias imagens e cada uma delas corresponde a um valor de Default Step Length e ilustra o erro da função custo para os parâmetros LineSearchAccuracy e GradientConvergenceTolerance. A Figura 35 ilustra o tempo gasto pelo programa de corregistro. 

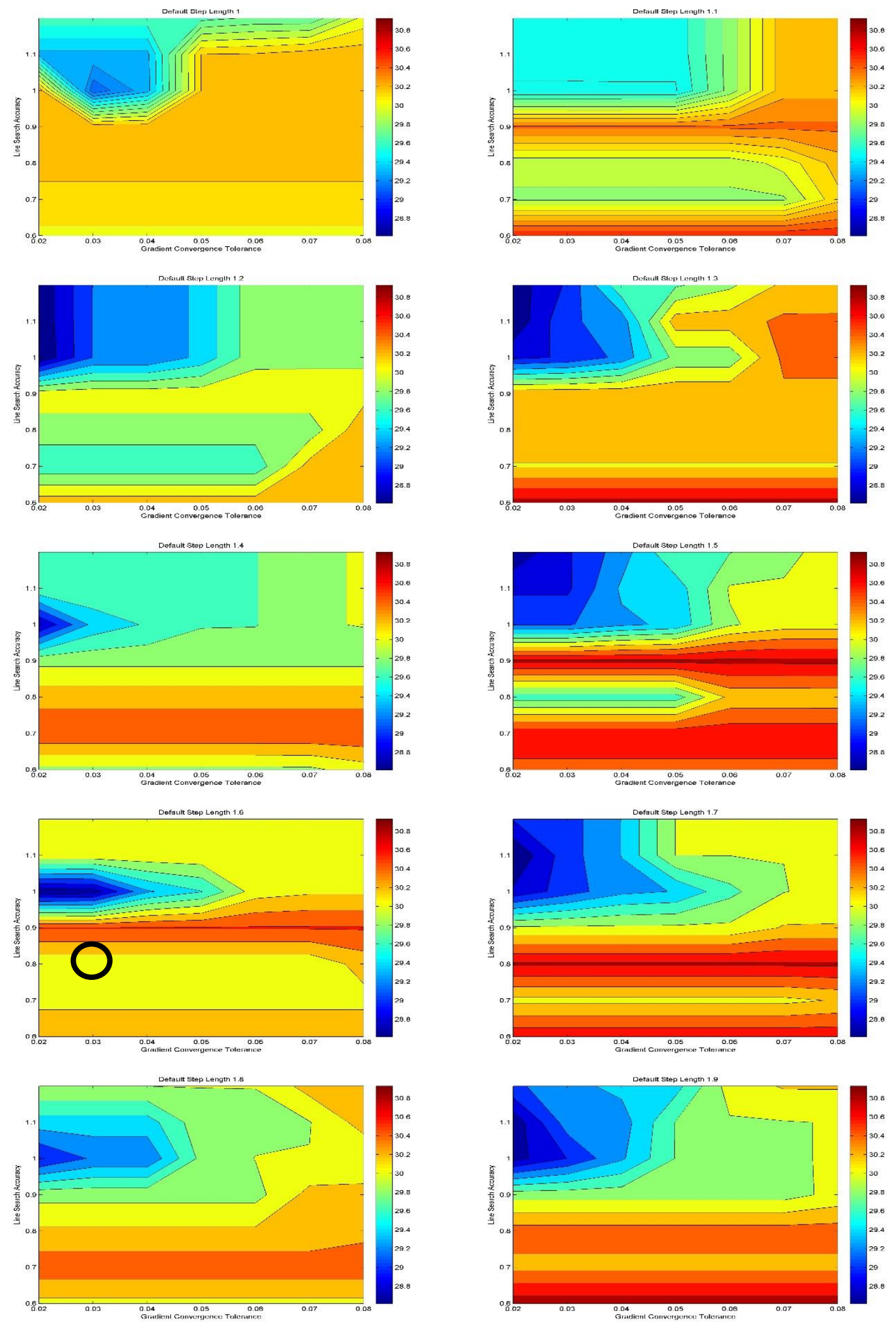

Figura 34: Valor final da função custo (erro) para vários valores de Default Step Length, Gradient Convergence Tolerance e Line Search Accuracy para uma imagem em Modo B deformada de $2 \%$ pela equação (14. A barra lateral ilustra os valores em pixels ao quadrado. 

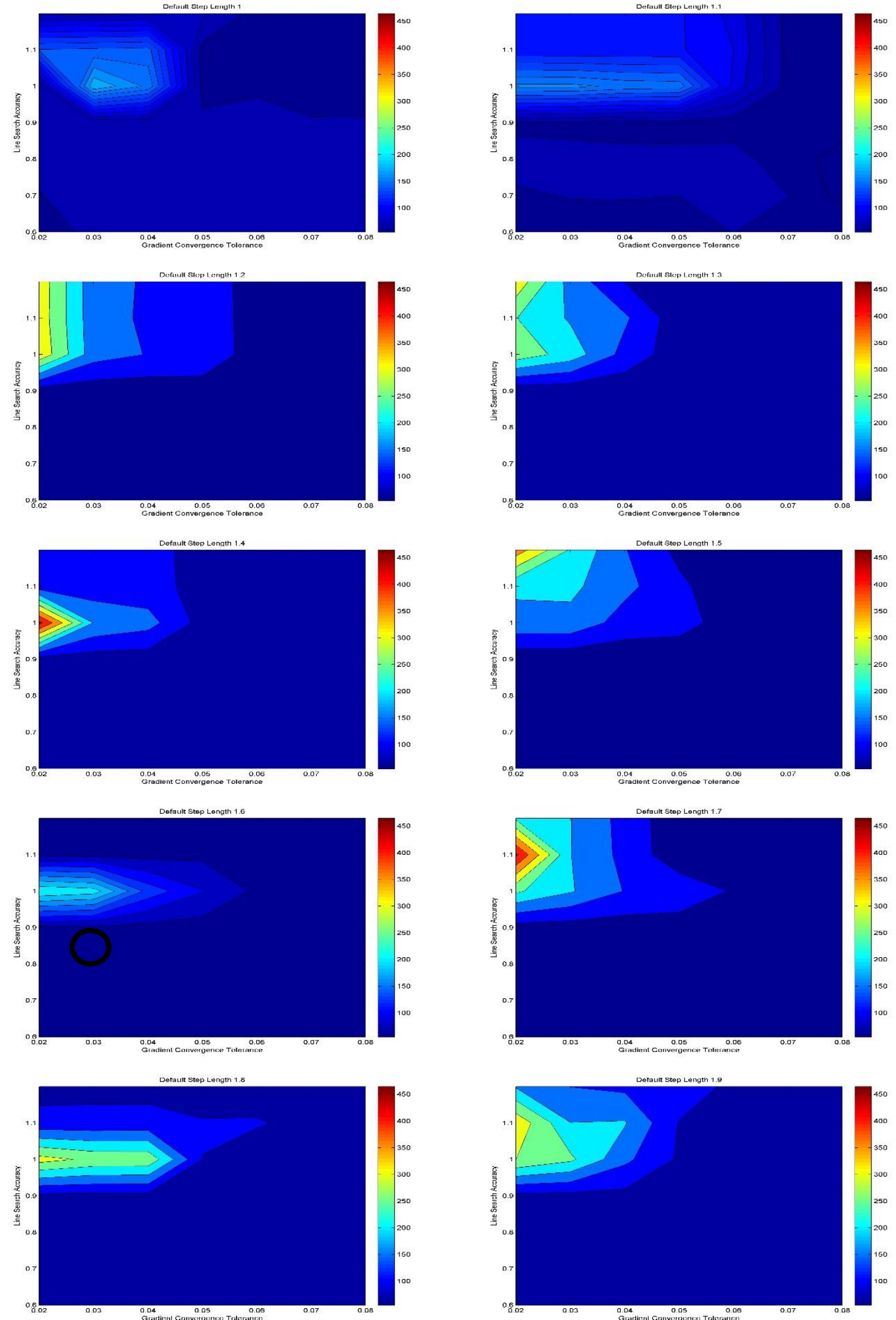

Figura 35: Tempo gasto no corregistro para vários valores de Default Step Length, Gradient Convergence Tolerance e Line Search Accuracy para uma imagem em Modo B deformada de $2 \%$ pela equação 14. A barra lateral ilustra os valores em segundos. 
Os valores de erro tendem a formar curvas de níveis com o mínimo próximo ao canto superior esquerdo. A análise das cores das figuras e de suas barras de valores demostram que os valores de erro variam no máximo de 28,8 a 30,8 pixels ao quadrado, ou seja, uma diferença de 2,0 que equivale a uma variação de aproximadamente $7 \%$, e que os valores mínimos são alcançados para os valores de $1,2,1,3,1,5,1,6,1,7$ e 1,9 de Default Step Length.

Os tempos, assim com o erro da função custo, tendem a formar curvas de níveis com o máximo próximo ao canto superior esquerdo, tornando a análise complementar. Ou seja, o menor erro do otimizador custa maior tempo de processamento. O gráfico de menor tempo de processamento é o Default Step Length igual a 1,6 e que possui um erro similar aos demais e com um máximo em torno de 1,0 para o Line Search Accuraccy. Sendo assim os valores de Gradient Convergence Tolerance e Line Search Accuraccy escolhidos são 0,03 e 0,8, respectivamente.

\subsubsection{Mapas de RF}

Para os mapas de RF a grade utilizada, justificada conforme a seção anterior, foi a $11 \times 17$. 

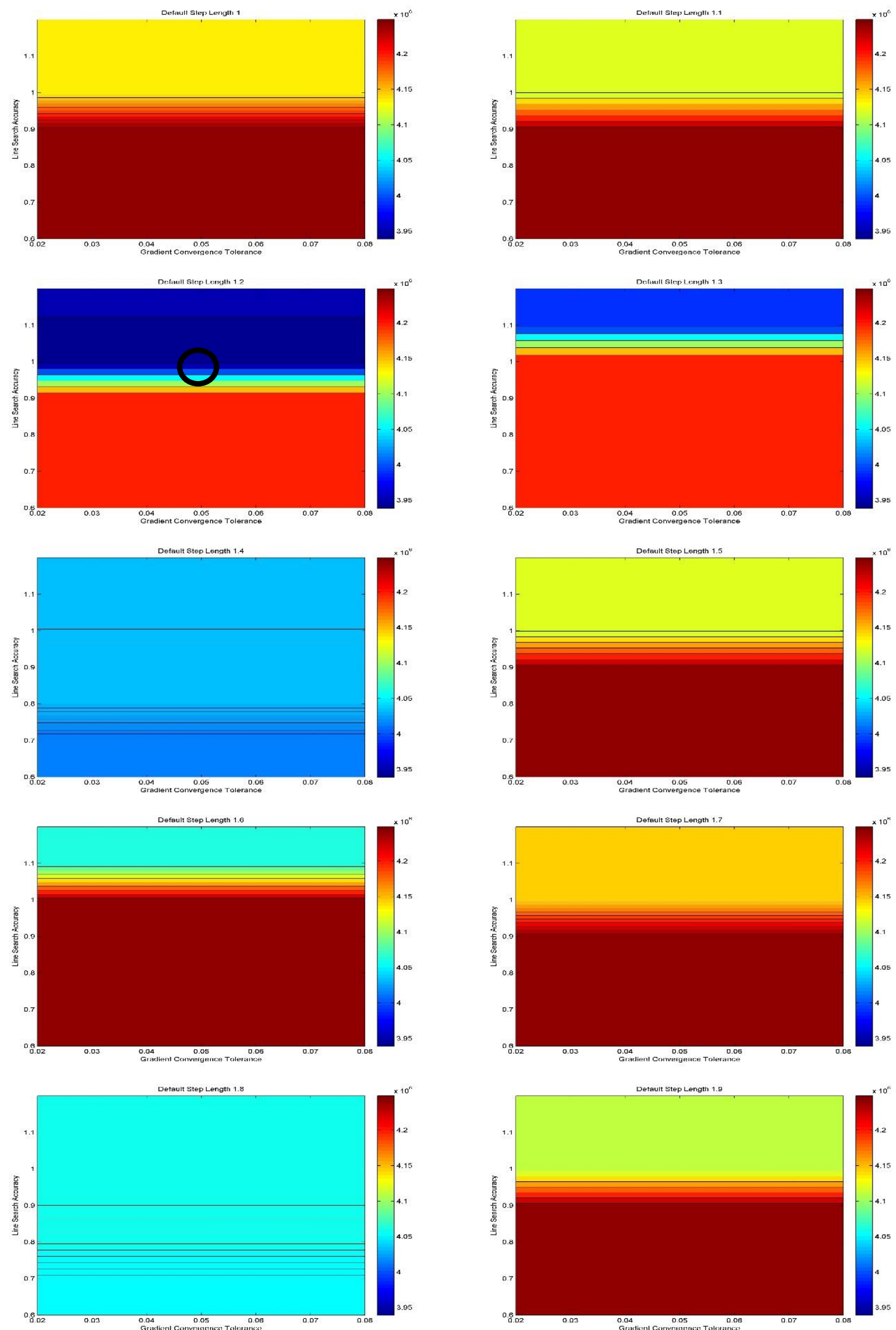

Figura 36: Valor final da função custo (erro) para vários valores de Default Step Length, Gradient Convergence Tolerance e Line Search Accuracy para um mapa de RF deformado de $2 \%$ pela equação (14. A barra lateral ilustra os valores em pixels ao quadrado. 

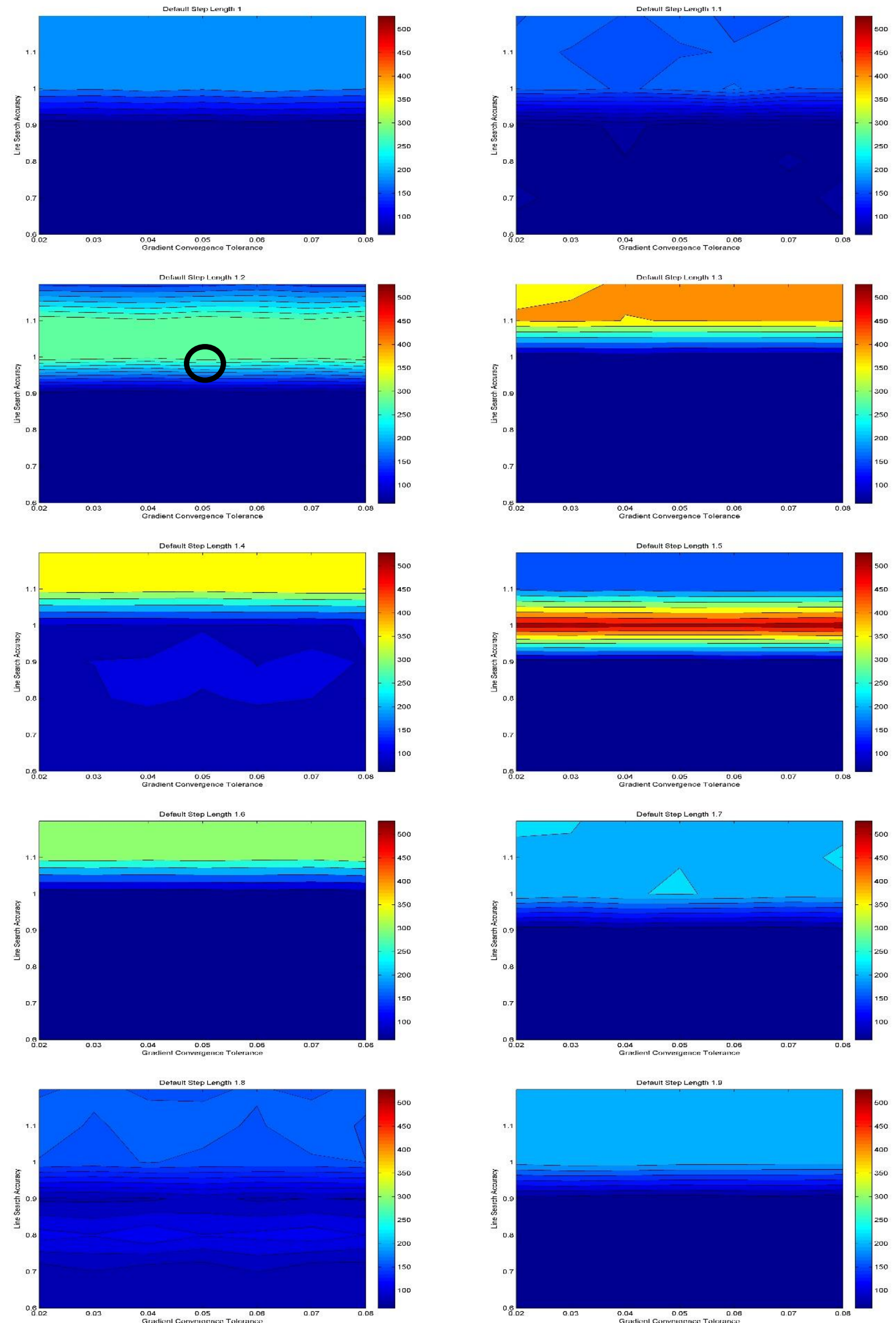

Figura 37: Tempo gasto no corregistro para vários valores de Default Step Length, Gradient Convergence Tolerance e Line Search Accuracy para um mapa de RF deformado de $2 \%$ pela equação (14. A barra lateral ilustra os valores em segundos. 
Os valores de erro formam faixas com regiões bem definidas e não demonstram nenhuma tendência com o Default Step Length. A análise das cores das figuras e de suas barras de valores demonstra que os valores de erro variam no máximo de $3,95 \times 10^{6}$ a $4,24 \times 10^{6}$ pixels ao quadrado, que equivale a uma variação de aproximadamente $7 \%$, e o valor mínimo é alcançados quando o Default Step Length é igual a 1,2. A figura a seguir ilustra os tempos gastos pelo programa de corregistro. Os tempos, assim com o erro, formam faixas com regiões bem definidas e não demonstram nenhuma tendência com o Default Step Length. É interessante notar que para os mapas de RF o Gradient Convergence Tolerance praticamente não interfere no resultado. O gráfico de menor tempo de processamento é o Default Step Length igual a 1,2, na qual a faixa do Step Length é de 1,0 a 1,1. Por base deste gráfico os valores de Gradient Convergence Tolerance e Line Search Accuraccy escolhidos são 0,05 (valor central) e 1,0, respectivamente.

\subsubsection{Comparação do Corregistro Entre Mapas RF e Imagens Modo-B}

Os parâmetros de processamento escolhidos, de acordo com as subseções anteriores estão na Tabela 3.

Tabela 3: Valores dos Parâmetros do Corregistro para Imagens em Modo B e mapas de RF

\begin{tabular}{|c|c|c|c|c|}
\hline & Grade & $\begin{array}{c}\text { Default Step } \\
\text { Length }\end{array}$ & $\begin{array}{c}\text { Gradient Convergence } \\
\text { Tolerance }\end{array}$ & $\begin{array}{c}\text { Line Search } \\
\text { Accuracy }\end{array}$ \\
\hline Modo B & $5 \times 11$ & 1,6 & 0,03 & 0,8 \\
\hline Mapas de RF & $11 \times 17$ & 1,2 & 0,05 & 1,0 \\
\hline
\end{tabular}

De modo a comparar os resultados utilizamos as imagens Figura 19 (tanto modo B e mapa de RF) nas quais foram aplicadas a transformação da equação (14) com a deformação (s) a 2\% e efetuado o corregistro de acordo com os parâmetros da Tabela 3. De modo a comparar os resultados utilizamos o programa Matlab para visualizar os mapas de deformação obtidos. 

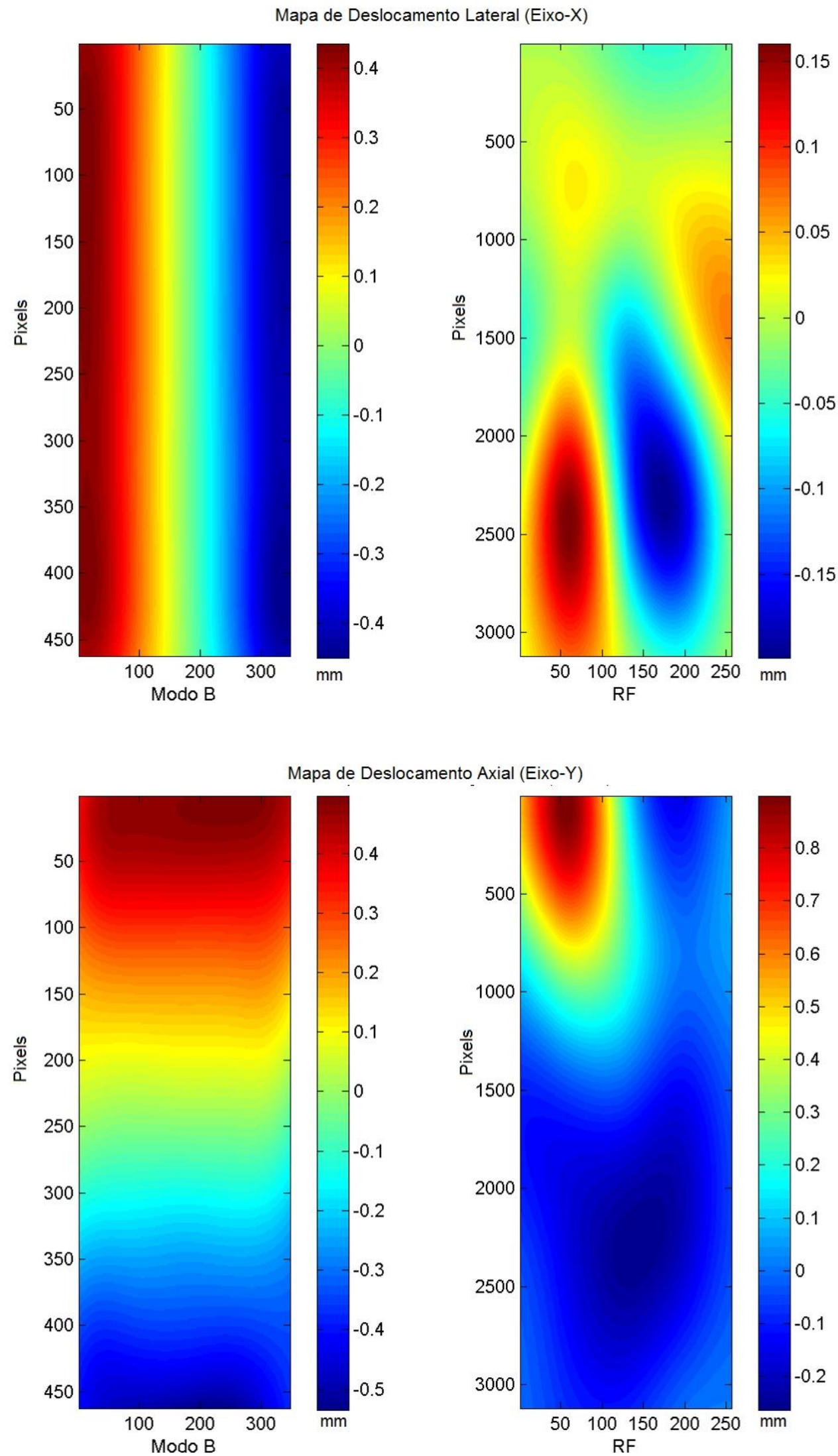

Figura 38: Comparação entre os mapas de deformação lateral (parte superior) e axial (parte inferior) obtidos pelo modo B (lado esquerdo) e pelos mapas de RF (lado direito), para as imagens da Figura 19. 
Os valores de deslocamento lateral obtidos com as imagens modo $B$ variam aproximadamente entre $-0,4$ e 0,4mm e os obtidos com os mapas de RF entre - 0,15 e $0,15 \mathrm{~mm}$. Os valores esperados para $2 \%$ de deformação centrada na inclusão, conforme a equação (14), estariam, aproximadamente, entre $-0,31$ a $0,31 \mathrm{~mm}$. Isto indica que, com os parâmetros utilizados, as imagens modo $B$ fornecem informações de deslocamento compatível com o experimento e os mapas de RF fornecem informações de deslocamento com um erro de aproximadamente $50 \%$. Os valores de deslocamento axial obtidos com as imagens modo $B$ variam aproximadamente entre $-0,5$ a $0,45 \mathrm{~mm}$ e os obtidos com os mapas de RF de $-0,2$ a $0,8 \mathrm{~mm}$, enquanto os valores esperados deveriam estar entre $-0,5$ a $0,5 \mathrm{~mm}$, o que novamente indica que as imagens em modo $B$ melhor descrevem os deslocamentos causados pelo experimento.

Como os mapas de RF possui valores na faixa de 16 bits e uma quantidade de pontos bem maior que as imagens em modo-B o otimizador não ajustou a busca adequadamente baseado nos parâmetros testados. Para o uso adequado do corregistro com características propostas neste trabalho teria sido necessário a estender a busca pelos valores dos parâmetros numa coleção de valores bem mais ampla que a testada neste trabalho. Outras opções seriam o uso de uma grade maior, o que diminuiria o grau de interpolação inerente da transformação por B-Splines, ou o uso de alguma decimação no dado. Mas, como modo B é o envelope do mapa de RF e tem por característica diminuir a influência local do sinal, o uso da decimação nos mapas de $\mathrm{RF}$ produziria um resultado próximo ao próprio modo $\mathrm{B}$.

\subsection{Fantoma de Parafina-Gel A}

A aquisição das imagens do fantoma Parafina-Gel $A$ foi feita somente em modo B e em duas etapas: 1 (antes da retirada) e 2 (após a retirada de 1,6 ml de liquido da inclusão). Os dados de processamento escolhidos, de acordo com as seções $5.2 \mathrm{e}$ 5.3, foram:

- Grade: $5 \times 11$

- Default Step Length: 1,6

- Gradient Convergence Tolerance: 0,03 
- Line Search Accuracy: 1,0

Utilizamos programa 4D-Slicer VV para visualizar as imagens conjuntamente com o mapa de deformação calculado.

\subsubsection{Aquisição Linear}

Foram adquiridos 27 fatias com espaçamento de $1 \mathrm{~mm}$ entre as fatias, ou seja, a varredura vai de $0 \mathrm{~mm}$ até o $26 \mathrm{~mm}$. Para descrever o movimento do fantoma como um todo foram avaliados as fatias das seguintes posições: 5, 10, 14, 18 e $23 \mathrm{~mm}$.

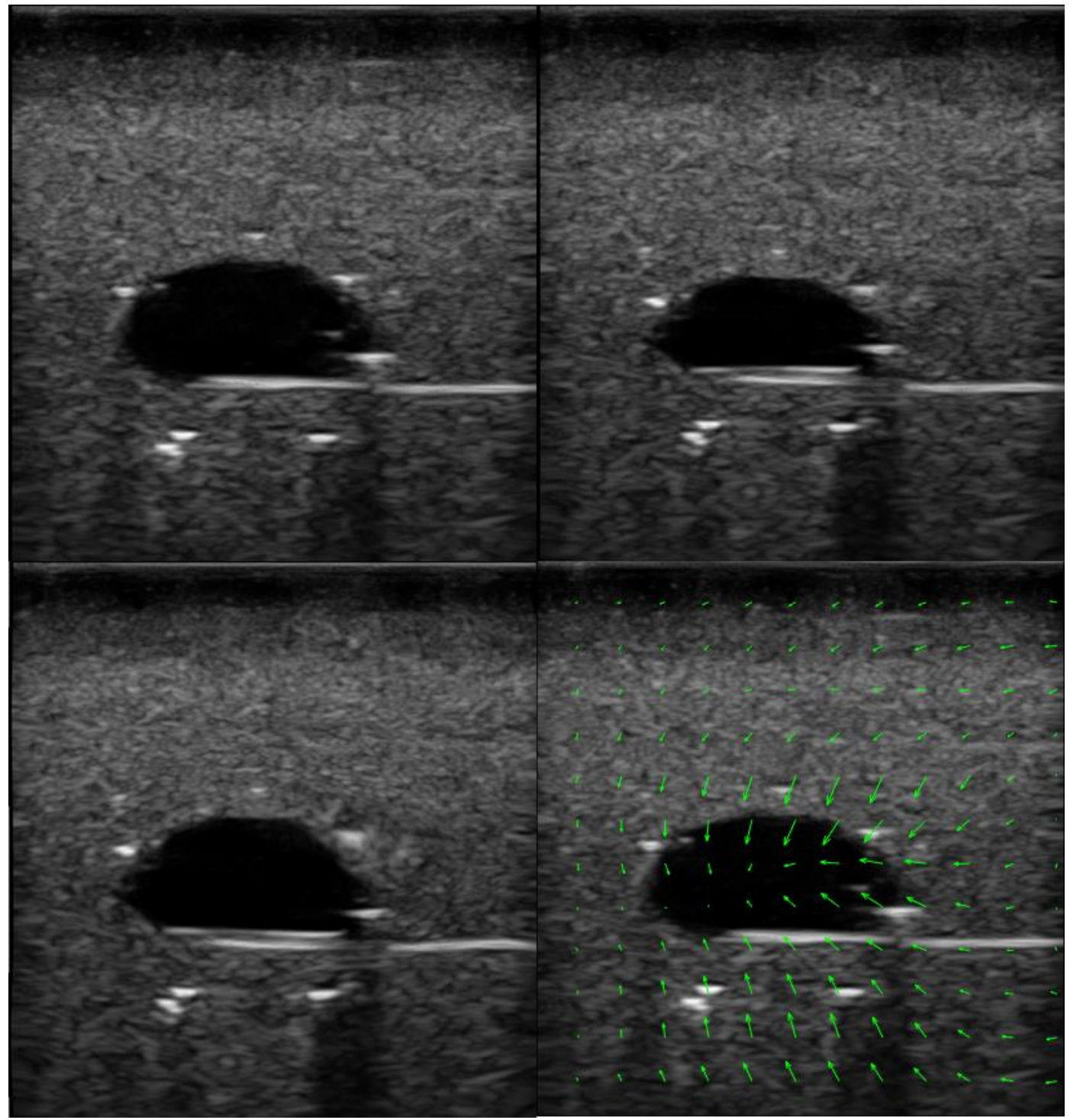

Figura 39: Processamento da fatia da posição de $5 \mathrm{~mm}$. A imagem superior esquerda é etapa 1, a imagem superior direita é a etapa 2, imagem inferior esquerda é a etapa 2 corregistrada e a imagem inferior direita é a etapa $1 \mathrm{com}$ o mapa de deformação calculado.

Aplicado o programa de corregistro entre as imagens da etapa 1 (antes da retirada) e da etapa 2, para a fatia da posição de $5 \mathrm{~mm}$, é obtido o mapa de deformação. A ilustração deste mapa sobre a imagem da etapa 1 está na imagem 
inferior direta da Figura 39, que demonstra qual foi o campo de deformação gerado pela retirada de liquido da inclusão. Pode se notar que há um deslocamento das estruturas adjacentes na direção da inclusão e com menor magnitude na região próxima à borda da esquerda. A aplicação deste mapa de deformação sobre a imagem da etapa 2 (superior direito da Figura 39) resulta na imagem corregistrada (inferior esquerda da Figura 39). A seguir temos as imagens referentes à fatia da posição de $10 \mathrm{~mm}$.

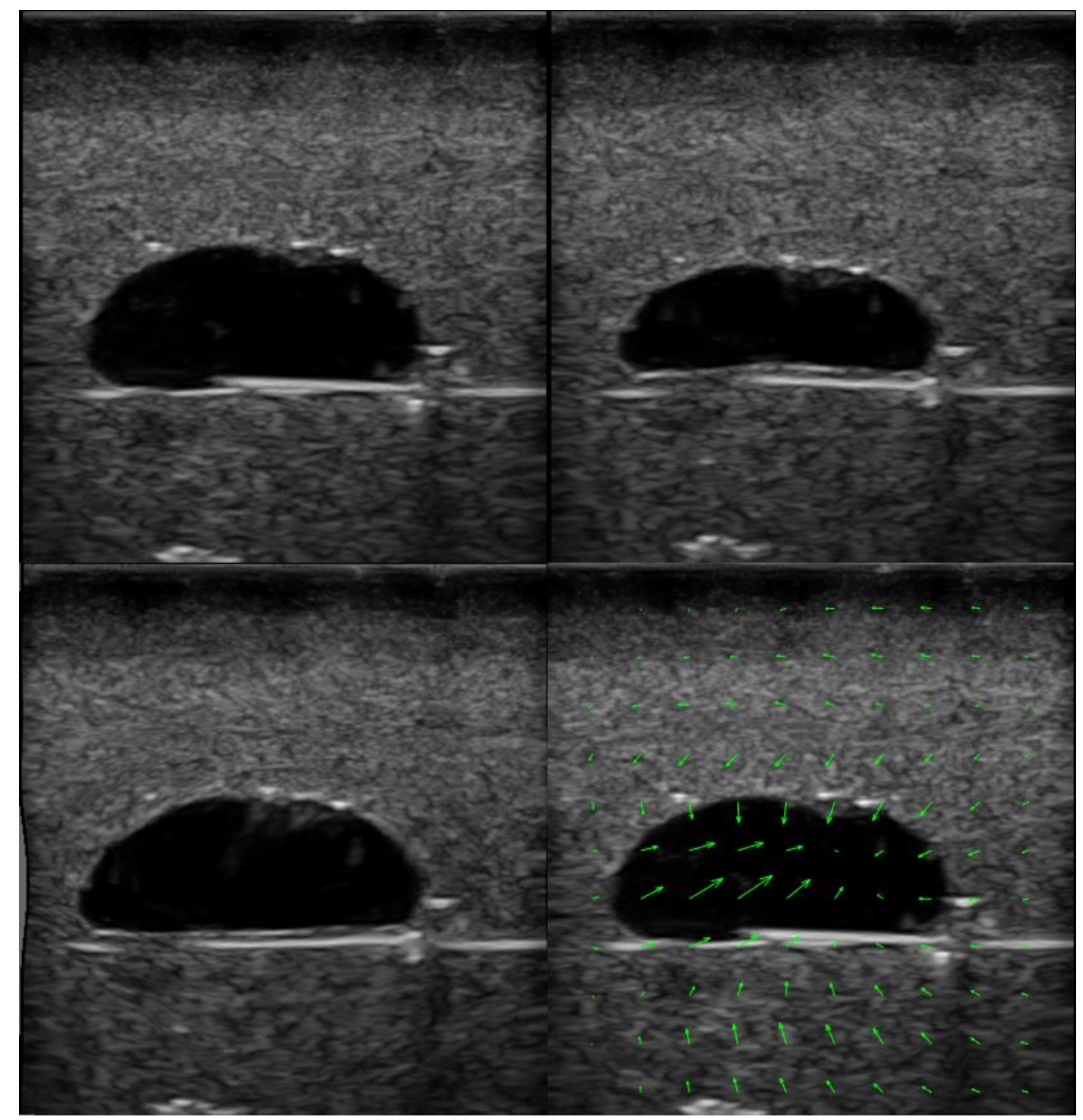

Figura 40: Processamento da fatia da posição de $10 \mathrm{~mm}$. A imagem superior esquerda é etapa 1, a imagem superior direita é a etapa 2, imagem inferior esquerda é a etapa 2 corregistrada e a imagem inferior direita é a etapa 1 com o mapa de deformação calculado.

Repetindo o procedimento na fatia da posição de $10 \mathrm{~mm}$ a Figura 40 ilustra os resultados seguindo os mesmos conceitos da análise anterior. Pode se notar que há um deslocamento das estrutura adjacentes na direção da inclusão com menor magnitude na região próxima à borda da esquerda. 


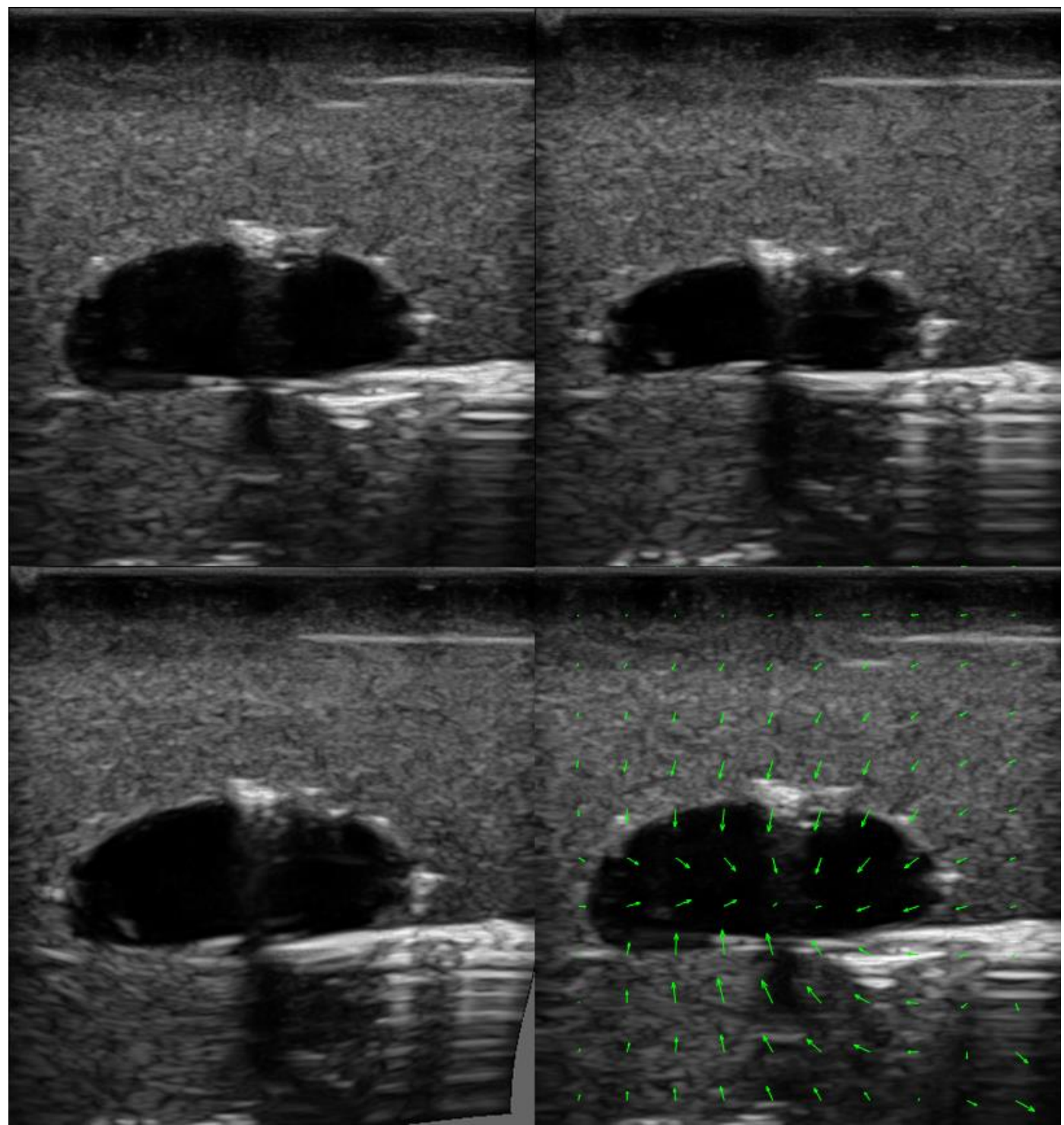

Figura 41: Processamento da fatia da posição de $14 \mathrm{~mm}$. A imagem superior esquerda é etapa 1, a imagem superior direita é a etapa 2, imagem inferior esquerda é a etapa 2 corregistrada e a imagem inferior direita é a etapa $1 \mathrm{com}$ o mapa de deformação calculado.

A Figura 41 ilustra os resultados para a fatia da posição de $14 \mathrm{~mm}$. O artefato que aparece no lado direito inferior é a agulha que foi utilizada para a retirada do líquido da inclusão que ela já estava posicionada na etapa 1 e não provocou influência no processamento. A distribuição do mapa de deformação é aproximadamente uniforme em direção à inclusão. 


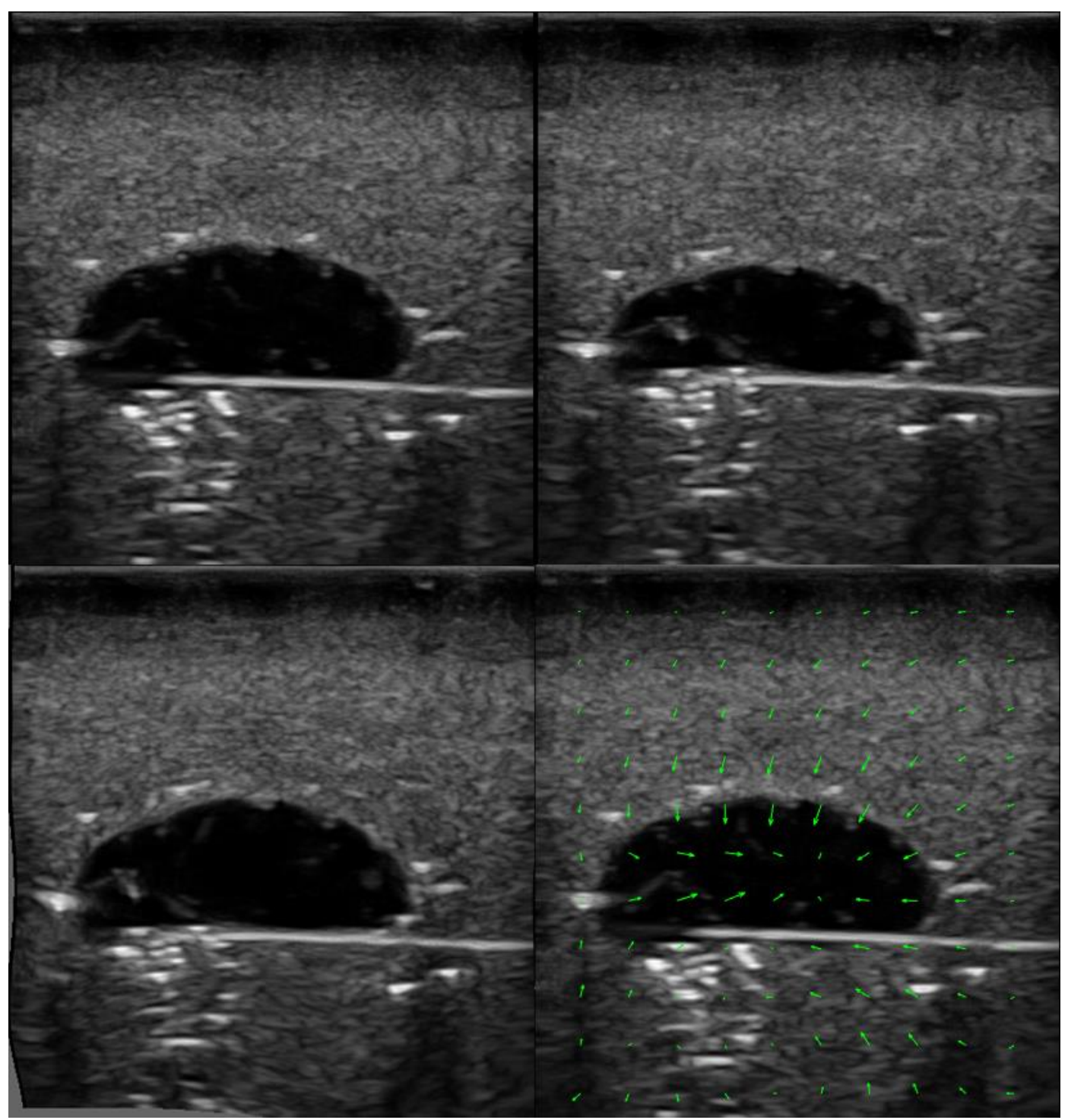

Figura 42: Processamento da fatia da posição de $18 \mathrm{~mm}$. A imagem superior esquerda é etapa 1, a imagem superior direita é a etapa 2, imagem inferior esquerda é a etapa 2 corregistrada e a imagem inferior direita é a etapa 1 com o mapa de deformação calculado.

A Figura 42 ilustra os resultados para a fatia da posição de 18mm. Da mesma forma que a fatia anterior, a distribuição do mapa de deformação é aproximadamente uniforme em direção à inclusão, mas com o centro deste mapa um pouco deslocado à direita. 


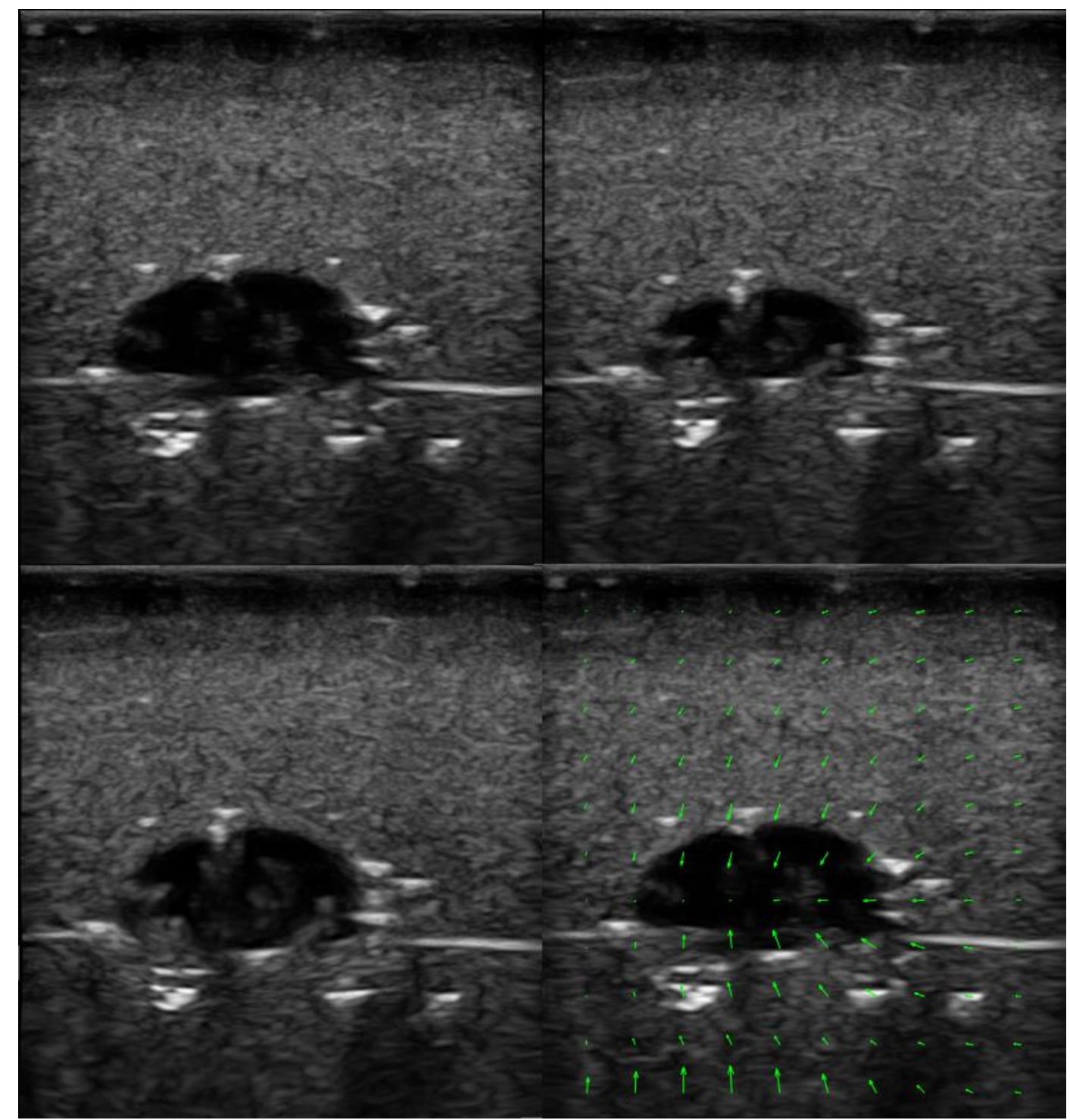

Figura 43: Processamento da fatia da posição de $23 \mathrm{~mm}$. A imagem superior esquerda é etapa 1, a imagem superior direita é a etapa 2, imagem inferior esquerda é a etapa 2 corregistrada e a imagem inferior direita é a etapa 1 com o mapa de deformação calculado.

A Figura 43 ilustra os resultados para a fatia da posição de $23 \mathrm{~mm}$. A menor magnitude de deslocamento se encontra próximo à borda direita da inclusão. Avaliando os resultados de todos estas fatias e o fato de que a inclusão tem um formato aproximadamente elipsoidal podemos inferir que:

- As fatias mais distantes do centro (5, 10 e 23mm) possuem menor deslocamento lateral. Isto se deve, provavelmente, a efeito das bordas laterais possuírem menos espaço para deslocamento que as bordas axiais. A inclusão é oval o que favorece o descolamento axial.

- Existe um cisalhamento entre as fatias periféricos, que pode ser notado nas duas primeiras fatias e na última.

- O artefato da imagem devido à agulha não interfere no corregistro. 


\subsubsection{Aquisição Angular}

Foram adquiridos 33 fatias de $\left(-32^{\circ}\right.$ a $\left.32^{\circ}\right)$, com espaçamento de $2^{\circ}$ entre as fatias. Escolhemos para a avaliação as fatias da posição angular de $-16^{\circ}$ e $18^{\circ}$. Nesta análise a ideia é retirar uma imagem do volume na etapa 1 para o ângulo selecionado e corregistrar com imagem adquirida neste ângulo na etapa 2. Depois repetimos o mesmo entre a etapa 2 e 3, quando estas estiverem presentes, e assim por diante. Desta forma o corregistro é sempre realizado entre uma fatia retirada do volume e uma adquirida. Isto é feito para ser possível sempre o corregistro a partir de um volume como acontece nas situações reais. Para descrever um plano angular ao volume da imagem, foram feitos dois procedimentos: reamostragem do volume do fantoma de 27 para 108 fatias de forma a diminuir o espaçamento e tornar mais suave a interpolação (espaçamento final de $0,25 \mathrm{~mm}$ ) e uma interpolação reamostrando todo o volume de forma que a fatia central passasse a situar na mesma posição espacial que a fatia adquirida pelo sistema de rastreio. Para estes procedimentos foi utilizado o template ResamplelmageFilter. Seguem as imagens abaixo.

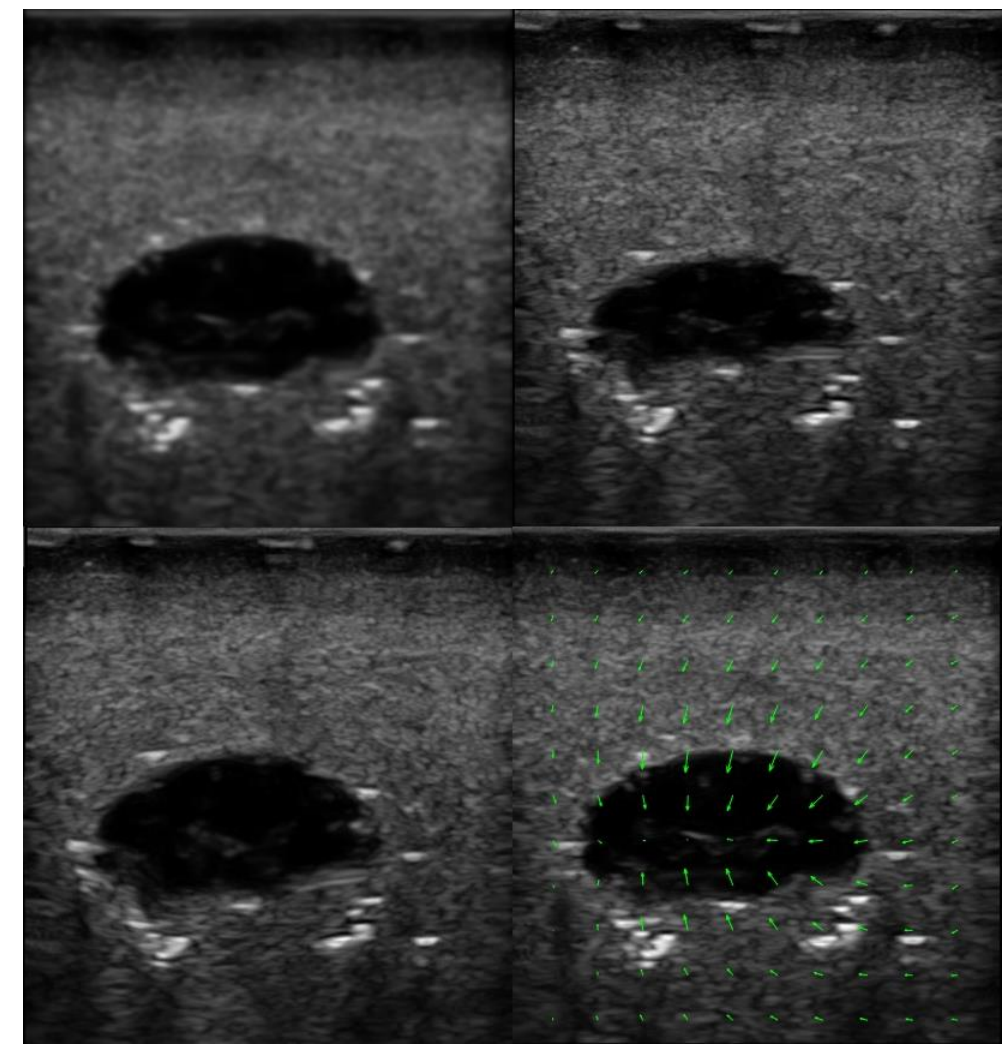

Figura 44: Processamento da fatia de $-16^{\circ}$. A imagem superior esquerda é etapa 1 , a imagem superior direita é a etapa 2, imagem inferior esquerda é a etapa 2 corregistrada e a imagem inferior direita é a etapa 1 com o mapa de deformação calculado. 


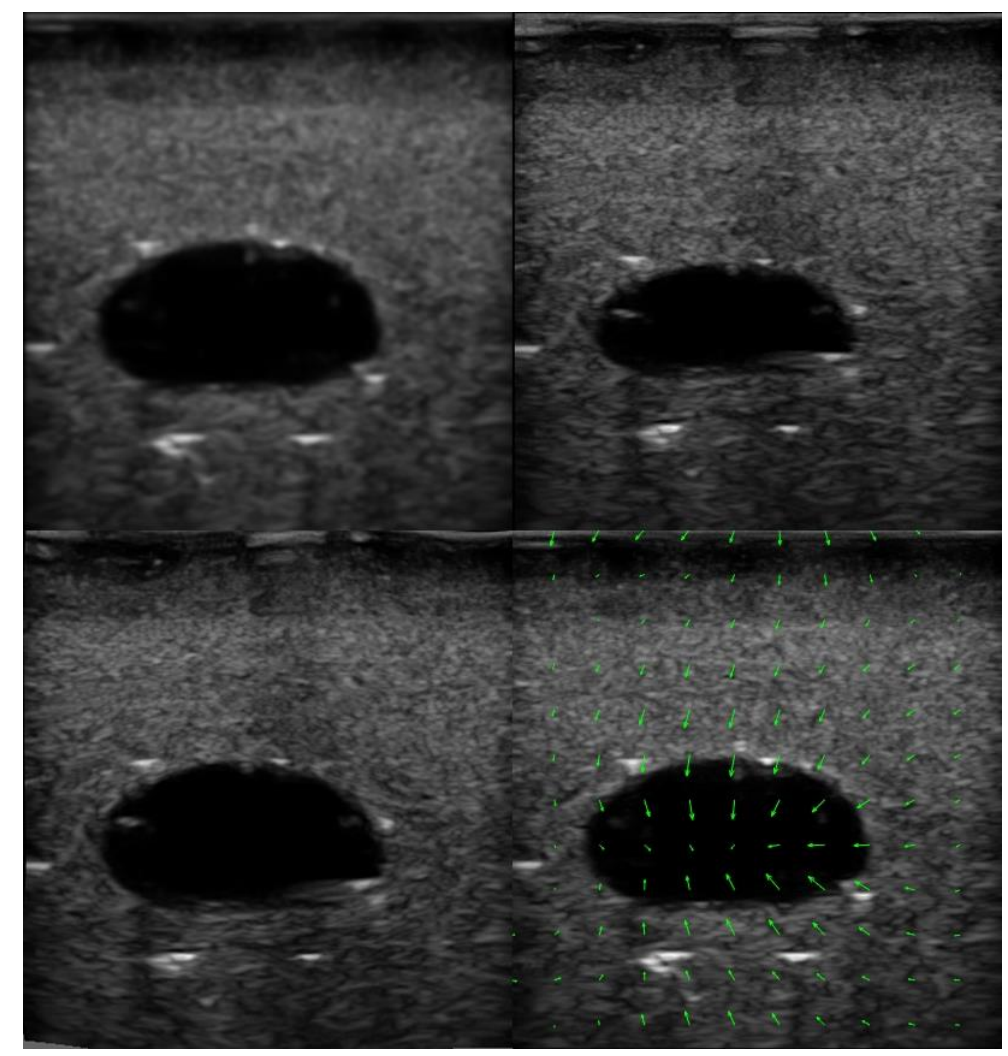

Figura 45: Processamento da fatia de 18‥ A imagem superior esquerda é etapa 1 , a imagem superior direita é a etapa 2, imagem inferior esquerda é a etapa 2 corregistrada e a imagem inferior direita é a etapa 1 com o mapa de deformação calculado.

Neste caso temos uma informação de qual foi o deslocamento calculado referente aos planos espaciais escolhidos. Isto traz uma informação relevante para o procedimento cirúrgico no qual é possível acompanhar, sabendo o ângulo, quais deformações a fatia de interesse está sujeita. Pela análise destes cortes somadas com as da aquisição linear é possível inferir que a deformação como um todo é aproximadamente isotrópica em relação à inclusão, ou seja, todos os campos de deslocamento no espaço 3D apontam para a inclusão. Isto significa que houve somente uma diminuição do volume, com poucos cisalhamentos.

\subsection{Fantoma de Parafina-Gel B}

Este fantoma possui um artefato causado pelo fundo da caixa onde ele se encontra. A aquisição das imagens do fantoma Parafina-Gel B foi feita somente em modo $B$ e em cinco etapas:

- 1 (antes da retirada) 
- 2 (retirada de $1 \mathrm{ml}$ da inclusão)

- 3 (total retirado da inclusão: 2,8 ml),

- 4 (total retirado da inclusão: $3,2 \mathrm{ml}$ )

- 5 (total retirado da inclusão: $4 \mathrm{ml}$ ).

Os dados de processamento escolhidos, de acordo com as seções 5.2 e 5.3, foram:

- Grade: $5 \times 11$

- Defaut Step Length: 1,6

- Gradient Convergence Tolerance: 0,03

- Line Search Accuracy: 0,8

\subsubsection{Aquisição Linear}

Foram adquiridos 12 fatias com espaçamento de $2 \mathrm{~mm}$ entre as fatias, ou seja, a varredura vai de $0 \mathrm{~mm}$ até $022 \mathrm{~mm}$. Para descrever o movimento do fantoma com um todo foram avaliados as fatias das seguintes posições: $4,8,12,16$ e $20 \mathrm{~mm}$. O corregistro de cada fatia foi realizado na seguinte sequência:

- Etapa $1 \mathrm{com} 2$

- Etapa 2 com 3

- Etapa 3 com 4

- Etapa 4 com 5

Desta forma podemos acompanhar a evolução dos deslocamentos da estruturas do fantoma. 


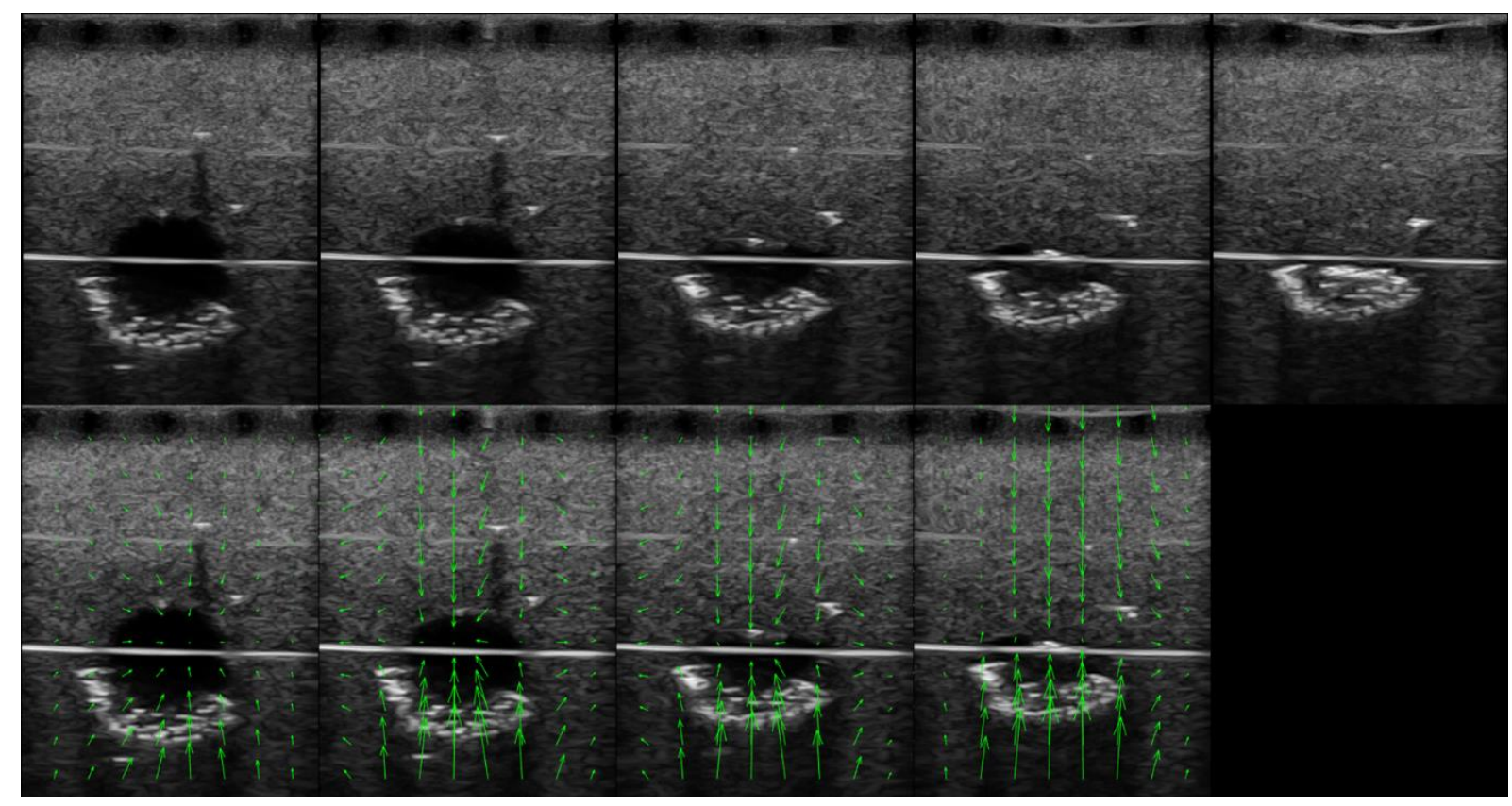

Figura 46: Processamento da fatia da posição de $4 \mathrm{~mm}$. As imagens superiores da esquerda para a direita correspondem às etapas: 1, 2, 3, 4 e 5. As imagens inferiores da esquerda para a direita são as etapas 1,2, 3 e 4, com a superposição do mapa deformação calculado que se aplicado leva a etapa posterior.

Na fatia da posição de $5 \mathrm{~mm}$, o mapa de deformação que leva a imagem da etapa 1 para a etapa 2 descreve um movimento de sucção para o centro da inclusão. Para as outras etapas isto se modifica um pouco, pois as componentes laterais apontam no sentido contrário à sucção, e isto se deve provavelmente à componente axial ser muito maior que a lateral o que provoca uma expansão lateral conforme podemos ver na Figura 46. 


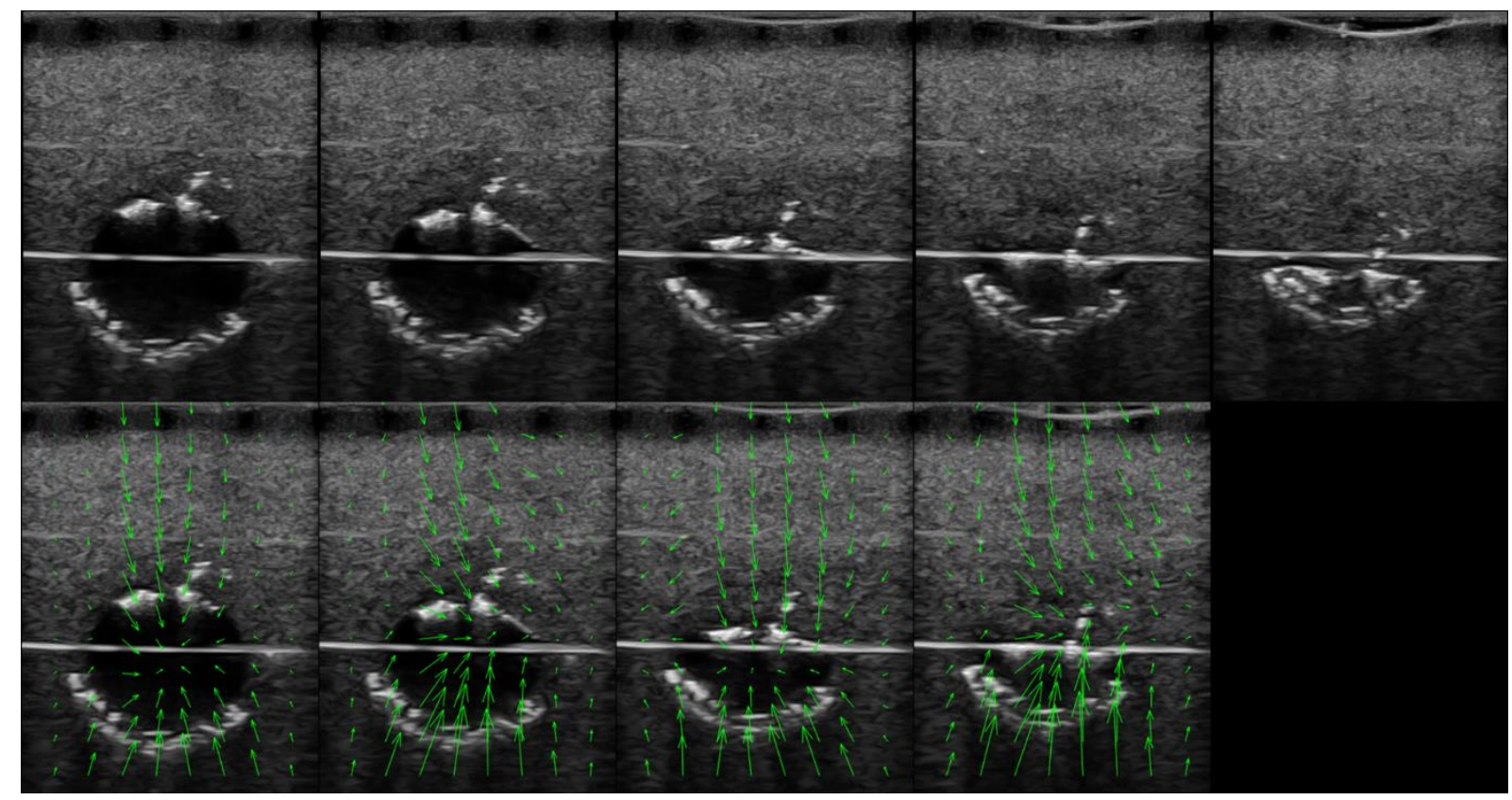

Figura 47: Processamento da fatia da posição de $8 \mathrm{~mm}$. As imagens superiores da esquerda para a direita correspondem às etapas: 1, 2, 3, 4 e 5. As imagens inferiores da esquerda para a direita são as etapas 1, 2, 3 e 4, com a superposição do mapa deformação calculado que se aplicado leva a etapa posterior.

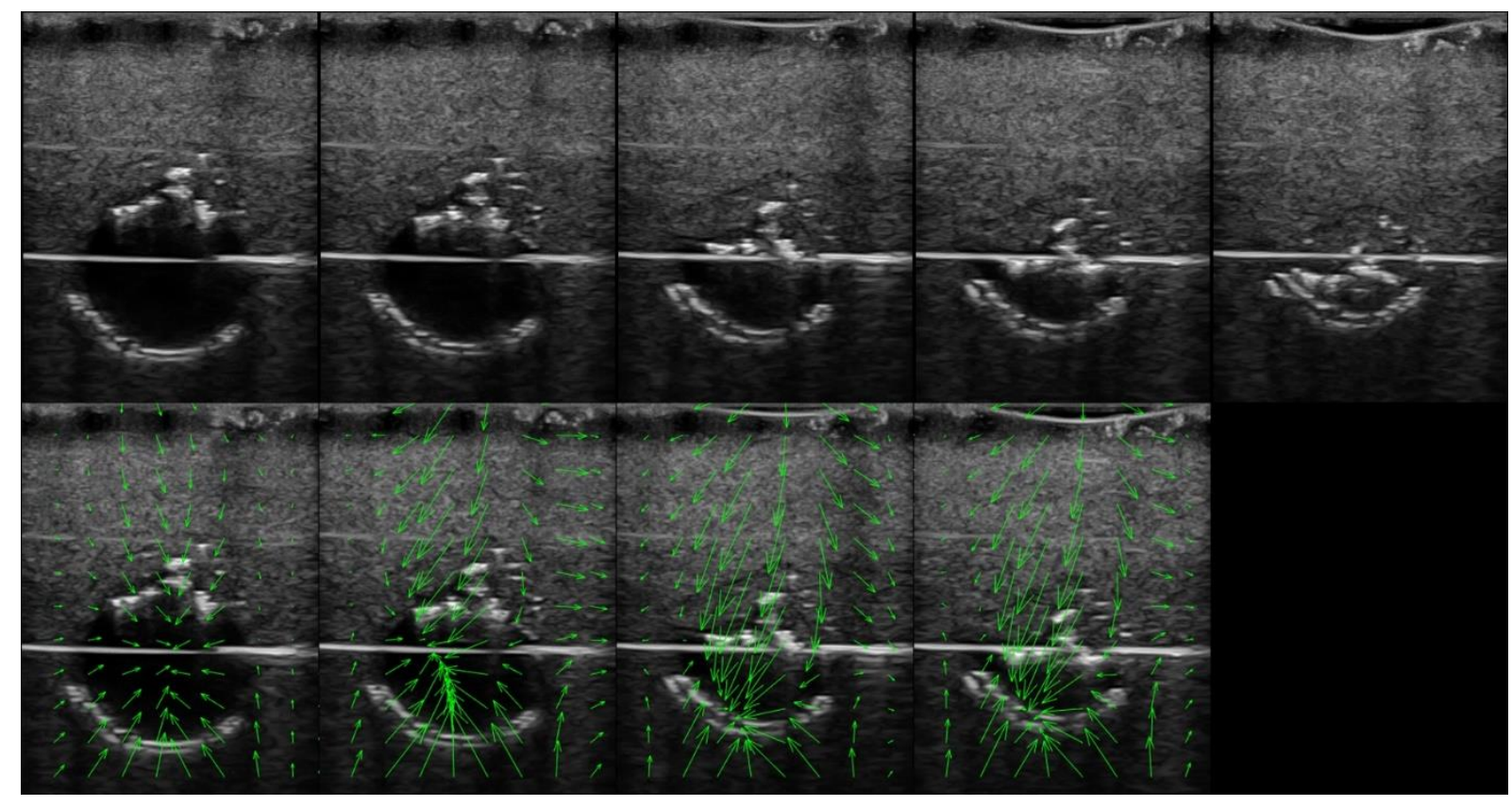

Figura 48: Processamento da fatia da posição de 12mm. As imagens superiores da esquerda para a direita correspondem às etapas: 1, 2, 3, 4 e 5. As imagens inferiores da esquerda para a direita são as etapas 1, 2, 3 e 4, com a superposição do mapa deformação calculado que se aplicado leva a etapa posterior. 


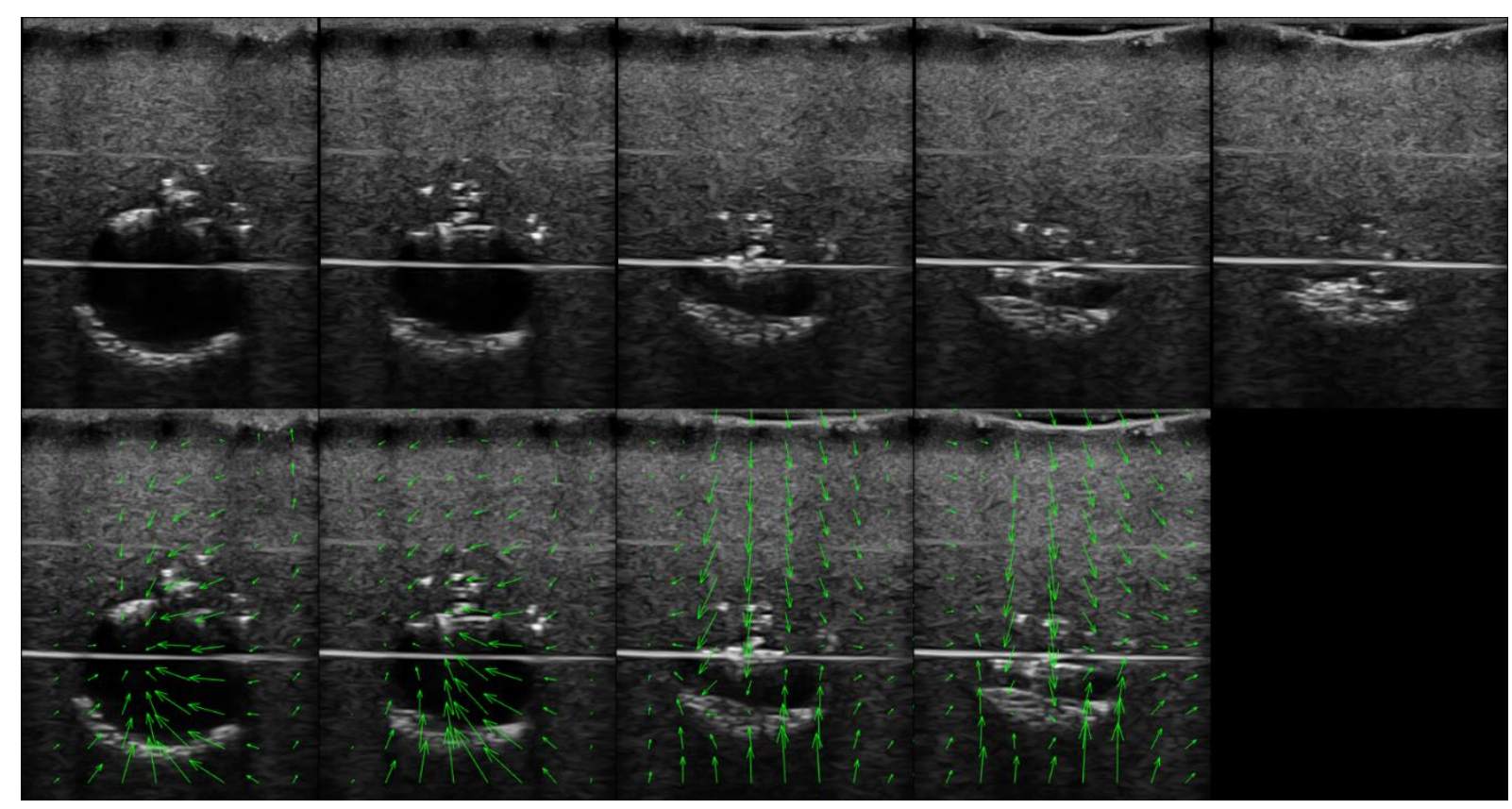

Figura 49: Processamento da fatia da posição de $16 \mathrm{~mm}$. As imagens superiores da esquerda para a direita correspondem às etapas: 1, 2, 3, 4 e 5. As imagens inferiores da esquerda para a direita são as etapas 1, 2, 3 e 4, com a superposição do mapa deformação calculado que se aplicado leva a etapa posterior.

Nas fatias 8, 12 e 16mm podemos dividir o comportamento em duas partes: as primeiras transições (etapas 1 para 2 e 2 para 3) o mapa de deslocamento ilustra a atração em aproximadamente todas as direções no sentido da inclusão, descrevendo uma sucção aproximadamente uniforme e as segundas transições (etapas 3 para 4 e 4 para 5) demonstra um predomínio da deformação axial, no sentido da inclusão, e uma deformação lateral em intensidade menor no sentido contrário ao da inclusão. Isto se deve ao fato da deformação axial ser muito maior provocando uma expansão lateral. 


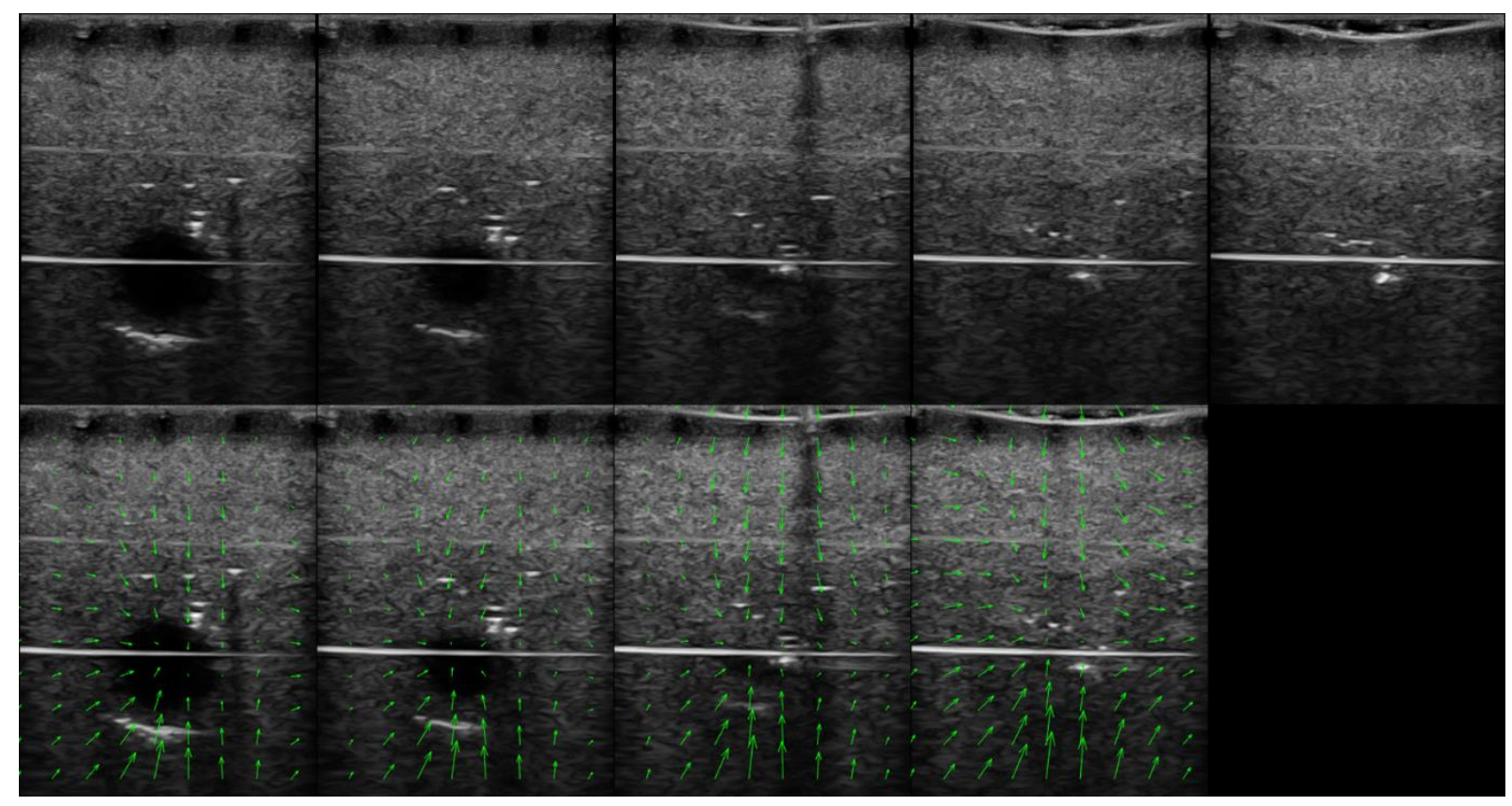

Figura 50: Processamento da fatia da posição de $20 \mathrm{~mm}$. As imagens superiores da esquerda para a direita correspondem às etapas: 1, 2, 3, 4 e 5. As imagens inferiores da esquerda para a direita são as etapas 1, 2, 3 e 4, com a superposição do mapa deformação calculado que se aplicado leva a etapa posterior.

A fatia $20 \mathrm{~mm}$ se situa mais distante do centro que as outras que foram avaliadas e, possui um comportamento similar as demais fatias avaliadas. De forma geral este fantoma se comportou, inicialmente num movimento em direção a inclusão e posteriormente houve o predomínio da deformação axial com afastamento das estruturas laterais. Comparada com as simulações podemos dizer que o movimento inicial pode ser descrito aproximadamente pela equação (14 (Sucção) e o movimento final pela equação (13 (Poisson).

\subsubsection{Aquisição Angular}

Foram adquiridos 20 fatias de $\left(-20^{\circ}\right.$ a $\left.18^{\circ}\right)$, com espaçamento de $2^{\circ}$ entre as fatias. Escolhemos para a avaliação as fatias da posição angular de $-8^{\circ}$ e $12^{\circ}$. O procedimento de análise é o mesma da seção anterior e reamostragem do volume do fantoma foi feita de 12 para 48 fatias (espaçamento final de $0,5 \mathrm{~mm}$ ). 


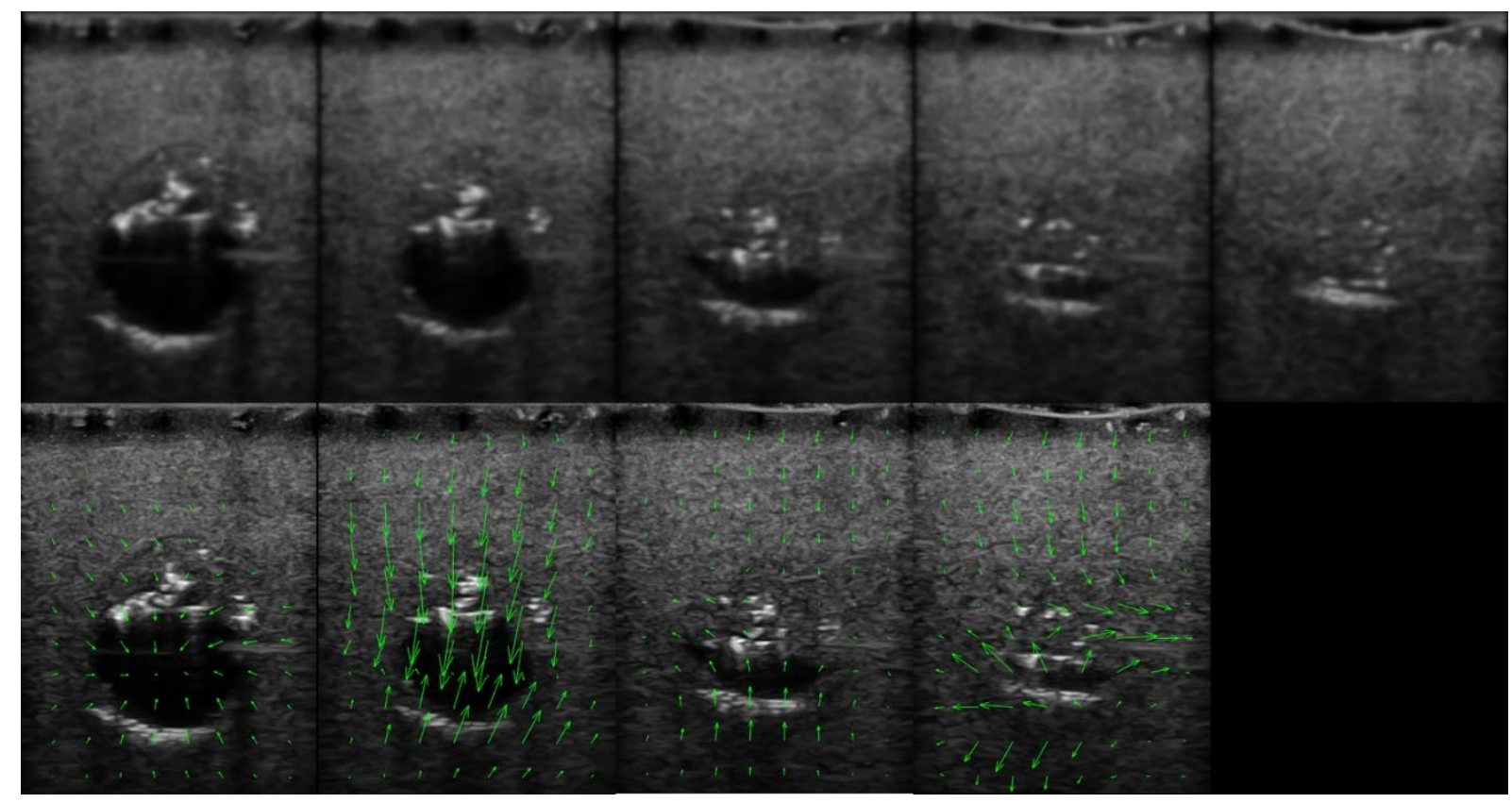

Figura 51: Processamento da fatia de $-12^{\circ}$. As imagens superiores da esquerda para a direita correspondem às etapas: 1, 2, 3, 4 e 5. As imagens inferiores da esquerda para a direita são as etapas 1, 2, 3 e 4, com a superposição do mapa deformação calculado que se aplicado leva a etapa posterior.

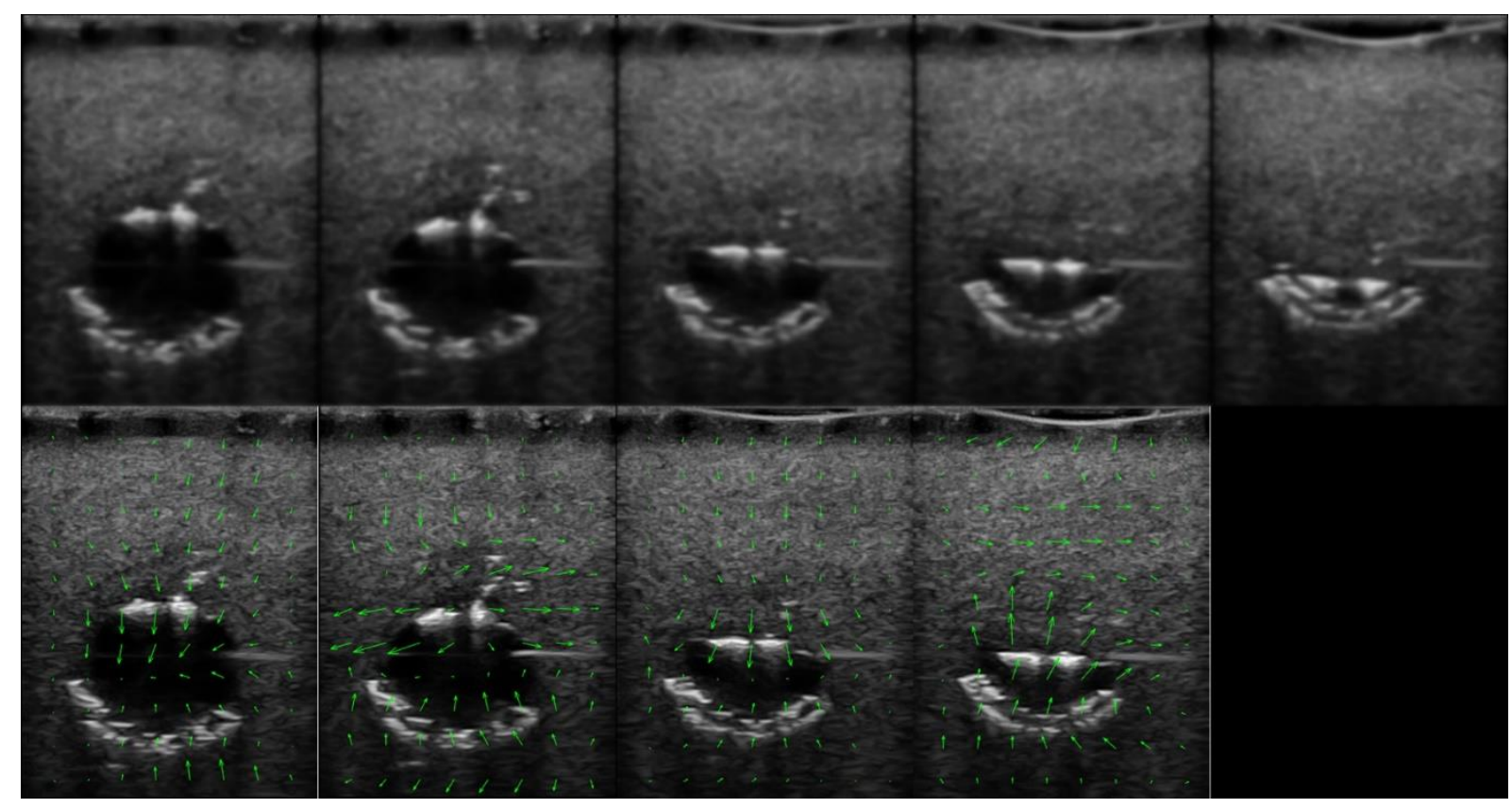

Figura 52: Processamento da fatia de $8^{\circ}$. As imagens superiores da esquerda para a direita correspondem às etapas: 1, 2, 3, 4 e 5 . As imagens inferiores da esquerda para a direita são as etapas 1,2, 3 e 4, com a superposição do mapa deformação calculado que se aplicado leva a etapa posterior.

Para o ângulo de $12^{\circ}$ e entre as etapas 1 e 2 , o campo de deslocamento descreve uma sucção, entre as etapas 2-4 há um predomínio do deslocamento axial e entre as etapas 4 e 5 é possível perceber os cisalhamentos. No caso do ângulo de $-8^{\circ}$ a análise os comportamentos são similares às etapas do ângulo de $12^{\circ}$, exceto 
para a última transição, na qual o campo de deslocamento sofre um cisalhamento na região bem acima da inclusão, mostrando um padrão não isotrópico.

\subsection{Fantoma de Gelatina}

Este fantoma possui um encapsulamento de parafina cristal-gel sobre inclusão. A aquisição das imagens do fantoma de Gelatina foi feita somente em modo B e em quatro etapas:

- 1 (antes da retirada)

- 2 (retirada de 1,4 $\mathrm{ml}$ da inclusão)

- 3 (total retirado da inclusão: $2,4 \mathrm{ml}$ )

- 4 (total retirado da inclusão: 4,0 ml)

Os dados de processamento escolhidos, de acordo com as seções seções 5.2 e 5.3, foram:

- Grade: $5 \times 11$

- Default Step Length: 1,6

- Gradient Convergence Tolerance: 0,03

- Line Search Accuracy: 0,8

\subsubsection{Aquisição Linear}

Foram adquiridos 21 fatias com espaçamento de $1 \mathrm{~mm}$ entre as fatias, ou seja, a varredura vai de $0 \mathrm{~mm}$ até o $20 \mathrm{~mm}$. Para descrever o movimento do fantoma com um todo foram avaliadas as fatias da seguintes posições: 2, 6, 10, 14 e 18mm. 0 corregistro de cada fatia foi realizado na seguinte sequência:

- Etapa 1 com 2

- Etapa 2 com 3

- Etapa 3 com 4

Desta forma podemos acompanhar a evolução dos deslocamentos da estruturas do fantoma por meio das Figura 53 a Figura 57. 


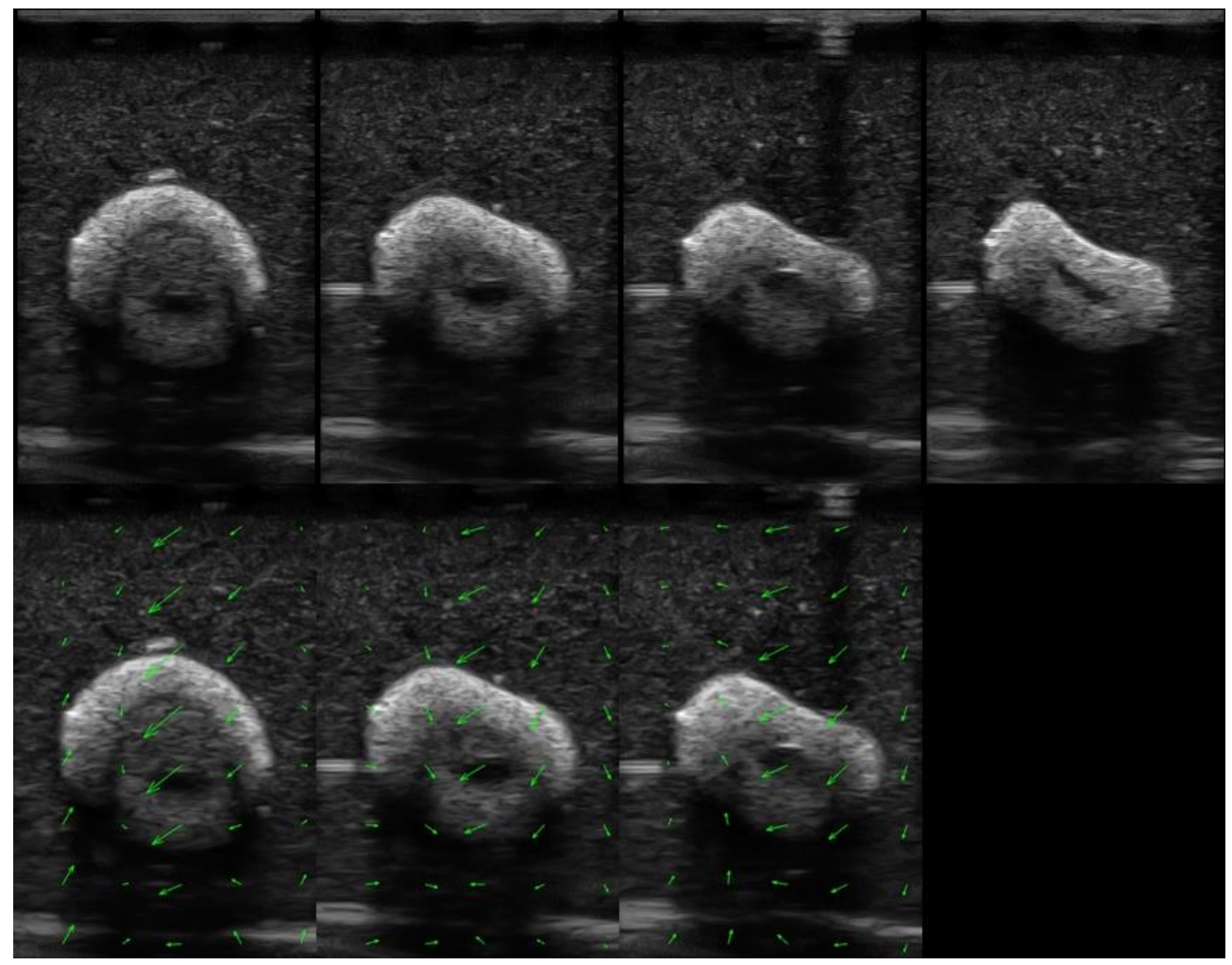

Figura 53: Processamento da fatia da posição de $2 \mathrm{~mm}$. As imagens superiores da esquerda para a direita correspondem às etapas: 1, 2, 3 e 4. As imagens inferiores da esquerda para a direita são as etapas 1,2 e 3, com a superposição do mapa deformação calculado que se aplicado leva a etapa posterior.

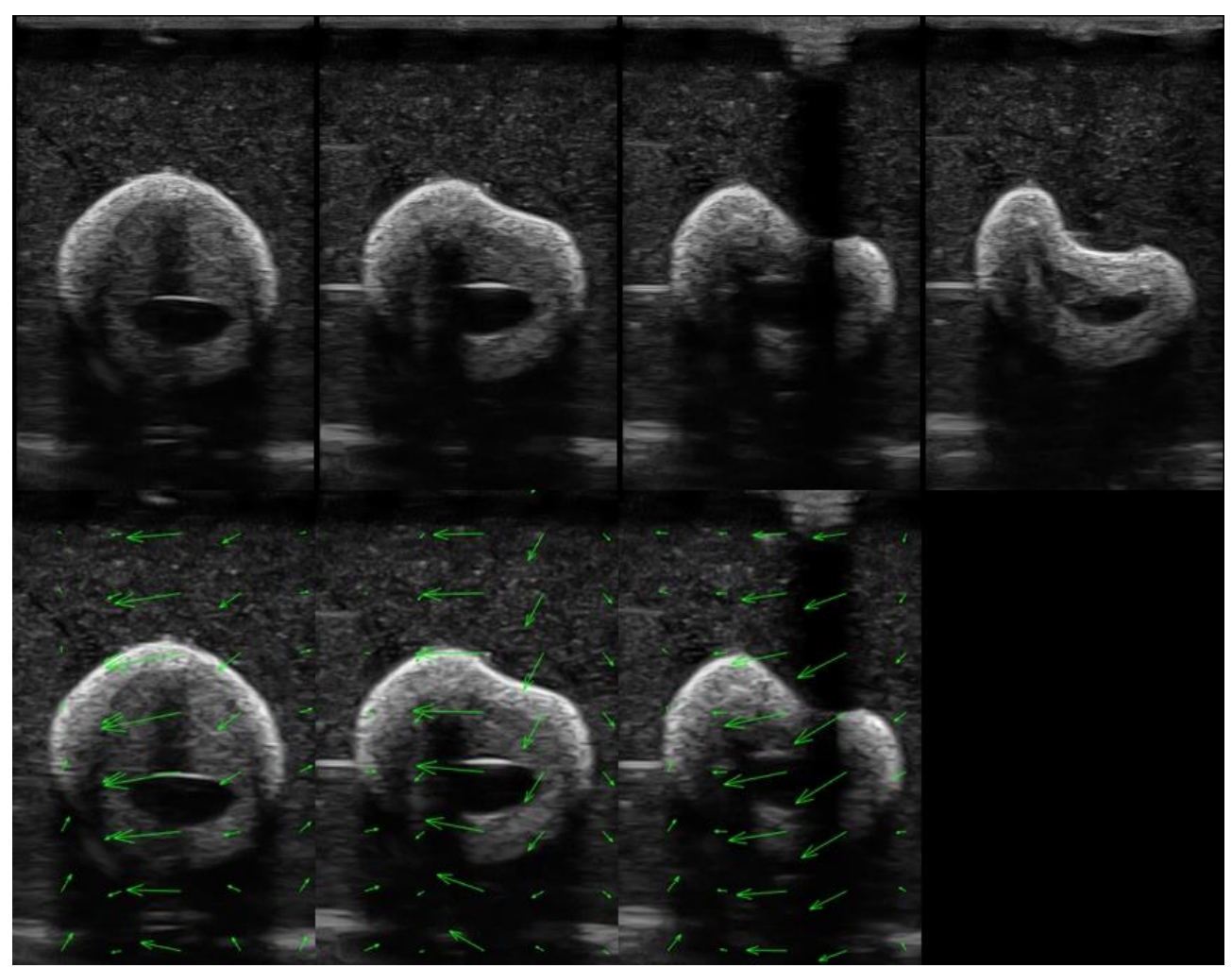

Figura 54: Processamento da fatia da posição de $6 \mathrm{~mm}$. As imagens superiores da esquerda para a direita correspondem às etapas: 1, 2, 3 e 4. As imagens inferiores da esquerda para a direita são as etapas 1,2 e 3, com a superposição do mapa deformação calculado que se aplicado leva a etapa posterior. 


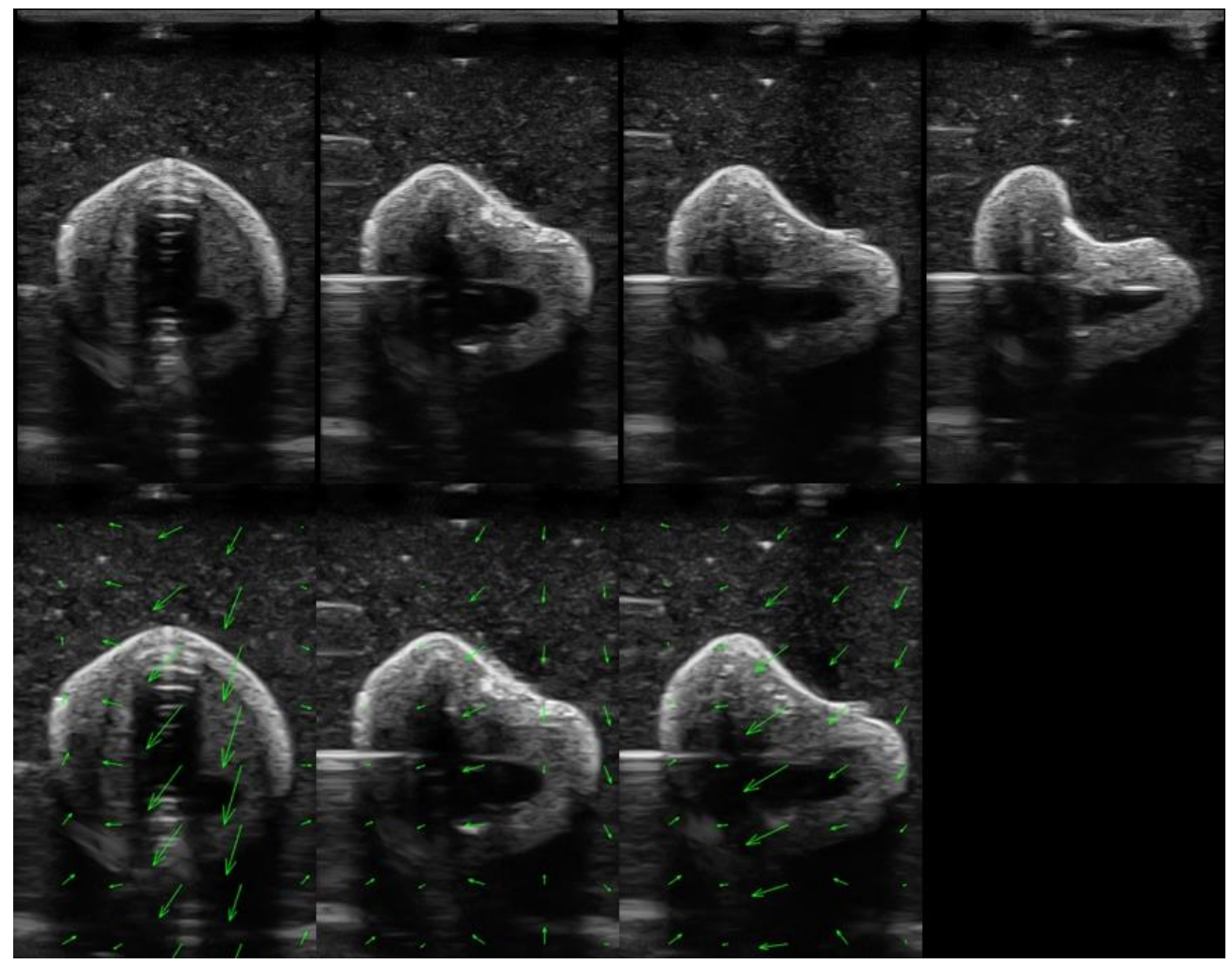

Figura 55: Processamento da fatia da posição de $10 \mathrm{~mm}$. As imagens superiores da esquerda para a direita correspondem às etapas: 1,2, 3 e 4 . As imagens inferiores da esquerda para a direita são as etapas 1, 2 e 3, com a superposição do mapa deformação calculado que se aplicado leva a etapa posterior.

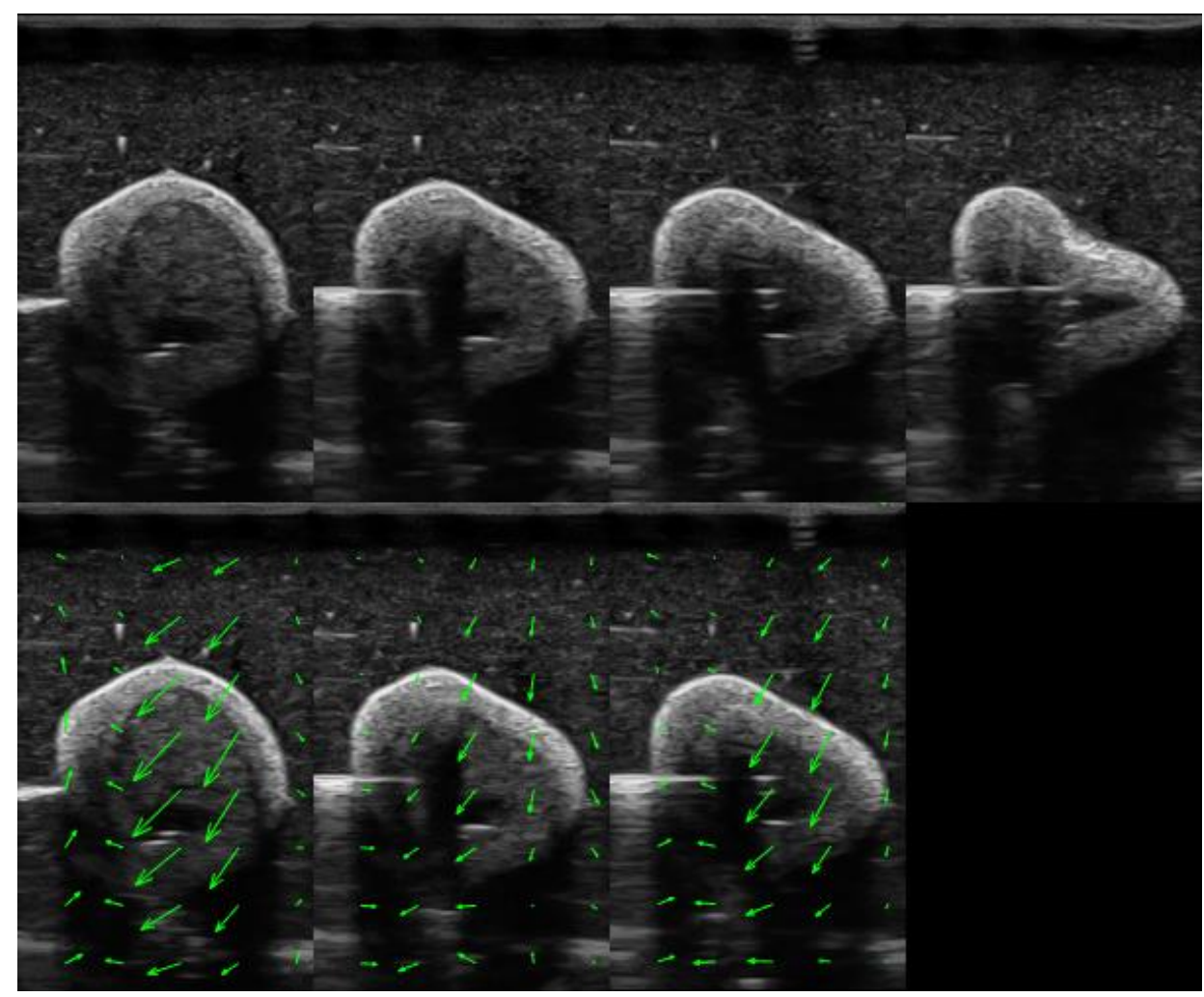

Figura 56: Processamento da fatia da posição de $14 \mathrm{~mm}$. As imagens superiores da esquerda para a direita correspondem às etapas: 1,2, 3 e 4 . As imagens inferiores da esquerda para a direita são as etapas 1, 2 e 3, com a superposição do mapa deformação calculado que se aplicado leva a etapa posterior. 


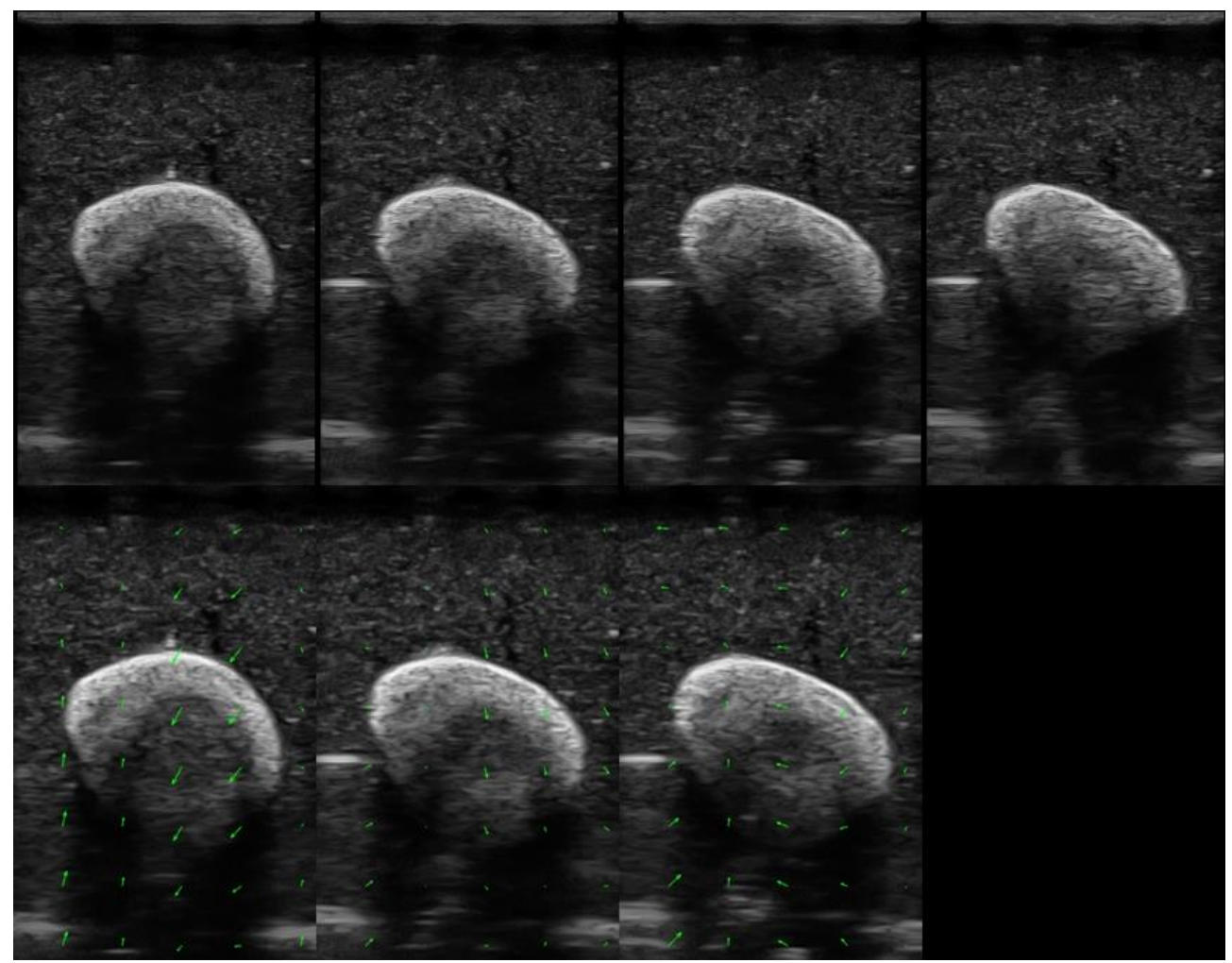

Figura 57: Processamento da fatia da posição de $18 \mathrm{~mm}$. As imagens superiores da esquerda para a direita correspondem às etapas: 1,2, 3 e 4 . As imagens inferiores da esquerda para a direita são as etapas 1, 2 e 3, com a superposição do mapa deformação calculado que se aplicado leva a etapa posterior.

De forma geral o comportamento dos mapas de deformação deste fantoma segue a uma linha em diagonal e no sentido do canto superior direito para o canto inferior esquerdo. Isto se deve, provavelmente, ao fato do encapsulamento ter um ponto mais frágil na região superior direita e concentrar a deformação neste ponto, causando a maior deflexão da superfície da inclusão.

\subsubsection{Aquisição Angular}

Foram adquiridos 27 fatias de (-26ㅇ a $\left.26^{\circ}\right)$, com espaçamento de $2^{\circ}$ entre as fatias. Escolhemos para a avaliação a fatia da posição angular de $-8 \%$. O procedimento é o mesmo das seções 5.4 .2 e 5.5.2. A reamostragem do volume do fantoma foi de 12 para 48 fatias (espaçamento final de $0,5 \mathrm{~mm}$ ). As imagens do processamento estão na Figura 58. 


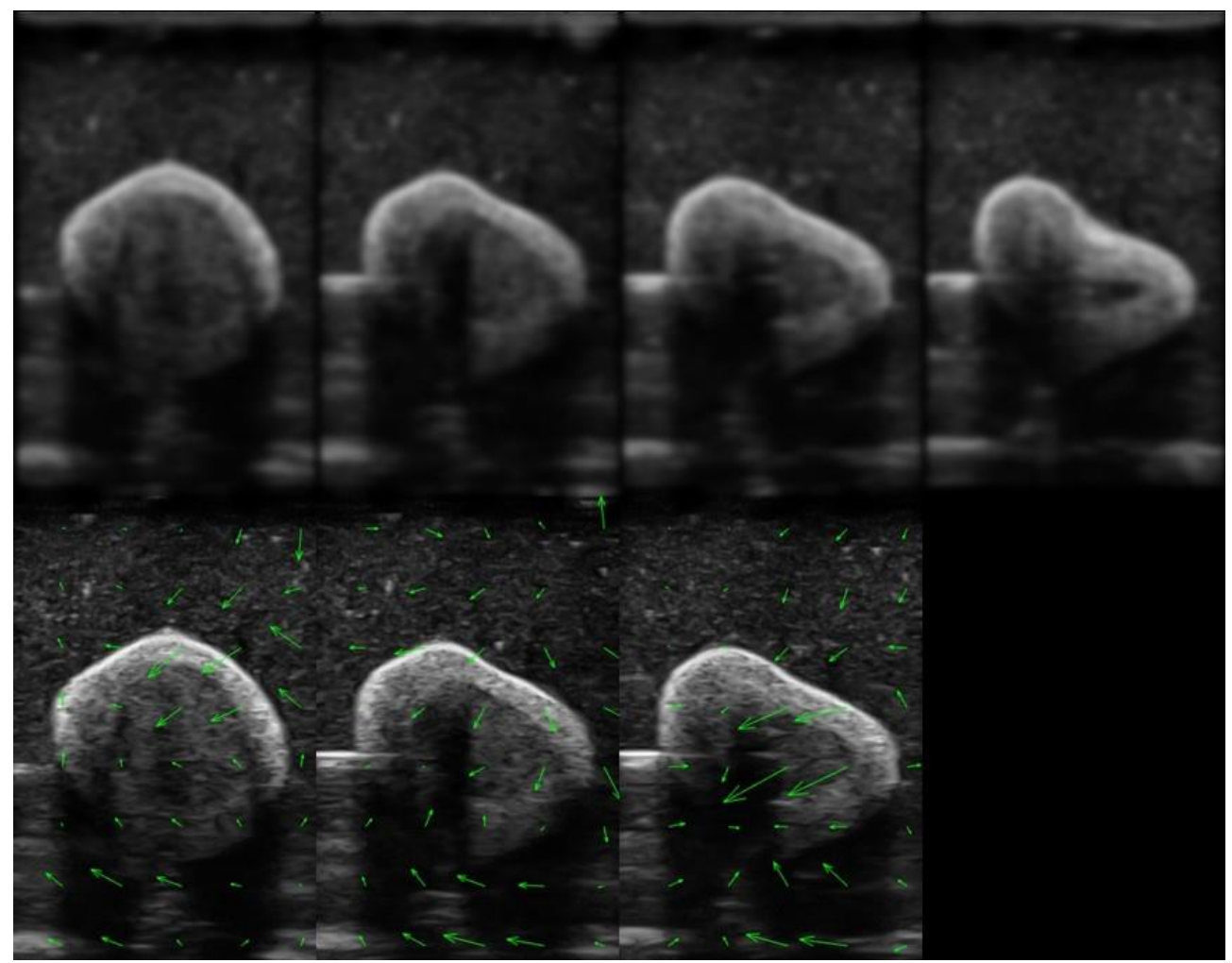

Figura 58: Processamento da fatia de $-8^{\circ}$. As imagens superiores da esquerda para a direita correspondem às etapas: 1, 2, 3 e 4 . As imagens inferiores da esquerda para a direita são as etapas 1,2 e 3, com a superposição do mapa deformação calculado que se aplicado leva a etapa posterior.

Neste caso temos uma informação de qual foi o deslocamento calculado referente aos planos espaciais escolhidos. Isto traz uma informação relevante para o procedimento cirúrgico no qual é possível acompanhar, sabendo o ângulo, quais deformações a fatia de interesse está sujeita.

\subsection{Fantoma Antropomórfico}

Este fantoma foi construído com gelatina e possui a morfologia de um encéfalo humano. A aquisição das imagens foi feita em seis etapas e como este fantoma não possui uma inclusão liquida, as etapas neste caso, se referem à retirada de pedaços do fantoma, na qual foi utilizada uma broca: 1 (antes da retirada) e 2-6 (retiradas de materiais sólidos).

Os dados de processamento escolhidos, de acordo com as seções 5.2 e 5.3, foram:

- Grade: $5 \times 11$ 
- Defaut Step Length: 1,6

- Gradient Convergence Tolerance: 0,03

- Line Search Accuracy: 0,8

Foi feita somente a aquisição linear composta de 13 fatias, com espaçamento de $1 \mathrm{~mm}$ entre estes, e para descrever o movimento do fantoma com um todo foram avaliadas as fatias da seguintes posições: $0,3,6$ e $9 \mathrm{~mm}$.

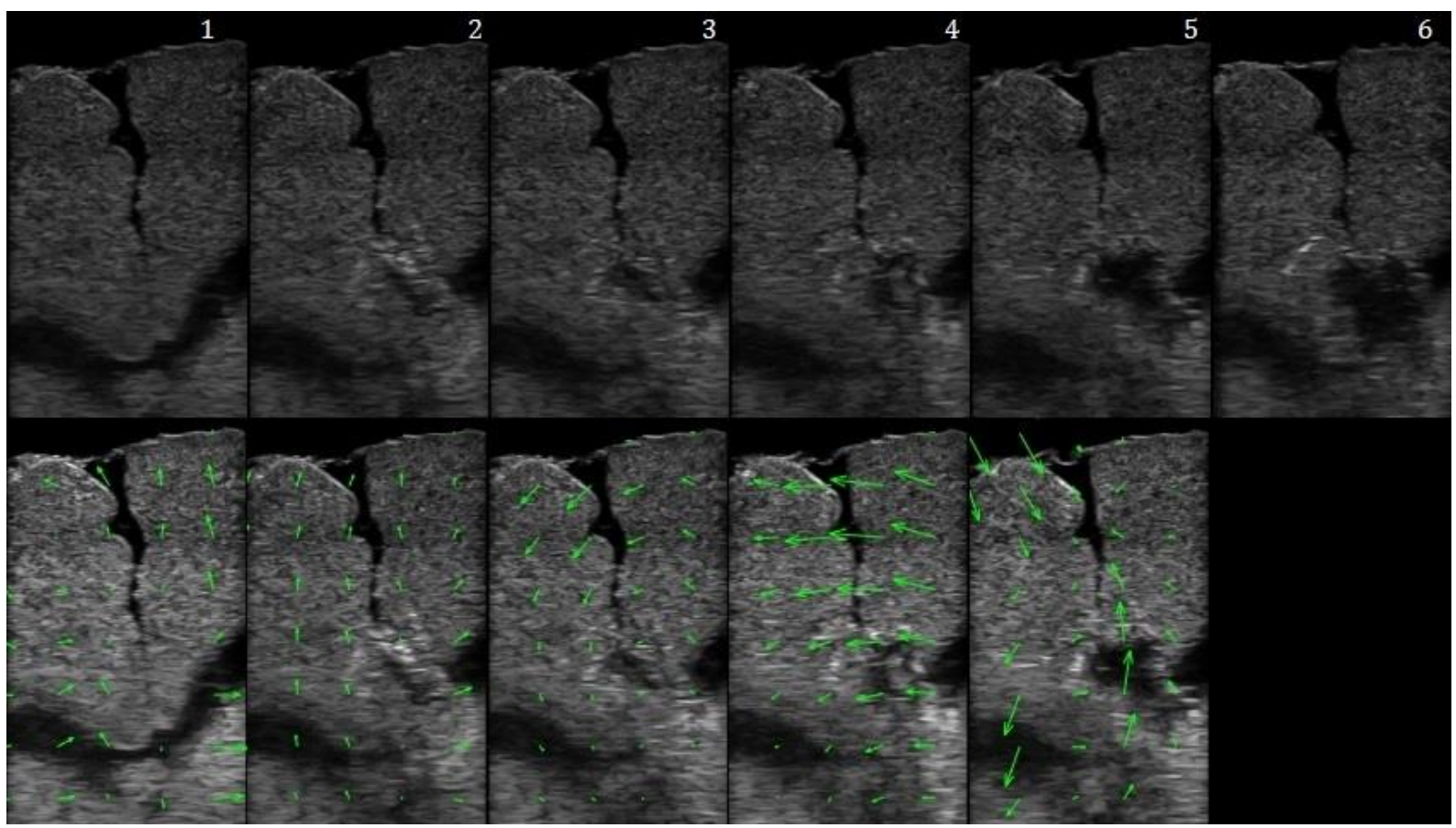

Figura 59: Processamento da fatia da posição de $0 \mathrm{~mm}$. As imagens superiores da esquerda para a direita correspondem às etapas: $1,2,3,4,5$ e 6 . As imagens inferiores da esquerda para a direita são as etapas 1, 2, 3, 4 e 5, com a superposição do mapa deformação calculado que se aplicado leva a etapa posterior.

A fatia da posição de $0 \mathrm{~mm}$ é o mais próximo do ponto de entrada da broca e por conseguinte o mais afetado. Alterações mínimas são perceptíveis até a etapa 3 , de onde em diante a retirada de material se torna mais evidente até a etapa 6 onde a região retirada se torna bem perceptível. 


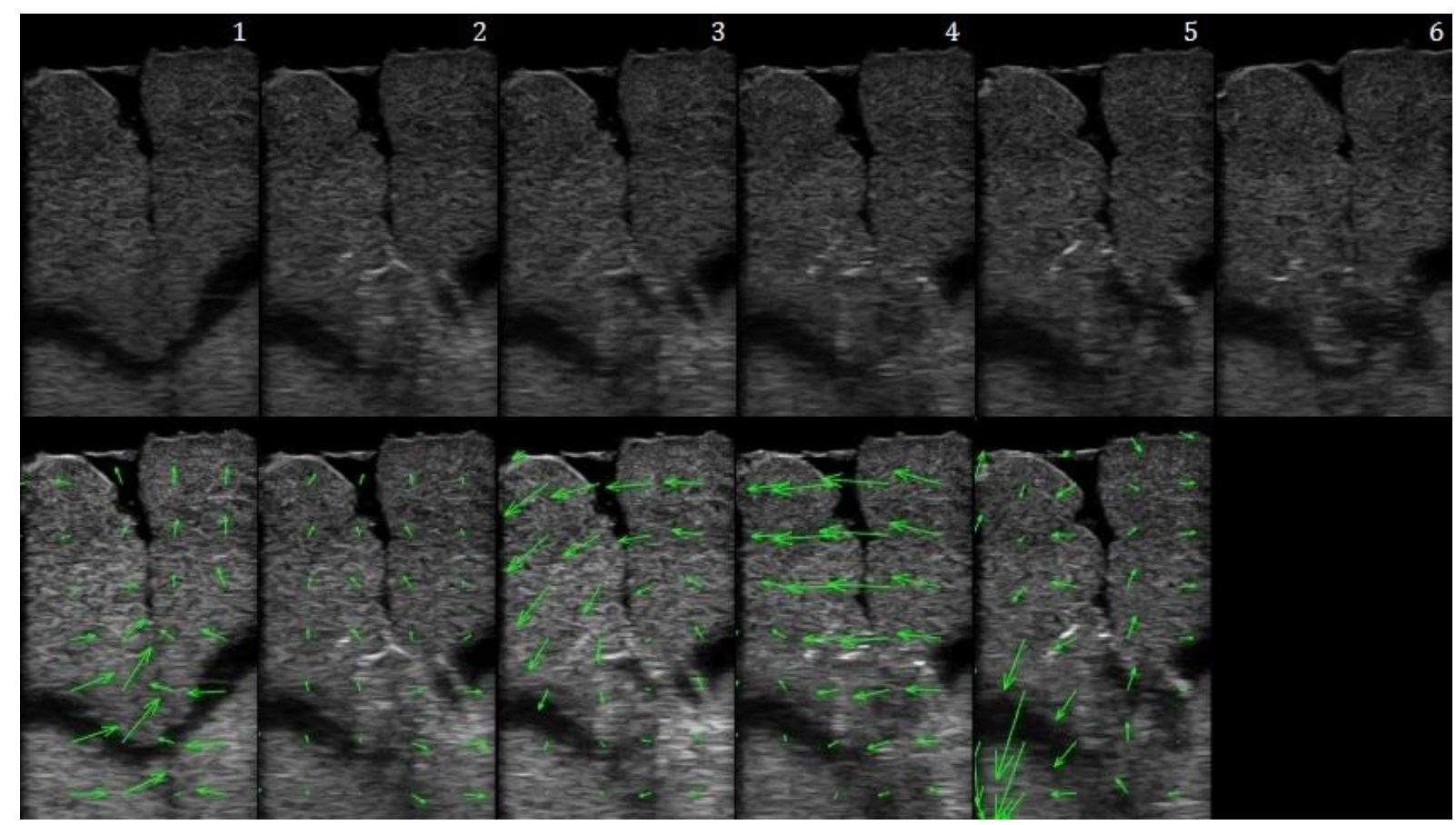

Figura 60: Processamento da fatia da posição de 3mm. As imagens superiores da esquerda para a direita correspondem às etapas: 1,2, 3, 4, 5 e 6. As imagens inferiores da esquerda para a direita são as etapas 1, 2, 3, 4 e 5, com a superposição do mapa deformação calculado que se aplicado leva a etapa posterior.

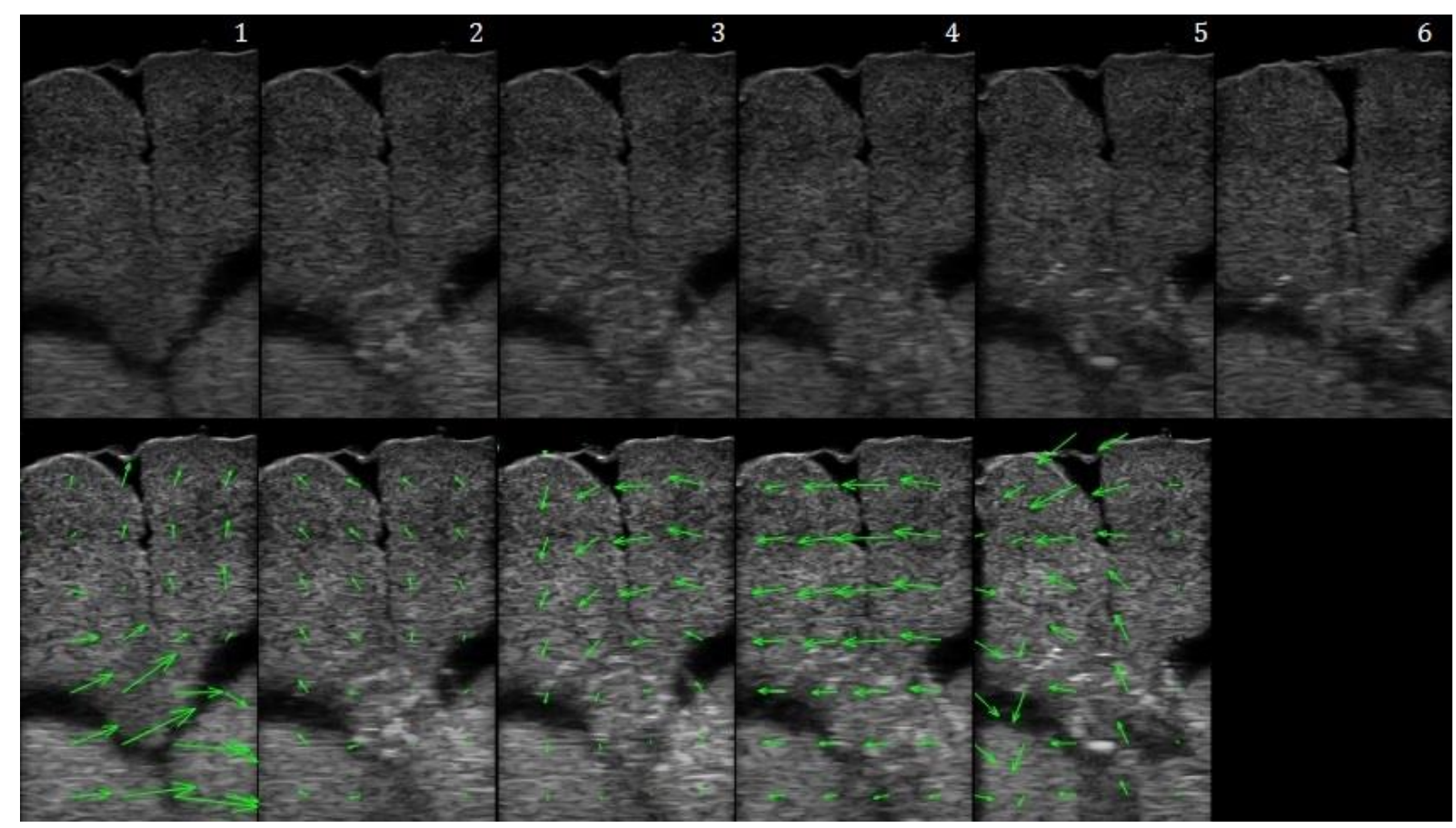

Figura 61: Processamento da fatia da posição de $6 \mathrm{~mm}$. As imagens superiores da esquerda para a direita correspondem às etapas: 1,2, 3, 4, 5 e 6 As imagens inferiores da esquerda para a direita são as etapas 1, 2, 3, 4 e 5, com a superposição do mapa deformação calculado que se aplicado leva a etapa posterior. 


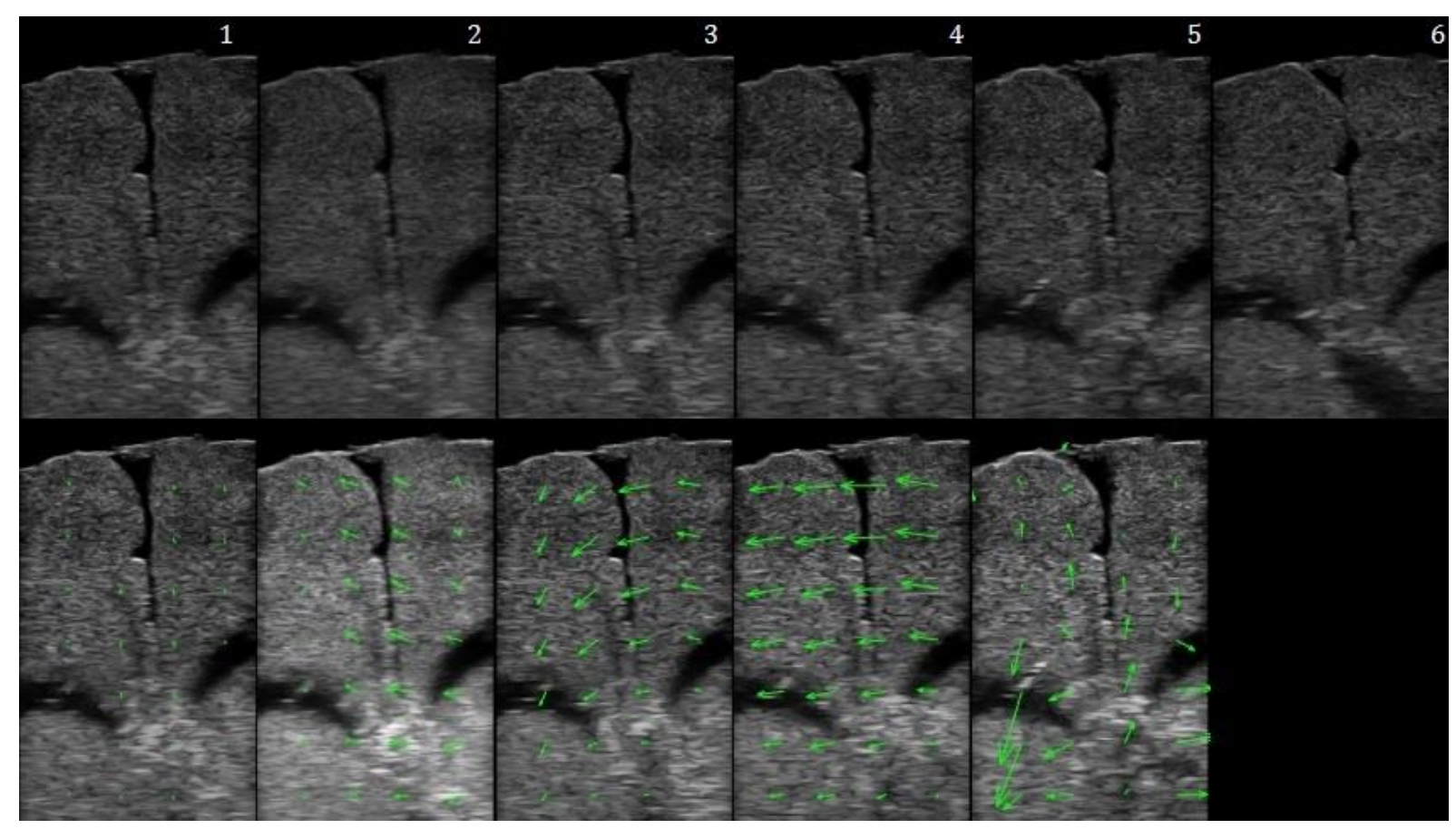

Figura 62: Processamento da fatia da posição de $9 \mathrm{~mm}$. As imagens superiores da esquerda para a direita correspondem às etapas: 1, 2, 3, 4, 5 e 6 As imagens inferiores da esquerda para a direita são as etapas 1, 2, 3, 4 e 5, com a superposição do mapa deformação calculado que se aplicado leva a etapa posterior.

É importante descrever que a incisão inicia próxima à fatia de 0mm e caminha em diagonal para fatia de $9 \mathrm{~mm}$, portanto a interferência da perturbação também segue nesta ordem. Por isso, entre as etapas 1 e 2, nas fatias 3 e $6 \mathrm{~mm}$ apresentam um campo aproximado de torção.

Entre as etapas 3 e 4 é possível notar o campo de torções em torno da região retirada e entre as etapas 4 e 5 para todos as fatias o corregistro mostra um campo de deformação que demonstra claramente uma translação para a esquerda. Isto se deve ao fato do fantoma ter se deslocado entre estas etapas, o que não permite a visualização da deformação, uma vez que a translação foi muito maior que a deformação. Isso poderia ser contornado aplicando um corregistro rígido antes do não-rígido de modo a retirar a componente de translação.

Há também o aparecimento de alguns campos difusos devido à acomodação do material e a entrada de óleo na região retirada. 


\section{Discussões e Conclusões}

O objetivo deste trabalho foi o estudo do corregistro livre não-rígido de uma simulação cirúrgica de retirada de uma inclusão, utilizando fantomas, imagens de ultrassom e a biblioteca ITK (o que envolve a transformação B-Splines, o otimizador LBFGS e a métrica de similaridade soma do quadrado das diferenças).

Inicialmente foi inspecionada a relação do tempo e erro do corregistro com a deformação. Para as imagens em modo $\mathrm{B}$, as deformações até $5 \%$, sem nenhuma otimização dos parâmetros do corregistro, é factível sem uso excessivo de tempo computacional. Para os mapas de RF, a priori, as deformações até $9 \%$ são realizáveis sem divergência do algoritmo e sem variações significativas de tempo computacional. Estes valores de deformações são suficientes para aplicações deste trabalho. Foi analisada a influência da grade em relação a dois tipos diferentes de deformação: uma que simule a aplicação de tensão superficial na parte superior da imagem, respeitando a razão de Poisson, que são típicas da elastografia à mão livre, e outra que simule a sucção de uma inclusão pelo seu centro, ambas com valor de $2 \%$. O tamanho da grade, levando em consideração o erro e o tempo, obtidos foram $5 \times 11$ para as imagens em Modo B e 11x17 para os mapas de RF, independentemente do tipo de deformação. Foi interessante notar que os gráficos de erro possuem, em geral, baixa variação, que os de tempo formam desenhos de fractais e que a escolha foi feita, predominantemente, pelo tempo de processamento. Também foram analisados os parâmetros do otimizador LBFGS em relação ao tempo e ao erro, perante uma deformação de $2 \%$. Os parâmetros foram avaliados em faixas de 1,0 a 1,9 para 0 Default Step Length, de 0,6 a 1,2 para o Line Search Accuracy e de 0,02 a 0,08 para o Gradient Convergence Tolerance. $O$ valores obtidos foram 1,6, 0,03 e 0,8 para as imagens modo B e 1,2, 0,05 e 1,0 para os mapas de RF para obtidos para Defaut Step Length, Gradient Convergence Tolerance e Line Search Accuraccy respectivamente. Os gráficos referentes ao modo $B$ formam regiões aproximadamente convexas e bem definidas e os referentes aos mapas de RF formam faixas, o que indica Gradient Convergence Tolerance praticamente não interfere no resultado. $O$ otimizador não ajustou a busca adequadamente baseado nos parâmetros testados e isto se deve à natureza dos mapas de RF que possuem valores na escala de 16 bits e uma quantidade de pontos bem maior que as imagens em modo B. Para o uso adequado 
do corregistro com características propostas neste trabalho teria sido necessário a estender a busca pelos valores dos parâmetros numa coleção de valores bem mais ampla que a testada neste trabalho.

$\mathrm{Na}$ fase de aplicação foram utilizados dois fantomas de parafina-gel e dois de gelatina. O primeiro fantoma de parafina (Fantoma $A$ ), foi deformado uma única vez pela sucção da inclusão e através do corregistro, utilizando os parâmetros calculados anteriormente, foi possível estudar os mapas de deslocamentos que indicam que além da sucção, os campos também indicam movimento de torções da estrutura. 0 segundo fantoma (Fantoma B) foi deformado em três diferentes níveis. Inicialmente, os deslocamentos das estruturas internas deste fantoma podem ser descritas pela equação (14 (Sucção) e para as últimas deformações pela equação (13 (Poisson). Para este fantoma também foi estudado o corregistro entre fatias adquiridas em diferentes ângulos de corte. Foi demonstrado que é possível medir os deslocamentos desta forma que simula uma aquisição durante um processo cirúrgico. O fantoma de gelatina cúbico também foi estudado e de forma geral o comportamento dos mapas de deformação deste fantoma segue uma linha em diagonal e no sentido do canto superior direito para o canto inferior esquerdo. Há a predominância do deslocamento causado pela deflexão que aparece em grande magnitude inclusive nesta análise. Por último foi estudado um fantoma de gelatina Antropomórfico que simula a topologia de um cérebro humano e a simulação do procedimento cirúrgico foi feita utilizando uma broca para retirar uma região de interesse. Por meio do corregistro foi demonstrado as torções causadas durante o procedimento de perfuração do tecido cerebral, bem como acompanhar a evolução dessa remoção entre as fatias de 0 a 9mm. Há também o aparecimento de alguns campos difusos devido à acomodação do material e à entrada de óleo na região retirada.

Finalmente podemos assegurar que este trabalho vem acrescentar dados que não estão presentes na literatura, como o corregistro entre imagens de ultrassom voltadas ao procedimento cirúrgico, nem o framework que utiliza a transformação por BSplines e o otimizador LBFGS, ainda não há estudos quantitativos sobre estes, 0 que demonstra importância deste trabalho. A imagens de ultrassom têm sido largamente utilizadas em aplicações de medida de deslocamento e o uso da técnica aqui descrita se mostra promissora no uso das imagens em Modo $B$, mas requer estudos mais aprofundados para os mapas de RF. É possível inferir os movimentos das estruturas no espaço utilizando imagens (duas dimensões) e o futuro deste 
trabalho é utilizar o corregistro em 3 dimensões apesar do alto tempo computacional envolvido nesta operação. 


\section{Referências}

[1] J. Haase, "Neuronavigation," Childs Nerv. Syst., vol. 15, no. 11-12, pp. 755757, 1999.

[2] D. Araújo, H. Machado, R. Oliveira, V. Terra-Bustamante, D. Barros de Araújo, A. Santos, and A. Sakamoto, "Brain surface reformatted imaging (BSRI) in surgical planning for resections around eloquent cortex," Childs Nerv. Syst., vol. 22, no. 9, pp. 1122-1126, 2006.

[3] V. C. Terra, F. A. Scorza, E. A. Cavalheiro, L. Wichert-Ana, K. G. F. D. Pinto, H. R. Machado, and A. C. Sakamoto, "Pediatric epilepsy surgery and sudden unexpected death epilepsy: the contribution of a Brazilian epilepsy surgery program," Childs Nerv. Syst., vol. 26, no. 8, pp. 1075-1079, Mar. 2010.

[4] O. C. Snead, "Surgical treatment of medically refractory epilepsy in childhood," Brain Dev., vol. 23, no. 4, pp. 199 - 207, 2001.

[5] D. W. Roberts, A. Hartov, F. E. Kennedy, M. I. Miga, and K. D. Paulsen, "Intraoperative Brain Shift and Deformation: A Quantitative Analysis of Cortical Displacement in 28 Cases," Neurosurgery, vol. 43, no. 4, 1998.

[6] M. El Beltagy, M. Aggag, and M. Kamal, "Role of intraoperative ultrasound in resection of pediatric brain tumors," Childs Nerv. Syst., vol. 26, no. 9, pp. 1189-1193, 2010.

[7] C. la Fougère, A. Rominger, S. Förster, J. Geisler, and P. Bartenstein, "PET and SPECT in epilepsy: A critical review," Epilepsy Behav., vol. 15, no. 1, pp. 50-55, May 2009.

[8] R. M. Comeau, A. F. Sadikot, A. Fenster, and T. M. Peters, "Intraoperative ultrasound for guidance and tissue shift correction in image-guided neurosurgery," Med. Phys., vol. 27, no. 4, pp. 787-800, 2000.

[9] J. B. A. Maintz and M. A. Viergever, "A survey of medical image registration," Med. Image Anal., vol. 2, no. 1, pp. 1 - 36, 1998.

[10] J. Ophir, I. Céspedes, H. Ponnekanti, Y. Yazdi, and X. Li, "Elastography: A quantitative method for imaging the elasticity of biological tissues," Ultrason. Imaging, vol. 13, no. 2, pp. $111-134,1991$.

[11] T. W. de Lemos, "Phantom para treinamento de neuronavegação guiada por imagens de ultra-som e de ressonância magnética," text, Universidade de São Paulo, 2008.

[12] S. L. Vieira, "Desenvolvimento de um 'phantom' para treinamento de biopsia de mama guiada por ultra-som," Mestrado em Física Aplicada à Medicina e Biologia, Faculdade de Filosofia, Ciências e Letras de Ribeirão Preto-Universidade de São Paulo, Ribeirão Preto, SP, Brasil, 2005.

[13] R. C. Gonzalez and R. E. Woods, Digital Image Processing, 2nd ed. Boston, MA, USA: Addison-Wesley Longman Publishing Co., Inc., 2001.

[14] E. P. Rodrigues, "Avaliação de métricas para o corregistro não rígido de imagens médicas," Doutorado em Física Aplicada à Medicina e Biologia, Faculdade de Filosofia, Ciências e Letras de Ribeirão Preto,Universidade de São Paulo, Ribeirão Preto, SP, Brasil, 2010.

[15] T. L. Szabo, Diagnostic ultrasound imaging: inside out(Biomedical Engineering). Elsevier Academic Press, 2004. 
[16] "Sonix_RP_Basics." [Online]. Available:

http://www.ultrasonix.com/wikisonix/index.php/Sonix_RP_Basics. [Accessed: 01-Nov2014].

[17] "An Open Source, Fast Ultrasound B-Mode Implementation for Commodity Hardware," 2010.

[18] L. Gao, K. J. Parker, R. M. Lerner, and S. F. Levinson, "Imaging of the elastic properties of tissue-A review," Ultrasound Med. Biol., vol. 22, no. 8, pp. 959 - 977, 1996.

[19] X. Liang, A. L. Oldenburg, V. Crecea, S. Kalyanam, M. F. Insana, and S. A. Boppart, "Modeling and measurement of tissue elastic moduli using optical coherence elastography," in Optics in Tissue Engineering and Regenerative Medicine II, San Jose, CA, USA, 2008, vol. 6858, p. 685803.

[20] R. Muthupillai, D. Lomas, P. Rossman, J. Greenleaf, A. Manduca, and R. Ehman, "Magnetic resonance elastography by direct visualization of propagating acoustic strain waves," Science, vol. 269, no. 5232, pp. 1854-1857, 1995.

[21] J. Ophir, S. Alam, B. Garra, F. Kallel, E. Konofagou, T. Krouskop, C. Merritt, R. Righetti, R. Souchon, S. Srinivasan, and T. Varghese, "Elastography: Imaging the elastic properties of soft tissues with ultrasound," J. Med. Ultrason., vol. 29, no. 4, pp. 155-171, 2002.

[22] T. Z. Pavan, "Estudos de técnicas ultrassônicas para análise de propriedades mecânicas de meios viscoelásticos," text, Universidade de São Paulo, 2011.

[23] A. R. Skovoroda, S. Y. Emelianov, and M. O'Donnell, "Tissue elasticity reconstruction based on ultrasonic displacement and strain images," Ultrason.

Ferroelectr. Freq. Control IEEE Trans. On, vol. 42, no. 4, pp. 747 -765, Jul. 1995.

[24] M. O'Donnell, A. R. Skovoroda, B. M. Shapo, and S. Y. Emelianov, "Internal displacement and strain imaging using ultrasonic speckle tracking," Ultrason.

Ferroelectr. Freq. Control IEEE Trans. On, vol. 41, no. 3, pp. 314 -325, May 1994.

[25] M. Mridha and S. Ödman, "Noninvasive method for the assessment of subcutaneous oedema," Med. Biol. Eng. Comput., vol. 24, no. 4, pp. 393-398, 1986.

[26] A. S. Saada, Elasticity Theory and Applications. Pergamon Press, 1974.

[27] Y. Zhu and T. J. Hall, "A modified block matching method for real-time freehand strain imaging," Ultrason. Imaging, vol. 24, no. 3, pp. 161-176, 2002.

[28] B. H. Friemel, L. N. Bohs, and G. E. Trahey, "Relative performance of twodimensional speckle-tracking techniques: normalized correlation, non-normalized correlation and sum-absolute-difference," in Ultrasonics Symposium, 1995.

Proceedings., 1995 IEEE, 1995, vol. 2, pp. $1481-1484$ vol.2.

[29] M. L. Palmeri, S. A. McAleavey, G. E. Trahey, and K. R. Nightingale, "Ultrasonic tracking of acoustic radiation force-induced displacements in homogeneous media," Ultrason. Ferroelectr. Freq. Control IEEE Trans. On, vol. 53, no. 7, pp. $1300-1313$, Jul. 2006.

[30] T. Z. Pavan, E. L. Madsen, G. R. Frank, A. A. O. Carneiro, and T. J. Hall, "Nonlinear elastic behavior of phantom materials for elastography," Phys. Med. Biol., vol. 55, no. 9, p. 2679, 2010.

[31] K. Hoyt, F. Forsberg, and J. Ophir, "Comparison of shift estimation strategies in spectral elastography," Ultrasonics, vol. 44, no. 1, pp. 99 - 108, 2006.

[32] J. V. Hajnal, Medical Image Registration (Biomedical Engineering), 1st ed. CRC Press, Cambridge, 2001.

[33] L. Ibanez, W. Schroeder, L. Ng, and J. Cates, "The ITK software guide second edition updated for ITK version 2.4," Download Httpwww Itk Org, 2003. 
[34] L. Chmielewski and D. Kozinska, "Image registration," in Proceedings of the 3rd Polish Conference on Computer Pattern Recognition Systems. MiBków (Poland): KOSYR, 2003, pp. 163-168.

[35] A. M. Kosevich, E. M. Lifshitz, L. D. Landau, and L. P. Pitaevskii, Course of Theoretical Physics, Volume VII: Theory of Elasticity. Butterworth-Heinemann, 1986. [36] D. Rueckert, L. I. Sonoda, C. Hayes, D. L. G. Hill, M. O. Leach, and D. J. Hawkes, "Nonrigid registration using free-form deformations: application to breast MR images," IEEE Trans. Med. Imaging, vol. 18, no. 8, pp. 712-721, Aug. 1999.

[37] J.-P. Thirion, "Image matching as a diffusion process: an analogy with Maxwell's demons," Med. Image Anal., vol. 2, no. 3, pp. 243-260, Sep. 1998.

[38] R. Byrd, P. Lu, J. Nocedal, and C. Zhu, "A Limited Memory Algorithm for Bound Constrained Optimization," SIAM J. Sci. Comput., vol. 16, no. 5, pp. 1190-1208, Sep. 1995.

[39] P. Viola and W. M. Wells, III, "Alignment by maximization of mutual information," in Computer Vision, 1995. Proceedings., Fifth International Conference on, 1995, pp. $16-23$.

[40] M. Bayer, T. J. Hall, L. P. Neves, and A. a. O. Carneiro, "Two-Dimensional Simulations of Displacement Accumulation Incorporating Shear Strain," Ultrason. Imaging, vol. 36, no. 1, pp. 55-73, Jan. 2014.

[41] J. Maurer, C.R., J. M. Fitzpatrick, M. Y. Wang, J. Galloway, R.L., R. J. Maciunas, and G. S. Allen, "Registration of head volume images using implantable fiducial markers," Med. Imaging IEEE Trans. On, vol. 16, no. 4, pp. 447 -462, Aug. 1997.

[42] T. Varghese, J. A. Zagzebski, G. Frank, and E. L. Madsen, "Elastographic imaging using a handheld compressor," Ultrason. Imaging, vol. 24, no. 1, pp. 25-35, 2002. 